\title{
A new specimen of Palvennia hoybergeti: Implications for cranial and pectoral girdle anatomy in ophthalmosaurid ichthyosaurs
}

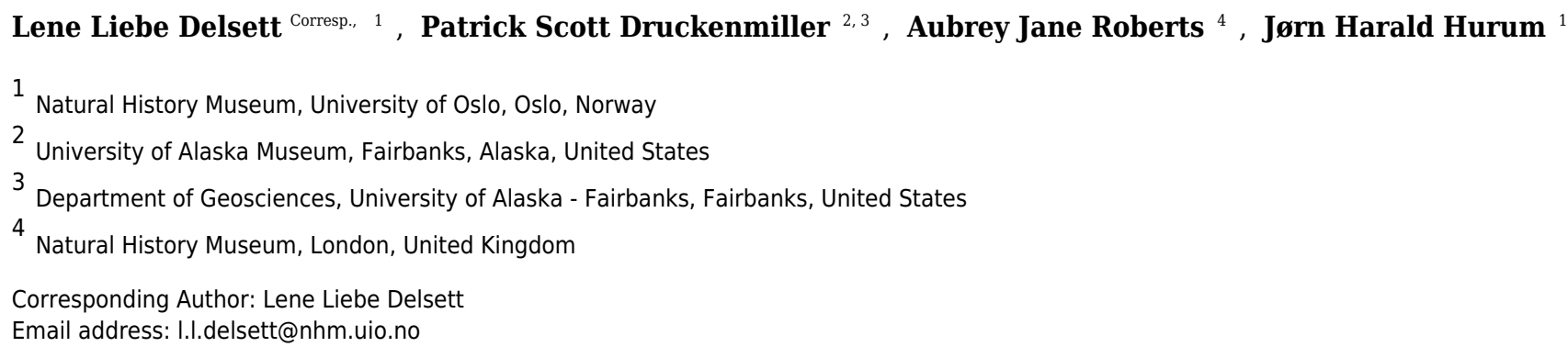

The Late Jurassic Slottsmøya Member Lagerstätte on Spitsbergen preserves a diverse array of marine reptiles, including four amed taxa of ophthalmosaurid ichthyosaurs. One of these, Palvennia hoybergeti, is based on the single holotype specimen (SVB 1451) with an incomplete skull. A newly discovered specimen (PMO 222.669) with a disarticulated but largely complete skull and anterior postcranium is described, which considerably expands our knowledge of this taxon. Two additional new ophthalmosaurid specimens with pectoral girdles from the same member are described. The taxonomic utility of the ophthalmosaurid pectoral girdle is contentious, and an assessment of seven pectoral girdles from the Slottsmøya Member provides a basis for addressing this question via a 2D landmark principal component analysis of baracromian coracoids. The analysis reveals a taxonomic signal in the coracoids but also highlights the degree of individual variation. Commonly used phylogenetic characters do not fully encapsulate the degree of variation seen in coracoids and in some cases combine analogous features. 


\section{A new specimen of Palvennia hoybergeti: Implications for cranial and pectoral}

2 girdle anatomy in ophthalmosaurid ichthyosaurs

3

4 Lene Liebe Delsett ${ }^{1}$, Patrick Scott Druckenmiller ${ }^{23}$, Aubrey Jane Roberts ${ }^{4}$, Jørn Harald

5 Hurum ${ }^{1}$

$6 \quad{ }^{1}$ Natural History Museum, University of Oslo, Oslo, Norway

$7 \quad{ }^{2}$ University of Alaska Museum, Fairbanks, Alaska, US

$8 \quad{ }^{3}$ Department of Geosciences, University of Alaska Fairbanks, Alaska, US

$9 \quad{ }^{4}$ Natural History Museum, UK

11 Corresponding author: Lene Liebe Delsett, 1.1.delsett@nhm.uio.no

\section{Abstract}

14 The Late Jurassic Slottsmøya Member Lagerstätte on Spitsbergen preserves a diverse array of marine reptiles, including four named taxa of ophthalmosaurid ichthyosaurs. One of these, Palvennia hoybergeti, is based on the single holotype specimen (SVB 1451) with an incomplete skull. A newly discovered specimen (PMO 222.669) with a disarticulated but largely complete skull and anterior postcranium is described, which considerably expands our knowledge of this taxon. Two additional new ophthalmosaurid specimens with pectoral girdles from the same member are described. The taxonomic utility of the ophthalmosaurid pectoral girdle is contentious, and an assessment of seven pectoral girdles from the Slottsmøya Member provides a basis for addressing this question via a $2 \mathrm{D}$ landmark principal component analysis of baracromian coracoids. The analysis reveals a taxonomic signal in the coracoids but also highlights the degree of individual variation. Commonly used phylogenetic characters do not fully encapsulate the degree of variation seen in coracoids and in some cases combine analogous features.

\section{Introduction} Ichthyopterygia was one of the major secondarily aquatic vertebrate clades that existed during the Mesozoic. Fossils are found from the Early Triassic (Olenekian) to the early Late Cretaceous 
31 (Cenomanian). The Late Jurassic was an interval with great species richness of thunnosaurian

32 ichthyosaurs that evolved an elongated skull with an enormous eye and forefins larger than

33 hindfins (Bardet, 1992; Motani, 2005; Fischer et al., 2016).

34

35 The Slottsmøya Member Lagerstätte (SML) on Spitsbergen, Norway (Fig. 1, 2), is well known 36 for its abundance of marine reptile remains (ichthyosaurs and plesiosaurians) from the latest Jurassic and the earliest Cretaceous (Hurum et al., 2012; Delsett et al., 2016). Four new monospecific ophthalmosaurid genera and three undetermined species of ophthalmosaurids have recently been described (Druckenmiller et al., 2012; Roberts et al., 2014; Delsett et al., 2017). Another 19 additional specimens have been collected, and three of those specimens are described in this paper. The most complete, PMO 222.669, consists of an anterior portion of an individual that we refer to the SML species Palvennia hoybergeti (Druckenmiller et al., 2012) based on its similarity to the holotype specimen (SVB 1451) in their overlapping material. The new specimen greatly increases our knowledge regarding the anatomy of this species, including new information from the skull as well as the first information regarding the morphology of the pectoral girdle and forefins. Additionally, two disarticulated and incomplete ophthalmosaurid specimens, PMO 222.658/PMO 230.097 (material from the same specimen, see Material and methods) and PMO 224.250, are described.

Combined with currently described material from the locality, the new specimens offer insight into pectoral girdle variation of ophthalmosaurid ichthyosaurs. The homology of certain features on the elements of the ichthyosaurian pectoral girdle as well as its architecture in life was the subject of heated early debates (e. g. Home, 1818; Seeley, 1874; Hulke, 1892; Seeley, 1893), but is now known to be relatively similar to terrestrial reptiles (Johnson, 1979; Sander, 2000), consisting of a pair of coracoids and scapulae, a pair of clavicles and an interclavicle. As is common in aquatic tetrapods, the scapula is not fused to the coracoid (Sander, 2000). Historically, the iconic species Ophthalmosaurus icenicus was erected on the basis of characters in the pectoral girdle and forefin (Seeley, 1874; Moon \& Kirton, 2016), but the actual taxonomic utility of pectoral girdle elements in post-Triassic ichthyosaurs has been questioned (McGowan, 1974; Johnson, 1979; Druckenmiller \& Maxwell, 2010; Moon \& Kirton, 2016). A challenge is 
62 specimen. In this study, we use geometric morphometrics on coracoids to investigate the range of

63 individual variation and phylogenetic signal.

64

\section{Geological setting}

66 The Slottsmøya Member is one of four members of the Agardhfjellet Formation, in the

67 Janusfjellet Subgroup of the Adventdalen Group (Fig. 2). The SML consists of Tithonian to

68

69 Berriasian-aged sediments that crop out north of the town of Longyearbyen on Spitsbergen, the largest island in the Svalbard archipelago, located between $74^{\circ}$ and $81^{\circ}$ North and $10^{\circ}$ and $35^{\circ}$ East. Deposition of the unit occurred broadly in an offshore transition when Svalbard was located farther south, at a paleolatitude of $63^{\circ}-66^{\circ}$ North (Torsvik et al., 2012). The sedimentology and stratigraphy of the Agardhfjellet Formation is described in detail in other contributions (Collignon \& Hammer, 2012; Dypvik \& Zakharov, 2012; Hammer, Collignon \& Nakrem, 2012; Koevoets et al., 2016; Koevoets, 2017; Koevoets et al., 2018), but the Slottsmøya Member is a $70-100$ metres thick, upwards-coarsening unit made up primarily of dark-grey to black shales, paper shales and siltstones with higher invertebrate abundance than in the other members in the formation (Collignon \& Hammer, 2012; Koevoets, 2017). The 0 metre level in the section is set at a remarkable echinoderm-rich bed laterally continuous throughout the study area and probably representing a storm deposit (Rousseau \& Nakrem, 2012; Rousseau, Gale \& Thuy, 2018).

The oxygenation fluctuated repeatedly during the deposition of the member, with periodic oxygenation of the bottom waters (Collignon \& Hammer, 2012; Koevoets, 2017). Two of the three specimens described here, PMO 222.669 and PMO 224.250, were found in the part of the section with the highest abundance of vertebrate remains (10-20 metres above the echinoderm bed), many of which are articulated or partly articulated (Delsett et al., 2016)(Fig. 2). PMO 222.669 was partly covered in bivalves and crinoids situated on the actual skeletal elements, similar to a previously described specimen (PMO 222.670; Ophthalmosauridae indet.) (Delsett et al., 2017), and as the specimens were found only one metre apart stratigraphically, this could represent an event with more oxic bottom conditions. However, significant bivalve abundances are also found in parts of the section with relatively low oxygen levels (Koevoets, 2017), and 
92 total organic content seems to covary more closely with the degree of articulation of the

93 vertebrates than does oxygenation (contra Delsett et al. 2016).

94

95 In the uppermost part of the member, a sudden change in the environment is recorded through 96 significant changes in the invertebrate and teleost fauna (Koevoets, 2017). In this part of the 97 section, just above one of the specimens described herein (PMO 230.097), 15 methane seeps 98 were described (Hryniewicz et al., 2015). Overall, the preservation of the vertebrates in the entire 99 member is more three-dimensional than would normally be expected with the known compaction 100 rate (Hammer, Collignon \& Nakrem, 2012), likely as a consequence of early barite

101 permineralization in many of the elements, which in turn is probably a result of dissolution of

102 barite in the sea water due to methane seepage (Delsett et al., 2016).

103

\section{Material and methods}

105 PMO 222.658/PMO 230.097 is an ichthyosaur specimen from which elements were collected

106 two different years: in 2009 and 2010, and the elements were originally catalogued separately.

107 From here on out, the museum number on the remains collected first (PMO 230.097) will be

108 used in the text. The ichthyosaur specimen PMO 222.669 was collected in 2011 and PMO

109224.250 in 2012. The stratigraphic position of the specimens was determined with a total station.

110 The specimens were collected in protective plaster jackets and transported to NHM in Oslo for

111 mechanical preparation. PMO 222.669 was largely covered in siderite, gypsum and barite, and

112 an air scribe and a sand blaster were used to remove the matrix. The taphonomy and stratigraphic

113 position of the specimens has previously been discussed in Delsett et al. (2016). An additional

114 unassigned ophthalmosaurid specimen that is under description, PMO 222.667, is included for

115 comparative purposes, as it was in Roberts et al. (2014). The specimens are housed in the

116 palaeontological collections of Natural History Museum, Oslo. The most commonly used

117 chronostratigraphic names (e.g. Tithonian) will be used in this work instead of the regional

118 names (e.g. Volgian). The following permits were given by the Governor of Svalbard for the

119 excavations in 2009, 2010, 2011 and 2012: 2006/00528-13, RIS ID 3707; RIS ID: 4760 and

120 2006/00528-39. 
122 The taxonomic utility of the post-Triassic ichthyosaurian pectoral girdle has been challenged

123 (Maxwell \& Druckenmiller, 2011; Lomax, 2017). Because seven SML specimens with relatively

124 well-preserved pectoral girdles have now been recovered, it provides an opportunity to test the

125 assertion that there is little taxonomic signal in the pectoral girdles. Here, we conduct a principal

126 component analysis (PCA) on 2D landmarks of coracoids from a larger set of baracromian

127 ichthyosaurs including six of the SML specimens. Geometric morphometrics is well suited for

128 evaluating shape difference, and coracoids are frequently preserved in their entirety (Lomax,

129 2017) with a well-defined outline in dorsal and ventral view making them suited for a PCA on

130 2D landmarks. In contrast, ichthyosaurian scapulae have processes arranged in orthogonal

131 planes, which reduces the efficiency of $2 \mathrm{D}$ methods to capture the fine variations of their

132 morphology.

133

134 To understand the degree of individual variation, one aim of the analysis is to determine whether

135 Ophthalmosaurus and Stenopterygius coracoids can be separated on the basis of this method.

136 The two genera were chosen for this purpose as they are known from multiple specimens.

137 Coracoid landmarks were digitized from photographs either taken by the authors in museum

138 collections or provided by colleagues. Only adult specimens where all landmarks could be scored

139 were included. Photographs were taken from directly above the element to reduce distortion.

140 Both left and right coracoids were used and mirrored to ensure comparable values. Six

141 landmarks were selected (Fig. 3) with an aim of maximizing the quantity of shape information

142 based on points used in descriptions and/or phylogenetic characters. Landmarks 2 - 6 are

143 homologous points based on contact between the coracoid and other skeletal elements, i. e.

144 anterior and posterior ends of facets for the other coracoid, the scapula and the humerus.

145 Landmark 1 represents the anterolateral corner of the anteromedial process of the coracoid, an

146 often used feature in descriptions and in phylogenetic analysis. Coordinates for each landmark

147 were found using Adobe Photoshop (CS6 ver. 13, Knoll et al.). The analysis was run in PAST

148 (Hammer, Harper \& Ryan, 2001) and included a Procrustes fitting of the values before the PCA.

149 To investigate the properties of each principal component, the Deformations function was used,

150 which shows how the landmarks act as the PC values change. In addition a discriminant analysis

151 was run between two assigned groups: Ophthalmosaurus and Stenopterygius. A MANOVA test

152 was run to test the groups, set to 4 constraints. 
153

154 A total of 30 specimens were included in the analysis (Table 1), with the majority represented by

155 two genera, Ophthalmosaurus and Stenopterygius. Additional specimens include

156 ophthalmosaurid species for which only a single specimen is known and three undetermined

157 ophthalmosaurids from the SML. Stenopterygius material was not separated on a sub-generic

158 level in the analysis as no pectoral girdle characters are currently used to differentiate at a species

159 level (Johnson, 1979; Maxwell, 2012). In addition, the inclusion of the non-ophthalmosaurid

160 genus Stenopterygius was to investigate whether it can be clearly separated from

161 ophthalmosaurids. Certain taxa with known preserved coracoids (Platypterygius australis,

162 Nannopterygius enthekiodon and Baptanodon natans) were not included in this study due to a

163 lack of data or insufficient photo quality.

164

\section{Institutional abbreviations}

166 CAMSM Sedgwick Museum of Earth Sciences, UK; CMN Canadian Museum of Nature, 167 Canada; GLAHM The Hunterian Museum, University of Glasgow, Glasgow; IRSNB Royal 168 Belgian Institute of Natural Sciences, Brussels, Belgium; LEICT New Walk Museum and Art 169 Gallery, Leicester, UK; LEIUG University of Leicester, MANCH Manchester Museum, UK;

170 NHMUK Natural History Museum, UK; OUMNH Oxford University Museum, UK; PMO

171 Natural History Museum, paleontological collections, Oslo, Norway; SMNS Staatliches Museum

172 für Naturkunde Stuttgart, Germany; SMSS Städtisches Museum Schloss Salder, Salzgitter,

173 Germany, SNHM Staatliches Naturhistorisches Museum Braunschweig, Germany; SNSB-BSPG,

174 Bayerische Staatssammlung für Paläontologie und Geologie, Munich, Germany; UPM

175 Paleontological Museum of Undory, Ul'yanovsk, Russia.

176

177 Systematic palaeontology

178 Ichthyosauria de Blainville 1835

179 Neoichthyosauria Sander 2000

180 Thunnosauria Motani 1999

181 Ophthalmosauridae Baur 1887

182

183 Palvennia hoybergeti Druckenmiller et al. 2012 


\section{New material of the holotype specimen (Fig. 4)}

186 Remark: Several elements from the Palvennia hoybergeti holotype (SVB 1451) that were not

187 included in the original description (Druckenmiller et al., 2012) were discovered during a more 188 careful examination of the material. These elements include the articulars, the second jugal, an 189 assemblage of forefin elements and some very poorly preserved and partial elements from the 190 pectoral girdle and forefins. The articulars and zeugo- and autopodial elements will be described 191 here as they represent overlapping material with the new specimen described below.

192

\section{Articular}

194 Both articulars are preserved (Fig. 4A, B). They are mediolaterally compressed taphonomically, 195 and the left articular is incomplete. The articular is clearly anteroposteriorly longer than 196 dorsoventrally tall, as in Janusaurus lundi (Roberts et al., 2014). In Ophthalmosaurus icenicus 197 the anteroposterior length is only slightly longer or equal in length (LEIUG 90986, MANCH 198 L10301, pers. obs. LLD, AJR), whereas in Mollesaurus periallus it is dorsoventrally taller than anteroposteriorly long (Fernández, 1999). In anterior view, the articular surface is directed anteriorly and medially with a triangular outline, as in Acamptonectes densus (Fischer et al., 2012). The lateral margin of this surface is concave, the dorsomedial margin is convex and the

202 ventromedial margin is concave. In contrast, the medial side of the element is convex. A thin

203 flange extends ventrally from the anteroposterior midpoint. In medial view, the dorsal margin of 204 the element is slightly concave, in contrast to Sisteronia seeleyi (Fischer et al., 2014b), 205 Arthropterygius chrisorum and Platypterygius australis (Kear, 2005; Maxwell, 2010), all of 206 which are narrowest posteriorly and dorsally convex. The posterior end is not mediolaterally 207 thickened in comparison to the middle of the element, in contrast to Platypterygius australis 208 (Kear, 2005). The lateral surface, which articulates with the surangular, is flat.

\section{Zeugo- and autopodial elements}

211 Nine disarticulated zeugo- and autopodial elements are present in the holotype (Fig 4C). They

212 are interpreted based on their similarities with PMO 222.669 and are strikingly similar to the

213 latter. The elements are interpreted as a radius, an intermedium, a pisiform, distal carpal 3, three 
214 metacarpals and two phalanges. The element interpreted to be the pisiform is relatively larger

215 than in PMO 222.669, otherwise the relative sizes and morphologies are similar.

216

217

218

219

Referred material: PMO 222.669, a partially articulated and almost complete anterior half of a

220 moderately large ichthyosaur (Figs. 5-13, Table 2, Supplemental table 1).

221

222

Locality: Island of Spitsbergen, north side of Janusfjellet, approximately 13 kilometres north of 223 Longyearbyen, Svalbard, Norway. UTM WGS84 33X 05196228695649.

Horizon and stage: Slottsmøya Member, Agardhfjellet Formation, Janusfjellet Subgroup, late Tithonian, Late Jurassic. 15.5 metres above the echinoderm marker bed (Delsett et al., 2016).

\section{Emended differential diagnosis for Palvennia hoybergeti}

229

Moderately large ophthalmosaurid ichthyosaur with one autapomorphy (shown with *) and unique character combination: relatively short rostrum with snout ratio of 0.59 (relatively longer in Caypullisaurus bonapartei and more gracile in Aegirosaurus leptospondylus, Nannopterygius enthekiodon (Kirton, 1983; Bardet \& Fernández, 2000; Fernández, 2007)); very large orbit (comparatively smaller in Cryopterygius kristiansenae, Brachypterygius extremus,

234 Caypullisaurus bonapartei (McGowan, 1976; Fernández, 1997; Druckenmiller et al., 2012)); strongly bowed jugal (relatively straight in Cryopterygius kristiansenae, Brachypterygius extremus (McGowan, 1976; Druckenmiller et al., 2012)); narrow postorbital bar (broad in Cryopterygius kristiansenae, Caypullisaurus bonapartei (Fernández, 2007; Druckenmiller et al., 2012)); frontals mediolaterally broad on skull roof (little frontal exposure on skull roof in Athabascasaurus bitumineus, Ophthalmosaurus icenicus (Druckenmiller \& Maxwell, 2010; Moon \& Kirton, 2016)); long frontal-postfrontal contact (short in Platypterygius australis, Ophthalmosaurus icenicus (Kear, 2005; Moon \& Kirton, 2016)); *very large pineal foramen; posterolateral process on pterygoid present (absent in Platypterygius australis (Kear, 2005)); extracondylar area of basioccipital not visible in posterior view (visible in Ophthalmosaurus

244 icenicus, Sveltonectes insolitus, Acamptonectes densus (Fischer et al., 2011; Fischer et al., 2012; 
245 Moon \& Kirton, 2016)) and lacking a ventral notch (ventral notch in Ophthalmosaurus icenicus, 246 Mollesaurus periallus (Fernández, 1999; Moon \& Kirton, 2016)); lateral and ventral surface of

247 basioccipital with broad extracondylar area of finished bone (very narrow extracondylar area in

248 Sveltonectes insolitus, Brachypterygius extremus (McGowan, 1976; Fischer et al., 2011));

249 anterior face of basioccipital lacks notochordal pit and basioccipital peg (present in

250 Arthropterygius chrisorum (Maxwell, 2010)); short and robust paroccipital process of opisthotic

251 (elongated in Ophthalmosaurus icenicus, Acamptonectes densus (Fischer et al., 2012; Moon \&

252 Kirton, 2016)); gracile and constricted stapedial shaft (robust shaft without constriction in

253 Platypterygius australis and Ophthalmosaurus icenicus (Kear, 2005; Moon \& Kirton, 2016));

254 anteromedial process of coracoid present (absent in Platypterygius australis, P. hercynicus and

255 Caypullisaurus bonapartei (Kear, 2005; Fernández, 2007; Kolb \& Sander, 2009)); medial stem

256 of the interclavicle is longer than the transverse bar (transverse bar longer in Caypullisaurus

257 bonapartei and Aegirosaurus leptospondylus (Bardet \& Fernández, 2000; Fernández, 2007));

258 facet for preaxial accessory element (absent in Cryopterygius kristiansenae, Nannopterygius

259 enthekiodon, Sveltonectes insolitus (Kirton, 1983; Fischer et al., 2011; Druckenmiller et al.,

260 2012)); proximal end of humerus slightly wider than distal end in dorsal view (distal end wider

261 in Ophthalmosaurus icenicus, Cryopterygius kristiansenae, Platypterygius australis (Kear, 2005;

262 Druckenmiller et al., 2012; Moon \& Kirton, 2016)); absence of humerus-intermedium contact

263 (contact in Brachypterygius extremus, Maiaspondyluys lindoei and Aegirosaurus leptospondylus

264 (Kirton, 1983; Bardet \& Fernández, 2000; Maxwell \& Caldwell, 2006)); phalanges rounded and

265 not tightly packed (rectangular and tightly packed in Cryopterygius kristiansenae, Sveltonectes

266 insolitus, Platypterygius australis (Kear, 2005; Fischer et al., 2011; Druckenmiller et al., 2012)).

267

268 Preservation

269 Based on the orientation of the articulated skull roof, braincase and vertebrae as preserved in the

270 excavation site, PMO 222.669 landed on its dorsal side on the sea floor after death (Fig. 5;

271 Delsett et al. 2016). The specimen was covered with crinoid, ophiuroid and bivalve remains,

272 possibly indicating prolonged exposure on the sea bottom in oxygenated bottom waters as an

273 "ichthyosaur fall”, and scavenging might be a cause for the partly disarticulated status (Dick,

274 2015; Delsett et al., 2016). The elements of the rostrum (splenials, dentaries and premaxillae)

275 and the anterior part of the nasals are preserved together with the teeth anteriorly. Posterior to the 
276 rostral elements is a small disruption of the layers due to permafrost with elements from the

277 palate and skull roof. The nasals and frontals are relatively well preserved, but some other

278 remains in this area are not discernable and probably include the prefrontals and maxillae. The

279 skull roof is preserved in articulation with the basicranium. The left surangular is preserved in

280 articulation with the prearticular and the articular on the right side of the skull, and is turned 180

281 degrees posteriorly. In close proximity are both angulars. The right surangular is complete but

282 distorted. The atlas-axis complex is preserved along with 24 presacral vertebral centra found in

283 articulation with dorsal ribs in two short series. The centra are three dimensionally preserved and

284 not compressed. Small pieces from as many as three vertebral centra are preserved directly

285 posterior to the axis. Preservational factors preclude most measurements. The specimen

286 preserves only a few neural arches, including that of the atlas axis, as well as some broken

287 gastralia. Two humeri are preserved in articulation with the zeugopodium and some autapodial

288 elements. The left forefin is dorsoventrally compressed and the description is based primarily on

289 the right forefin. Although the scapulae are reasonably three dimensional and nearly complete,

290 the left scapula has suffered some deformation. The clavicle-interclavicle complex is deformed

291 and fractured.

292

\section{Ontogeny}

294 PMO 222.669 is interpreted to be an adult specimen. The wings on the pterygoid quadrate ramus

295 are robust and of relatively similar size, and the basipterygoid processes are distinct, both

296 indications of an adult stage (Fischer et al., 2011; Kear \& Zammit, 2014). This is supported by

297 well- developed distal facets on the humerus and a finished bone surface on all skeletal elements

298 (Johnson, 1977). The specimen is of the same size as the adult holotype of Palvennia hoybergeti

299 and is relatively large compared to other SML specimens, which also support an adult stage

300 (Druckenmiller et al., 2012; Roberts et al., 2014; Delsett et al., 2017).

301

302 Premaxilla (Fig. 6)

303 The preservation of the premaxillae in PMO 222.669 is superior to that seen in the holotype of

304 Palvennia hoybergeti (SVB 1451)(Druckenmiller et al., 2012). They are preserved with their

305 medial contact intact dorsally, but the ventral margins are rotated laterally due to dorsoventral

306 compression. The element is rounded in cross-section anteriorly and more mediolaterally 
307 compressed posteriorly, where it also increases in dorsoventral height. The dorsal margin is

308 mediolaterally very narrow in anterior view. In lateral view, two large anteroposteriorly

309 elongated foramina in the anterior portion develop into a groove posteriorly (fossa

310 premaxillaris), approximately at the same point as in Ophthalmosaurus icenicus and

311 Cryopterygius kristiansenae (Druckenmiller et al., 2012; Moon \& Kirton, 2016). The lateral and

312 medial walls of the dental groove are of the same dorsoventral height except at its posteriormost

313 end, where the lateral wall extends further ventrally as in Platypterygius hercynicus (Fischer,

314 2012). In the anterior portion of PMO 222.669 some slight depressions on the medial side of the

315 dental groove might represent distinct alveoli (Fischer et al., 2012).

316

\section{Nasals, frontals, parietals and postfrontals (Fig. 7)}

318 The skull roof preserves most interelement relationships, although some sutures are difficult to

319 discern. The nasals border the frontals anteriorly and laterally. As preserved, the left nasal is

320 covered laterally by the pterygoid. The elongated anterior portions of both nasals continue

321 through the fault zone, but because of distortion, the true anterior length is unknown. The lateral

322 portion of the nasal curves ventrally at a 90 degree angle compared to the dorsal surface. The

323 skull roof is conspicuously similar to the holotype (SVB 1451) in having an unusually large

324 parietal foramen bordered by the frontals anteriorly and laterally and the parietals posteriorly,

325 which is autapomorphic for this taxon. The frontals do not contact the supratemporal fenestra,

326 which is similar to the situation in Athabascasaurus bitumineus, Ophthalmosaurus icenicus and

327 Leninia stellans (Druckenmiller \& Maxwell, 2010; Fischer et al., 2013; Moon \& Kirton, 2016)

328 but different from many platypterygiine ophthalmosaurids (Fischer et al., 2011; Fischer et al., 329 2012).

330

331 The postfrontals border the supratemporal fenestra laterally and contact the supratemporals

332 posteriorly and the frontals anteriorly. The dorsoventrally thickest portion of the postfrontal is in

333 the region between the anterior and posterior portions, as in Platypterygius australis (Kear,

334 2005). Both postfrontals are preserved in articulation. The left is fairly complete and could be

335 taken out for study. Anteriorly it is articulated to the posterior part of the prefrontal, which is

336 oval in cross-section. The posterior portion is mediolaterally wider than in Platypterygius

337 australis (Kear, 2005). In dorsal view, the shape is similar to that of the holotype (Druckenmiller 
338 et al., 2012). The anterior margin is covered by the narrow fingerlike projection of the posterior

339 margin of the nasal. The lateral flange is very thin as in Ophthalmosaurus icenicus (Moon \&

340 Kirton, 2016). The medial margin of the element forms the lateral wall of the supratemporal

341 fenestra and is covered by the projecting finger of the supratemporal in somewhat more than the

342 posterior half of the anteroposterior length of the foramen. The supratemporal finger covers less

343 area than in Leninia stellans (Fischer et al., 2013). The medial margin is largely concave as in

344 Ophthalmosaurus icenicus (Moon \& Kirton, 2016), but the ridge demarcating the ventral border

345 of the concavity is diagonal and extends much further laterally in this specimen, making a larger

346 concavity.

347

348 Postorbital (Fig. 8A)

349 In PMO 222.669 both postorbitals are preserved. The right postorbital is nearly complete, but is

350 missing the dorsal-most and ventral-most portions of the element. Based on the holotype

351 specimen (SVB1451), the postorbital bar in Palvennia hoybergeti is known to be dorsoventrally

352 tall and mediolaterally narrow (Druckenmiller et al., 2012). The postorbital is anteroposteriorly

353 narrow compared to Cryopterygius kristiansenae (Druckenmiller et al., 2012). The anterior

354 margin is more strongly curved than Platypterygius australis (Kear, 2005) and instead resembles

355 Leninia stellans (Fischer et al., 2013). The cross-section of the dorsal-most two-thirds of the

356 element is triangular. It has a pronounced dorsoventrally oriented ridge near the dorsoventral

357 midpoint that is anteriorly inclined as in Leninia stellans (Fischer et al., 2013). From the ridge,

358 the element tapers towards the anterior and posterior margins. The posterior margin does not

359 have the pronounced posteroventral heel found in Ophthalmosaurus icenicus and Platypterygius

360 australis (Kear, 2005; Moon \& Kirton, 2016). The element is mediolaterally flatter in the more

361 ventral portion as in Ophthalmosaurus icenicus (Moon \& Kirton, 2016). In lateral view, the

362 surface texture of the anterior portion is dorsoventrally striated while the posterior portion is less

363 smooth and instead lightly wrinkled, the latter possibly representing an area for contact with the

364 quadratojugal. Medially, only the dorsalmost preserved part is striated, possibly for articulation

365 with the squamosal or the supratemporal.

366

367 Jugal (Fig. 8B) 
368 A complete left and an incomplete right jugal are preserved, which strongly resemble that of the

369 holotype specimen of Palvennia hoybergeti (SVB 1451)(Druckenmiller et al., 2012). In overall

370 morphology the jugal is strongly dorsally curved as in Ophthalmosaurus icenicus and

371 Paraophthalmosaurus ("Yasykovia"), but in contrast to Cryopterygius kristiansenae, which is

372 nearly straight (Arkhangelsky, 1997; Efimov, 1999b; Druckenmiller et al., 2012; Moon \&

373 Kirton, 2016). The jugal has a long suborbital bar and posteriorly ascending process. The

374 surborbital bar is straight and narrows dorsoventrally anteriorly, differing from the uniform jugal

375 seen in Athabascasaurus bitumineus (Druckenmiller \& Maxwell, 2010). The suborbital bar is

376 flattened in cross-section and not sub-circular as in Ophthalmosaurus icenicus and Leninia

377 stellans (Fischer et al., 2013; Moon \& Kirton, 2016). It lacks the interdigitating anterior end of

378 Brachypterygius extremus for insertion with the premaxilla (Kirton, 1983). In PMO 222.669, the

379 medial side has an anteroposteriorly elongated depression for articulation with the maxilla and a

380 second, smaller depression situated more posteriorly. Similar to the holotype of Palvennia

381 hoybergeti, the jugal lacks a distinct posteroventral heel such as that seen in Ophthalmosaurus

382 icenicus and Platypterygius australis (Kear, 2005; Moon \& Kirton, 2016), and instead curves

383 gradually into the posterior process, which ascends dorsally at an angle of approximately 60

384 degrees relative to the suborbital bar. In lateral view, it is widest anteroposteriorly at the

385 dorsoventral midpoint, above which it narrows dorsally, in contrast to the Palvennia hoybergeti

386 holotype. The size and outline of the posterior portion varies intraspecifically in

387 Ophthalmosaurus icenicus (e.g. CAMSM J29861 versus NHMUK PV R8653, pers. obs. LLD;

388 Moon \& Kirton 2016), thus, the difference to the holotype might represent individual variation.

389 The posterodorsal tip has a dorsoventrally oriented depression medially, a feature also found in

390 the holotype of Palvennia hoybergeti.

391

392 Lacrimal (Fig. 8C)

393 The left lacrimal was found in the left supratemporal fenestra. It is similar to that in the holotype

394 (SVB1451)(Druckenmiller et al., 2012), but because it is disarticulated, additional details can be

395 added. The dorsalmost portion of the dorsal projection shows an interdigitating structure with the

396 prefrontal as in Platypterygius australis, Ophthalmosaurus icenicus and Simbirskiasaurus

397 birjukovi (Kear, 2005; Fischer et al., 2014a; Moon \& Kirton, 2016), and some of the projections

398 of the prefrontal are preserved. The dorsal projection and middle part of the element are 
399

400

401

402

403

404

405

406

407

408

409

410

411

412

413

414

415

416

417

418

419

420

421

422

423 Pterygoid (Fig. 8E)

424 In PMO 222.669, the left pterygoid is complete except for the very tips of the thin lateral and

425 dorsal processes, whereas the right preserves a portion of the posterior ramus. In the holotype of

426

427

428

429

anteroposteriorly narrower than in Paraophthalmosaurus (UPM EP-II.7(1235) LLD pers. obs.) (Arkhangelsky, 1997) and Simbirskiasaurus birjukovi (Fischer et al., 2014a). On the lateral surface, fine striations radiate from the dorsal end of the narrow margin and in all directions. The medial surface is flatter than the lateral. The middle portion of the element and the dorsal projection are rugose and bears at least one foramen, as in Acamptonectes densus and Platypterygius australis (Kear, 2005; Fischer et al., 2012). The anterior process has a further anterior reach than in Aegirosaurus leptospondylus and Caypullisaurus bonapartei (Bardet \& Fernández, 2000; Fernández, 2007). In ventral view, the anterior process has a ridge running in anteroposterior direction in the lateral part and three small foramina medial to this. The posterior projection is divided into two anteroposteriorly directed grooves that decrease in depth posteriorly, for articulation with the maxilla and the jugal (Kear, 2005; Moon \& Kirton, 2016).

\section{Vomer (Fig. 8D)}

The left vomer was disarticulated close to the left pterygoid on the left side of the skull and is incomplete. Anteriorly, it is elongate and mediolaterally and dorsoventrally narrow; in the posterior half, the element widens into a dorsoventrally oriented sheet that gradually decreases in

height posteriorly. The dorsal sheet has an uneven outline in lateral view with at least two broken processes in the dorsal portion oriented dorsally and anteriorly, as in Ophthalmosaurus icenicus and Gengasaurus nicosiai (Moon \& Kirton, 2016; Paparella et al., 2016). The element is laterally convex with a lateral side that is more uneven than the smoother, medial side. The posterior extension is mediolaterally and dorsoventrally narrow and longitudinally striated. Ventrally, just posterior to the maximum dorsoventral height, there are striations radiating in all directions, which is also true for the medial and lateral surfaces.

Palvennia hoybergeti (SVB 1451), the pterygoid is only partially known (Druckenmiller et al., 2012). Overall the element is similar to the exposed portion seen in the holotype. Similar to other ophthalmosaurids as well as the non-ophthalmosaurid Hauffiopteryx, the pterygoid has a sheetlike anterior palatal ramus and a more complex, posterior quadrate ramus with three processes 
430 (Kear, 2005; Fischer et al., 2011; Marek et al., 2015; Moon \& Kirton, 2016). The anterior portion 431 is straight and not medially curved as in Platypterygius australis (Kear, 2005). Posterior to this is 432 a dorsoventrally oriented ridge that lacks the medial terrace seen in Ophthalmosaurus icenicus 433 (Moon \& Kirton, 2016)(MANCH L10307, AJR pers. obs.). Posterior to the ridge is a 434 mediolaterally wide horizontal shelf, which is very thin and not completely preserved, but with 435 some anterior processes as in Ophthalmosaurus icenicus (Moon \& Kirton, 2016). Anterior to the 436 quadrate ramus, the horizontal shelf is constricted, as in Ophthalmosaurus icenicus and the 437 Palvennia hoybergeti holotype (Druckenmiller et al., 2012; Moon \& Kirton, 2016). The ventral 438 side of the horizontal shelf is concave. On the quadrate ramus, the lateral and medial portions are 439 anteroposteriorly narrower than in Ophthalmosaurus icenicus and Platypterygius australis (Kear, 440 2005; Moon \& Kirton, 2016) and of approximately the same size, unlike Sveltonectes insolitus 441 where the lateral wing is smaller (Fischer et al., 2011). The dorsal portion has a more robust base 442 than in Ophthalmosaurus icenicus (Moon \& Kirton, 2016), with a square outline. Sisteronia 443 seeleyi also has a dorsal process with a thick base (Fischer et al., 2014b). The area between the 444 dorsal and lateral process articulated with the quadrate. In posterior view, the ventral side of the 445 posterior ramus is concave as in Sveltonectes insolitus (Fischer et al., 2011), but differs in 446 lacking a forked posterior end.

449 A complete hyoid is preserved in PMO 222.669, but this element is not known in the holotype 450 specimen of Palvennia hoybergeti (SVB 1451)(Druckenmiller et al., 2012). It was found near the 451 right side of the skull and has been displaced; as such it is not possible to definitively orient the 452 element (Kear, 2005; Kolb \& Sander, 2009; Fischer et al., 2011). The hyoid is transversely 453 compressed as in Ophthalmosaurus icenicus (Moon \& Kirton, 2016) and more curved than that 454 seen in Janusaurus lundi (Roberts et al., 2014) and one Ophthalmosaurus icenicus specimen 455 (NHMUK R3013, pers. obs. AJR). The hyoid is oval in cross-sectional shape, differing from that 456 of Platypterygius hercynicus and Sveltonectes insolitus, which are circular in cross-section for 457 parts of its length (Kolb \& Sander, 2009; Fischer et al., 2011). In medial and lateral view, the 458 dorsoventral height of the element is constant for almost the entire length, but widens 459 dorsoventrally into a spatula-shaped wider end. The other end has a square outline in medial 
460 view as in Platypterygius hercynicus (Kolb \& Sander, 2009) and is rugose, probably for

461 attachment of soft tissue. Both ends have elongate depressions on the medial and lateral sides.

462

463 Supratemporal

464 Both supratemporals are preserved (Fig. 7). As in Ophthalmosaurus icenicus, the most robust

465 portion of the element makes up the posterolateral corner of the cranium. From the posterolateral

466 portion, the anterior ramus extends on the lateral side of the supratemporal fenestra and meets

467 with the postfrontal anteriorly. The supratemporal does not contact the frontal in contrast to

468 Platypterygius hercynicus (Kolb \& Sander, 2009). In posterior view, one distinct and possibly

469 two posterolateral tubercles can be seen, possibly for muscle attachment. Two tubercles are

470 described for Ophthalmosaurus icenicus and UAMES 3411 (Druckenmiller \& Maxwell, 2013;

471 Moon \& Kirton, 2016). Two rami descend on the posterior side of the skull, one being directed

472 laterally and one medially, diagonally towards the middle of the basicranium. The quadrate

473 articulates with the lateral side of the lateral ramus. The lateral process also contacts the stapes,

474 as in Leninia stellans, Ophthalmosaurus icenicus and Baptanodon natans (Gilmore, 1905;

475 Fischer et al., 2013; Moon \& Kirton, 2016). The medial ramus overlaps the opisthotic and

476 terminates approximately on the middle of this element. The medial portion of the element is

477 thickened and becomes narrower medially.

478

479 Basioccipital (Figs 9A-D)

480 As in the Palvennia hoybergeti holotype (SVB 1451), the basioccipital lacks exposure of extracondylar area in posterior view (Fig. 9A). The extracondylar area is represented by a very

482 shallow peripheral groove of finished bone laterally and ventrally (Fig 9C-D) (Druckenmiller et

483 al., 2012; Fischer et al., 2014a) in contrast to many ophthalmosaurine ophthalmosaurids with a

484 large part of the extracondylar visible in posterior view, such as Ophthalmosaurus icenicus

485 (Moon \& Kirton, 2016), but is instead largely similar to Grendelius alekseevi (Zverkov, 486 Arkhangelsky \& Stenshin, 2015). The dorsal surface is better preserved in the new specimen 487 (Fig. 9B). The floor of the foramen magnum is wide posteriorly and decreases in mediolateral 488 width anteriorly, and has slightly elevated lateral walls. The floor of the foramen magnum does 489 not form a dorsal process as in Sisteronia seeleyi (Fischer et al., 2014b). The exoccipital facets 490 occupy most of the area lateral to the notochordal groove. The opisthotic facets are situated on 
491 the dorsal portion of the lateral surface, and are dorsoventrally elongated. These facets are raised

492 as in Sveltonectes insolitus in contrast to Acamptonectes densus (Fischer et al., 2011; Fischer et

493 al., 2012), where they are small. As in the holotype, a ventral notch is absent, but a small oval

494 depression is present on the ventral surface close to the anterior margin (Fig. 9D).

495

496 Basisphenoid (Fig. 9E)

497 The parabasisphenoid is visible in ventral view only as it is preserved in articulation to the skull

498 roof. The parasphenoid is preserved, but its anterior portion is not accessible. It originates in the 499 anterior portion of the ventral surface as in other ophthalmosaurids (Kear, 2005; Moon \& Kirton,

500 2016). It is oval in cross-section and dorsoventrally flattened. The basipterygoid processes

501 originate in the anteriormost portion of the ventral surface of the basisphenoid and are laterally

502 directed. They are distinct, but smaller than in Platypterygius australis (Kear, 2005) and

503 Sisteronia seeleyi (Fischer et al., 2014b) and instead resemble Ophthalmosaurus icenicus (Moon

$504 \&$ Kirton, 2016) and Sveltonectes insolitus (Fischer et al., 2011). In the anteroposteriorly

505 midpoint of the ventral surface is an anteroposteriorly oriented oval depression as in

506 Arthropterygius chrisorum (Maxwell, 2010). The carotid foramen exits on the posterior surface

507 as in Arthropterygius chrisorum (Maxwell, 2010), the Russian Arthropterygius sp. specimen

508 SGM 1502 and Platypterygius australis (posteroventral)(Kear, 2005; Zverkov et al., 2015), in

509 contrast to the ventral exit in e.g. Ophthalmosaurus icenicus. Grendelius alekseevi and

510 Sveltonectes insolitus (Fischer et al., 2011; Zverkov, Arkhangelsky \& Stenshin, 2015; Moon \&

511 Kirton, 2016). The foramen is positioned in the ventralmost portion of the posterior surface so

512 that it makes an incision to the posterior margin of the ventral surface in ventral view. The

513 margin is very similar to that in Brachypterygius extremus, but in that species the carotid is

514 interpreted to exit ventrally (McGowan, 1976; Kirton, 1983). The element is mediolaterally

515 narrowest in the posterior portion as is also seen in many ophthalmosaurids e.g. Platypterygius

516 australis and Brachypterygius extremus (McGowan, 1976; Kear, 2005).

517

518 Exoccipital (Fig. 9B)

519 The exoccipitals are better preserved in an articulated state in the new specimen than in the

520 holotype (SVB 1451)(Druckenmiller et al., 2012). Two foramina perforate the ventral portion of

521 the element in PMO 222.669; with the posterior being the largest, similar to those in 
522 Ophthalmosaurus icenicus and Athabascasaurus bitumineus (Druckenmiller \& Maxwell, 2010;

523 Moon \& Kirton, 2016). The holotype (SVB1451) of Palvennia hoybergeti lacks foramina

524 (Druckenmiller et al., 2012), probably due to taphonomic distortion or individual variation

525 (Maisch, 1997). Only one foramen is found in Sveltonectes insolitus whereas three are present in

526 Platypterygius australis and Brachypterygius extremus (McGowan, 1997; Kear, 2005; Fischer et

527 al., 2011). The ventral surface is convex and finely pitted, probably for cartilage in the

528 articulation with the basioccipital. The exoccipitals had a small contact with the opisthotic

529 laterally as in Ophthalmosaurus icenicus (Moon \& Kirton, 2016).

530

531 Opisthotic (Fig. 9F)

532 In PMO 222.669, both opisthotics are preserved in articulation with the basioccipital and 533 supratemporals, although the anterior surfaces are not visible. Information regarding these 534 elements is not available in the holotype of Palvennia hoybergeti (SVB 1451) due to poor 535 preservation. In posterior view, the element is pentagonal with a straight ventral margin. The 536 incomplete medial margin is the longest. The element possesses a small, medially directed 537 process probably for articulation with the exoccipital. This morphology differs from

538 Acamptonectes densus, which lacks this process and instead has a concave medial margin 539 (Fischer et al., 2012). The paroccipital process has a finished surface and is dorsolaterally 540 directed to articulate with the supratemporal. Compared to Ophthalmosaurus icenicus and

541 Platypterygius australis, the paraoccipital process is short and to a small degree set off from the 542 rest of the element (Kear, 2005; Moon \& Kirton, 2016), being in this regard more similar to that 543 of Sisteronia seeleyi (Fischer et al., 2014b) and more basal ichthyosaurs and the early Jurassic

544 Hauffiopteryx (Marek et al., 2015). The element lacks the lateral ridge present in Acamptonectes

545 densus (Fischer et al., 2012). The posterior surface of the opisthotic is flat and only lightly pitted.

546 The ventral side has a shallow groove dividing the facet for articulation with the stapes into two 547 parts.

548

549 Stapes (Fig. 9G)

550 Both stapes are preserved nearly in articulation with the basicranium. The most complete stapes

551 from the holotype (SVB 1451) was originally interpreted to be a left as it was found

552 disarticulated on the left side of the skull (Druckenmiller et al., 2012). However, based on the 
553 articulated material from the new specimen, we reinterpret that from the holotype as a right 554 element that was displaced to the left side of the skull. Morphologically, the element is overall 555 very similar to that of the holotype with a gracile shaft possessing an oval cross-section. The 556 lateral head is only very slightly anteroposteriorly wider compared to the shaft, slightly less than 557 in the holotype (Druckenmiller et al., 2012) and similar to Janusaurus lundi (Roberts et al., 558 2014) in contrast to the expanded lateral head in e. g. Grendelius alekseevi (Zverkov,

559 Arkhangelsky \& Stenshin, 2015). In anterior view, the quadrate facet covers most of the lateral

560 head of the element. The medial head is much wider than the shaft and takes up approximately

561 half of the mediolateral length of the element. In dorsal view, the opisthotic facet is triangular

562 and more posteriorly directed than in Ophthalmosaurus icenicus (Moon \& Kirton, 2016). In

563 ventral view, the basioccipital and basisphenoid facets are barely visible, but in medial view,

564 they are offset at an angle of approximately 45 degrees and lack a ridge between them, as 565 observed in Platypterygius australis (Kear, 2005). Leninia stellans has a large hyoid process, 566 whereas it is lacking in Sisteronia seeleyi, and this feature is probably variable in

567 ophthalmosaurids (Fischer et al., 2012; Fischer et al., 2013). In PMO 222.669, this process is 568 ventrally directed.

569

570 Quadrate (Figs. 9H-I)

571 The right quadrate is distorted whereas the left is very well preserved. In the holotype of

572 Palvennia hoybergeti (SVB 1451), the quadrates were not described due to poor preservation

573 (Druckenmiller et al., 2012). The quadrate has the classic C-shape with a convex medial outline

574 of the pterygoid lamella, and a laterally expanded occipital lamella, such as that seen in

575 Ophthalmosaurus icenicus and several other ophthalmosaurids (Fischer et al., 2013; Moon \&

576 Kirton, 2016). In dorsal view, the occipital lamella forms an angle of 120-130 degrees relative to

577 the pterygoid lamella, similar to Acamptonectes densus (Fischer et al., 2012). The element is

578 more laterally expanded than Platypterygius australis (Kear, 2005), Grendelius alekseevi

579 (Zverkov, Arkhangelsky \& Stenshin, 2015) and UAMES 3411 (Ophthalmosauridae indet.;

580 (Druckenmiller \& Maxwell, 2013). In contrast, Platypterygius hercynicus lacks an occipital

581 lamella (Kolb \& Sander, 2009). The facet for the pterygoid covers almost the entire lamella. As

582 in most ophthalmosaurids, a deep stapedial facet is situated just dorsal to the dorsal surface of the

583 articular condyle (Fig. 9H), although it is more ventrally placed in Sisteronia seeleyi and 
584 Grendelius alekseevi (YKM 56702) (Fischer et al., 2014b; Zverkov, Arkhangelsky \& Stenshin,

585 2015; Moon \& Kirton, 2016). The ventral margin of the facet is thickened, similar to

586 Ophthalmosaurus icenicus and Acamptonectes densus (Fischer et al., 2012; Moon \& Kirton,

587 2016). Medial to the stapedial facet is a tiny foramen. The medial margin is pitted and is

588 anteroposteriorly narrow dorsally and widens ventrally. Platypterygius australis differs in having

589 a groove along this margin (Kear, 2005) whereas the ophthalmosaurid UAMES 3411 is similar

590 to PMO 222.669 (Druckenmiller \& Maxwell, 2013). In ventral view the articular condyle is

591 roughly triangular (Fig. 9I). On the posterior side is a larger facet for the articular, which is

592 typical in most ophthalmosaurids (Kear, 2005; Fischer et al., 2012), but it is the smaller in

593 Gengasaurus nicosiai (Paparella et al., 2016). On the lateral margin is a smaller facet for

594 articulation with the surangular. A small facet lateral and posterior to this is interpreted to be for

595 the quadratojugal.

596

597 Articular (Figs. 10A-C)

598 Both articulars are preserved, the left being found in articulation with the surangular and covered 599 medially by the posterior bar of the prearticular, similar to Ophthalmosaurus icenicus (Moon \& 600 Kirton, 2016). The articulars of PMO 222.669 are similar to those of the holotype (SVB 1451), 601 but better preservation has revealed new information. As in the holotype, the articular differs

602 from most other ophthalmosaurids in being dorsoventrally tallest at the anterior end and broader 603 posteriorly. In medial view, ophthalmosaurid articulars are most commonly oval (Kear, 2005; 604 Maxwell, 2010; Fischer et al., 2014b; Moon \& Kirton, 2016). In PMO 222.669, the articular is 605 rectangular with a slight constriction at the anteroposterior midpoint as in the holotype of 606 Palvennia hoybergeti. The medial side (Fig. 10A) is convex and has a ridge running in the 607 anteroposterior direction which is not as narrow as in Baptanodon natans (Gilmore, 1905). The 608 ventral flange bears an elongated facet posteroventrally. A facet on the dorsal portion of the 609 medial surface has a roughened surface, but the dorsal surface is not thickened as in 610 Platypterygius australis (Kear, 2005). The element widens slightly mediolaterally at the 611 posterior end, which has a rounded outline in medial or lateral view. The surface at the posterior 612 end is more rugose than the rest of the medial side. The lateral surface (Fig. 10B) has an elevated 613 area in its anteroventral region and a double diagonal ridge crossing the element, as in 614 Arthropterygius chrisorum (Maxwell, 2010). In contrast, this ridge runs horizontally in 
615 Ophthalmosaurus icenicus (Moon \& Kirton, 2016). The area dorsal to this ridge articulated with 616 the surangular.

617

\section{Dentary (Fig. 6)}

619 In PMO 222.669, both dentaries are preserved and the left can be studied in both lateral and 620 medial views, whereas they are known in lateral view only from the holotype. The anterior tip is 621 narrow in lateral view compared to the blunter and wider tip in Brachypterygius and 622 Acamptonectes densus (McGowan, 1976; Fischer et al., 2012) and has a ventral margin that 623 curves dorsally, as in Platypterygius australis (Kear, 2005). Overall, the dentary is more robust 624 than the slender one in Aegirosaurus leptospondylus (Bardet \& Fernández, 2000). Anteriorly in 625 the element are preserved several teeth that are smaller than others and appear to be close to life 626 position. Posteriorly, the dental groove widens mediolaterally, resulting in a wide and very 627 shallow groove in the posteriormost half of the elements. Distinct alveoli are absent. On the 628 lateral side, some large foramina are present in the anteriormost portion of the ramus, organized 629 into two rows. These develop into a groove posteriorly that continues for the majority of the 630 anteroposterior length of the element and that deflect ventrally in the most posterior region, 631 possibly for articulation with the angular. The posteriormost portion of the lateral side bears a tall 632 anteroposteriorly oriented depression that widens posteriorly, probably for articulation with the 633 surangular. The medial surface is concave as in Ophthalmosaurus icenicus and Platypterygius 634 australis (Kear, 2005; Moon \& Kirton, 2016) through the entire anteroposterior length of the 635 element, mainly in the ventral half.

636

\section{Splenial (Fig. 6)}

638 Both splenials are completely preserved. In the holotype (SVB 1451), the left splenial is partly 639 visible in ventral view of the skull. The anterior end is forked as in Ophthalmosaurus icenicus 640 and Platypterygius australis (Kear, 2005; Moon \& Kirton, 2016), but the fork is relatively longer 641 than in these taxa and with very long anterior finger-like projections. As in Ophthalmosaurus 642 icenicus, the ventral finger is laterally concave and significantly longer than the dorsal (Moon \& 643 Kirton, 2016). The main body of the element (excluding the forked anterior portion) is 5-10 644 centimetres anteroposteriorly shorter than the surangular and the dentary. The dorsoventral 645 height gradually decreases posteriorly to approximately the same height as the surangular. For 
646 the posteriormost centimetres, the dorsal margin abruptly slopes posteriorly and has an uneven

647 outline as in the holotype specimen of Palvennia hoybergeti and Platypterygius australis (Kear,

648 2005). The posterior margin is significantly thinner than the thickened and subcircular shape

649 found in Pervushovisaurus (Fischer et al., 2014a), and from Cryopterygius kristiansenae, which

650 has a forked posterior end (Druckenmiller et al., 2012). The ventral margin is concave in

651 posterior view as in Platypterygius australis (Kear, 2005). In lateral view, at a point near of the

652 anterior one third of its length, is a small area on the ventral surface where the striations in the

653 surface radiates from in all directions, which might correspond to the point in Muiscasaurus

654 where the splenial becomes less robust because the symphysis ends (Maxwell et al., 2015). The

655 element is longitudinally striated on both its medial and lateral sides posterior to this point.

656 Posteriorly, the lateral surface facing the surangular has two anteroposteriorly oriented ridges.

657

658 Surangular (Figs. 10D-F)

659 Both surangulars are preserved. The right surangular is complete in anteroposterior length (Fig.

660 10D), whereas the left is three-dimensional, but lacks its anterior tip (Fig. 10E). Anteriorly, the

661 surangular curves dorsally in lateral view and is overall similar to Ophthalmosaurus icenicus

662 (Moon \& Kirton, 2016). The dorsal margin is mediolaterally wider and more rounded than the

663 ventral, giving an inverted tear-shape cross-section. In contrast, Pervushovisaurus bannovkensis

664 has a T-shaped cross-section (Fischer et al., 2014a). The anterior tip is mediolaterally and

665 dorsoventrally narrow, and gradually widens posteriorly. In medial view is an anteriorly placed

666 groove midway between the dorsal and ventral margins, interpreted as the symphyseal portion of

667 the Meckelian canal (Moon \& Kirton, 2016). The groove disappears just anterior to the

668 anteroposterior midpoint of the element and is not visible posteriorly, unlike Gengasaurus

669 nicosiai (Paparella et al., 2016) and Platypterygius australis (Kear, 2005). In lateral view (Fig.

670 10D), the longitudinal fossa surangularis is prominent, as in Ophthalmosaurus icenicus (Moon \&

671 Kirton, 2016), but unlike Sveltonectes insolitus, which lacks this feature (Fischer et al., 2011).

672 The fossa surangularis is grooved with a small dorsal overhang, and is dorsoventrally deepest in

673 the anteroposterior midpoint of the element. The surangular foramen is placed midway between

674 the dorsal and ventral margins where the fossa surangularis ends posteriorly. The left surangular

675 has two foramina on the lateral side. Posterior to the two foramina are two dorsal processes, the

676 smallest and most anterior of which is interpreted as the paracoronoid process. Posterior to this is 
677 a dorsomedially directed preglenoid process, also referred to as MAME (M. adductor

678 mandibulae extremus) process. This is similar to Ophthalmosaurus icenicus (Moon \& Kirton,

679 2016) and Janusaurus lundi (Roberts et al., 2014); in contrast Platypterygius australis has only

680 one process (Kear, 2005). The presence of a MAME process is intraspecifically variable in

681 Acamptonectes densus (Fischer et al., 2012). The posteriormost portion of the surangular is

682 shifted laterally posterior to the excavation for the glenoid fossa. The posterior margin has a

683 square outline in lateral or medial view and resembles Platypterygius hercynicus (Kolb \&

684 Sander, 2009) and P. australis (Kear, 2005). It is laterally convex and is more coarsely striated

685 than the rest of the element.

686

687 Angular (Figs. 10G-H)

688 Both angulars are preserved, disarticulated and displaced. It is not known how much of the 689 mandible the angular covered when in articulation. However, the element appears shorter relative

690 to the surangular than in Aegirosaurus leptospondylus, Ophthalmosaurus icenicus and

691 Cryopterygius kristiansenae, and it lacks the long, anterior extension seen in Ophthalmosaurus

692 icenicus (Bardet \& Fernández, 2000; Druckenmiller et al., 2012; Moon \& Kirton, 2016).

693 Anteriorly, the element is instead made up of two thin flanges. The smaller flange of the two is

694 situated medially and the other flange is dorsoventrally taller and on the lateral side. This is more

695 similar to Platypterygius australis, but differs in being longer anteriorly compared to PMO

696222.669 (Kear, 2005). At the anteriormost end of the angular of PMO 222.669 is a narrow

697 opening between two flanges ventrally. The shape and size of the two flanges resulted in more

698 lateral than medial exposure of the angular. Ophthalmosaurus icenicus, Pervushovisaurus

699 bannovkensis and Platypterygius australis have two or three grooves on the dorsal surface of the

700 angular, and some specimens of Acamptonectes densus have only one groove, as in PMO

701222.669 (Kear, 2005; Fischer et al., 2012; Fischer et al., 2014a; Moon \& Kirton, 2016). The

702 element curves dorsally in the posteriormost portion and has an oval cross-section.

703

704 Prearticular (Fig. 10E-F)

705 Both prearticulars are preserved, but neither of them is complete anteriorly. The left prearticular

706 was preserved in articulation with the surangular and articular. In life, this element was probably

707 completely covered in medial view by the (often) disarticulated splenial, similar to 
708 Ophthalmosaurus icenicus (Moon \& Kirton, 2016) and Platypterygius australis (Kear, 2005).

709 The element is mediolaterally thin. The maximum dorsoventral height is situated just anterior to

710 the paracoroniod process on the surangular, similar to Ophthalmosaurus icenicus and Janusaurus

711 lundi (Roberts et al., 2014; Moon \& Kirton, 2016). The dorsal margin is relatively taller

712 compared to the rest of the element than in Platypterygius australis (Kear, 2005). Between the

713 dorsal and ventral margin a small foramen pierces the element. Striations spread out from this

714 point in all directions on the medial and lateral faces of the element. The element decreases

715 abruptly in height towards the posterior bar, which is dorsoventrally short and more coarsely

716 striated than the rest of the element, possibly for muscle attachment (Kear, 2005). The

717 prearticular extends posteriorly almost to the posterior end of the articular. The ventral margin is

718 longitudinally grooved and bears coarse striations in all directions.

719

720 Dentition (Fig. 6C-F)

721 At least 126 teeth are preserved in the anteriormost part of the rostrum, displaced from the dental 722 groove of the premaxillae and dentaries. Additional disarticulated teeth are distributed over the

723 rest of the skull. In the anteriormost part of one dentary are preserved some small teeth almost in

724 life position, similar to the holotype specimen, although this was not noted in the original

725 description (Druckenmiller et al., 2012). The majority of the teeth are between 20 and 34

726 millimetres in height including the crown and root, and crown height varies from 12 to 15

727 millimetres in most teeth. The teeth are not distinctly different in shape nor size from those in the

728 holotype (SVB 1451)(Druckenmiller et al., 2012). The crown covers between one third and one

729 half of total tooth height, more than in Sveltonectes insolitus (Fischer et al., 2011). As in

730 Cryopterygius kristiansenae, the crown is slightly distally curved and has a subtly ridged enamel

731 except in the uppermost portion where they are smooth (Druckenmiller et al., 2012). The base of

732 the enamel layer is straight and well-defined and the crowns are circular in cross-section. An

733 acellular cementum ring (Maxwell, Caldwell \& Lamoureux, 2011) just ventral to the enamel

734 border transitions into fine striations ventrally as in the Russian Arthropterygius sp. . The root is

735 quadrangular in cross-section and slightly compressed in what is probably the labiolingual plane;

736 in this regard it is more similar to Sisteronia seeleyi than to Ophthalmosaurus icenicus and the

737 thickened root in Paraophthalmosaurus ("Yasykovia") (Arkhangelsky, 1997; Efimov, 1999b;

738 Fischer et al., 2014b; Moon \& Kirton, 2016). Many roots show distinct resorption cavities. 


\section{$740 \quad$ Sclerotic plates}

741 At least thirteen disarticulated sclerotic plates are preserved, but many details cannot be

742 discerned. The sclerotic plates are relatively longer compared to width than Platypterygius

743 hercynicus (Kolb \& Sander, 2009), being more similar to Ophthalmosaurus icenicus (Moon \&

744 Kirton, 2016). None of the plates has any thickened portion. The most complete plate measures

74562 millimetres in length, which is similar to Janusaurus lundi (Roberts et al., 2014), 37 in max

746 width (outer edge), 21 millimetres minimum (inner edge).

747

748 Pectoral girdle

\section{Clavicle-interclavicle complex (Fig. 11A)}

750 As in Ophthalmosaurus icenicus, the medial stem of the T-shaped interclavicle is longer than the

751 transverse bar (Moon \& Kirton, 2016), in contrast to Caypullisaurus bonapartei, where the

752 transverse bar is twice the length of the medial stem (Fernández, 1997) and Aegirosaurus

753 leptospondylus where the two are approximately the same length (Bardet \& Fernández, 2000),

754 pers. obs. LLD). The medial stem is unusually mediolaterally wide compared to many other

755 ophthalmosaurids (Druckenmiller et al., 2012) and resembles Grendelius alekseevi (Zverkov,

756 Arkhangelsky \& Stenshin, 2015), but this might be due to compression. The stem narrows

757 slightly towards its posterior end. The visceral side is flat, and in contrast to Janusaurus lundi,

758 there appears to be no trough (Roberts et al., 2014). The medial portion of the clavicle is

759 anteroposteriorly wider than in Athabascasaurus bitumineus (Druckenmiller \& Maxwell, 2010),

760 and is more similar to Paraophthalmosaurus (UPM EP-II-7(1235); pers. obs. LLD). The anterior

761 edge is thickened, and the facets for the scapulae are elongated. The posterodorsal tip of the

762 clavicle is dorsoventrally narrow, and widens gradually anteriorly, resembling PMO 222.667, in

763 contrast to the clavicle of Janusaurus lundi, which widens more abruptly anteriorly (Roberts et

764 al., 2014).

765

766 Scapula (Figs. 11B-F)

767 The left scapula has suffered some deformation in the anterior portion, affecting the shape of the 768 acromion process, which has become flattened, and the description is mainly based on the right 769 element. The anterior portion of the scapula is expanded more ventrally than the dorsal height of 
770 the acromion process (Fig. 11C, E). This is similar to that of Ophthalmosaurus icenicus and

771 Grendelius alekseevi (Zverkov, Arkhangelsky \& Stenshin, 2015; Moon \& Kirton, 2016),

772 whereas Platypterygius americanus and P. australis, in contrast, have an anterior part almost

773 similarly expanded dorsally and ventrally (Maxwell \& Kear, 2010; Zammit, Norris \& Kear,

774 2010). In lateral view (Fig. 11C), the acromion process is only slightly expanded dorsally, less

775 than PMO 222.667 and Paraophthalmosaurus ("Yasykovia"; UPM EP-II-7(1235), pers. obs.

776 LLD) (Efimov, 1999b) and more similar to Cryopterygius kristiansenae and Grendelius

777 alekseevi (Druckenmiller et al., 2012; Zverkov, Arkhangelsky \& Stenshin, 2015). It has a large

778 dorsolateral flange approaching the size of Sveltonectes insolitus (Fischer et al., 2011) and PMO

779 224.250, being considerably larger than in PMO 222.667. In anterior view, there is a

780 mediolaterally narrow portion ventral to the acromion process, but lacks a notch as in

781 Sveltonectes insolitus (Fischer et al., 2011). Ventral of this is the mediolaterally expanded

782 articular region with the coracoid and glenoid facets, the latter being the smaller of the two. Both

783 facets are deeply rugose and more demarcated from each other than in Keilhauia nui, PMO

784222.667 (Delsett et al., 2017) and Platypterygius americanus (Maxwell \& Kear, 2010). The

785 glenoid facet is almost circular in shape and faces more ventrally than in PMO 222.667. The

786 dorsal margin of the posterior shaft is nearly straight whereas the ventral margin is concave

787 resulting in a slight dorsoventral expansion in the posterior end as in Caypullisaurus bonapartei

788 (Fernández, 1997, MLP 83-XI-16-1, pers. obs. AJR), somewhat more than Keilhauia nui (Delsett

789 et al., 2017) and Baptanodon natans (Gilmore, 1905), but less than in Sveltonectes insolitus

790 (Fischer et al., 2011),Platypterygius americanus (Maxwell \& Kear, 2010) and Grendelius

791 alekseevi (Zverkov, Arkhangelsky \& Stenshin, 2015). The posterior shaft is relatively short

792 compared to the anterior portion compared to the more slender shaft in Grendelius alekseevi

793 (Zverkov, Arkhangelsky \& Stenshin, 2015)

794

\section{Coracoid (Figs. 11G-H)}

796 The coracoid is slightly anteroposteriorly longer than mediolaterally wide, as in Cryopterygius

797 kristiansenae (Druckenmiller et al., 2012) and Undorosaurus spp. (Efimov, 1999a) but not as

798 narrow as Paraophthalmosaurus (UPM EP-II-7(1235), pers. obs. LLD) and Nannopterygius

799 enthekiodon (Kirton, 1983). The scapular and glenoid facets are angled medially so that the

800 coracoid is mediolaterally narrower in the posterior part than in the middle, and makes the 
801 outline of the coracoid resemble that of Sveltonectes insolitus (Fischer et al., 2011), differing

802 from the hexagonal coracoid in Acamptonectes densus (Fischer et al., 2012) and the more

803 circular element in Platypterygius hercynicus (Kolb \& Sander, 2009) and P. australis (Zammit,

804 Norris \& Kear, 2010).

805

806 The coracoid possesses a well-defined anterior notch and an anteromedial process. Relative to

807 the size of the anteromedial process, the anterior notch is mediolaterally narrow compared to

808 Ophthalmosaurus icenicus and Acamptonectes densus (Fischer et al., 2012; Moon \& Kirton,

809 2016). The anterior notch is anteroposteriorly shorter than Keilhauia nui (Delsett et al., 2017) but

810 longer and narrower than in PMO 222.667 and Arthropterygius chrisorum (Maxwell, 2010). The

811 anterior process is straighter in dorsal view than the processes found in Sveltonectes insolitus

812 (Fischer et al., 2011) and Janusaurus lundi (Roberts et al., 2014). The dorsal surface is flat,

813 which is similar to PMO 222.667, in contrast to Ophthalmosaurus icenicus, which has coracoids

814 that have convex ("saddle-shaped") dorsal and ventral sides (Moon \& Kirton, 2016). The

815 posterior margin is dorsoventrally thin. The intercoracoid facet is not visible due to either

816 taphonomic or osteological damage. The scapular and glenoid facets are well demarcated and the

817 glenoid facet is the longest. The scapular facet is relatively longer compared to the glenoid facet

818 than in Ophthalmosaurus icenicus and Grendelius alekseevi (Zverkov, Arkhangelsky \&

819 Stenshin, 2015; Moon \& Kirton, 2016) and PMO 222.669 resembles Sveltonectes insolitus

820 (Fischer et al., 2011) in this aspect. The articular surface of the glenoid facet faces

821 ventrolaterally.

822

823 Humerus (Fig. 12)

824 The humerus is oriented based on McGowan and Motani (2003). The proximal end is slightly

825 anteroposteriorly narrower than the distal end, similar to but less pronounced than in Janusaurus

826 lundi (Roberts et al., 2014). Sveltonectes insolitus (Fischer et al., 2011) and Platypterygius

827 americanus possess a wider proximal than distal end (Maxwell \& Kear, 2010). In dorsal view,

828 the proximal end is not straight as in Janusaurus lundi and Arthropterygius chrisorum (Maxwell, 829 2010; Roberts et al., 2014) but is strongly convex.

830 
831 The dorsal process of the humerus of PMO 222.669 originates near the midpoint of the proximal

832 end similar to that seen in the Indian Ophthalmosauridae indet. KGMV-0501 (Prasad et al.,

833 2017), and its long axis is angled less anteriorly than in PMO 222.667, PMO 224.250 and PMO

834 230.097. The dorsal process extends to the proximodistal midpoint, as in Undorosaurus

835 gorodischensis (Efimov, 1999a) and Ophthalmosaurus icenicus (Moon \& Kirton, 2016). This is

836 proximodistally shorter than in Arthropterygius chrisorum (Maxwell, 2010) and Platypterygius

837 hercynicus (Kolb \& Sander, 2009), but longer than in Keilhauia nui (Delsett et al., 2017). In

838 anterior view the deltopectoral crest is dorsoventrally short and does not reach the midpoint of

839 the element on the ventral side, similar to Keilhauia nui (Delsett et al., 2017) and

840 Arthropterygius chrisorum (Maxwell, 2010). This contrasts the triangular and protruding crest

841 found in many other ophthalmosaurids (e.g. PMO 230.097, PMO 222.667, PMO 224.250,

842 (Fischer et al., 2012)). Its placement along the anterior margin of the ventral side is similar to

843 Ophthalmosaurus icenicus (Moon \& Kirton, 2016). Two pairs of rugosities, possibly

844 representing muscle insertion points, are located on the dorsal and ventral sides in the distal part

845 of the element. Small processes in this portion of the humerus are also found in Sveltonectes

846 insolitus and Ichthyosaurus anningae and might represent the same structures (Fischer et al.,

847 2011; Lomax \& Massare, 2015).

848

849 There are three distal articular facets for a preaxial accessory element, and the radius and ulna.

850 This is similar to all other SML ophthalmosaurids (including the partial humerus of the

851 Palvennia hoybergeti holotype) with the exception of Cryopterygius kristiansenae, which has

852 two facets on one humerus and three facets on the other in addition to several other

853 ophthalmosaurids e. g. Caypullisaurus bonapartei, Acamptonectes densus and Undorosaurus

854 (Fernández, 1997; Efimov, 1999a; Druckenmiller et al., 2012; Fischer et al., 2012; Arkhangelsky

855 \& Zverkov, 2014; Roberts et al., 2014; Zverkov et al., 2015; Delsett et al., 2017). In contrast,

856 Aegirosaurus leptospondylus, Maiaspondylus lindoei, Grendelius and Brachypterygius extremus

857 have a third facet for the intermedium (McGowan, 1976; Bardet \& Fernández, 2000; Maxwell \&

858 Caldwell, 2006; Zverkov, Arkhangelsky \& Stenshin, 2015), whereas Platypterygius americanus

859 has a third facet for a postaxial accessory element (Maxwell \& Kear, 2010). In PMO 222.669,

860 the facet for the radius is only slightly larger than the ulnar facet. In Ophthalmosaurus icenicus

861 specimens, the three facets vary in relative size and orientation (Moon \& Kirton, 2016). As in 
862 Gengasaurus nicosiai (Paparella et al., 2016) and Arthropterygius chrisorum (Maxwell, 2010)

863 the ulnar facet is not posteriorly deflected, unlike in Keilhauia nui (Delsett et al., 2017).

864

865 The right humerus may bear a pathological feature on the ventral side near the posterior margin, 866 probably a rugosity due to healing, resulting from a simple trauma (Pardo-Pérez et al., 2017).

867

868

869

\section{Zeugopodium and autopodium (Figs. 12A, B, D)}

Because the preserved forefin elements remain in articulation, it is possible to assign them with

870 confidence, based on Ophthalmosaurus icenicus and Cryopterygius kristiansenae

871 (Druckenmiller et al., 2012; Moon \& Kirton, 2016). The total number of digits is unknown. The

872 two larger elements that articulate with the distal end of the humerus are recognized as the radius

873 and ulna, leaving the anteroposteriorly smaller and anterior element to be interpreted as the

874 preaxial accessory element. The preaxial accessory element articulates with the humerus, radius,

875 radiale and a small unassigned distal element, possibly part of a supernumerary digit, and has no

876 additional anterior facets. The element is marginally anteroposteriorly longer than

877 proximodistally wide and is less dorsoventrally tall proximally than the radius and ulna.

878

879 The radius articulates with the intermedium and radiale distally, the ulna posteriorly and the

880 preaxial accessory element anteriorly. Of these, the radiale facet is the longest, followed by the

881 intermedium, preaxial accessory and ulna facet respectively. The humeral facet resembles that of

882 the ulna in being convex, but not as extreme as in Arthropterygius chrisorum (Maxwell, 2010).

883

884 The ulna is anteroposteriorly wider than proximodistally long, and proximodistally longer than

885 the radius as in Janusaurus lundi (Roberts et al., 2014) and Platypterygius hercynicus (Kolb \&

886 Sander, 2009). The proximal end is dorsoventrally approximately twice as tall as the distal end.

887 The articular facet with the humerus is convex. In addition, the ulna articulates with the radius,

888 intermedium and ulnare; the facet for the radius is approximately half the length of that for the

889 intermedium and ulnare, which are subequal in length. The posterior margin of the ulna is the

890 dorsoventrally shortest of the margins so that the ulna element tapers posteriorly (Fischer et al.,

891 2012), and it bears two distinct surfaces. One is situated proximally and is approximately $1 \mathrm{~cm}$

892 long, dorsoventrally thin and straight in dorsal view, with a finished surface, and is not concave 
893 as in Acamptonectes densus and Ophthalmosaurus icenicus (Fischer et al., 2012). The other

894 surface is a small, fifth facet directed posteriorly and slightly distally, probably for contact with a 895 pisiform as in Acamptonectes densus (Fischer et al., 2012).

896

897 The radiale, intermedium and ulnare are all anteroposteriorly wider than proximodistally long.

898 The ulnare articulates with the intermedium anteriorly, an unidentified distal element that could

899 represent metacarpal 5 and distal carpal 4 , with the facet for the ulna being the longest. The

900 intermedium is anteroposteriorly wider than proximodistally long and articulates with the ulnare,

901 distal carpal 4 and 3 and possibly the radiale. The radiale articulates with distal carpals 2 and 3 ,

902 as well as the unidentified anterior element, with the longest facet for the radius. The three distal

903 carpals are of approximately the same size. It is unclear how many elements distal carpal 3 and 4

904 articulated with distally. Distal carpal 2 articulated with the unknown anterior element

905 proximally, and at least one metacarpal distally.

906

907 Distal to this, the fin preserves respectively seven (on the right) and five (on the left) elements,

908 representing metacarpals and phalanges. The elements are circular or oval in dorsal view, not

909 squared as in Platypterygius australis (Zammit, Norris \& Kear, 2010), Platypterygius hercynicus

910 (Kolb \& Sander, 2009) and Sveltonectes insolitus (Fischer et al., 2011). An interesting feature is

911 that the forefin elements seem to decrease abruptly in size distally, resulting in small metacarpals

912 compared to the distal carpals and even smaller phalanges distal to the metacarpals. Both forefins

913 were found in articulation, but might be missing distal elements. However, elements of such a

914 small size occurring in the fourth and fifth row distal to the humerus is uncommon, and differ

915 from many species with preserved forefins such as Cryopterygius kristiansenae, Platypterygius

916 hercynicus, Aegirosaurus leptospondylus, Grendelius alekseevi and Brachypterygius extremus

917 (Kirton, 1983; Bardet \& Fernández, 2000; Kolb \& Sander, 2009; Druckenmiller et al., 2012;

918 Zverkov, Arkhangelsky \& Stenshin, 2015). Some forefins of Ophthalmosaurus icenicus and

919 Baptanodon natans (Gilmore, 1906; Moon \& Kirton, 2016) have a relatively abrupt decrease in

920 zeugopodial and autopodial size, but the distalmost elements preserved in PMO 222.669 are even

921 smaller than their counterparts in those species.

922 
923 Two small elements were found associated with the left forefin, out of which one has the shape

924 of half an oval and could represent the pisiform. The other is circular in dorsal view and probably

925 a phalanx.

926

927 Vertebral column (Fig. 13)

928 The atlas and axis are fully fused. There is no visible suture, but if the dia- and parapophyses of

929 the axis are assumed to be situated on the anterior margin, the two centra are of approximately

930 the same anteroposterior length, in addition to having the same maximum mediolateral width.

931 The anterior (Fig. 13A) and posterior articular faces of the centrum are both pentagonal with a

932 pronounced ventral keel, resulting in an overall cordate outline, similar to the holotype of

933 Palvennia hoybergeti (Druckenmiller et al., 2012) and Platypterygius hercynicus (Kolb \&

934 Sander, 2009). The element is relatively mediolaterally wider compared to height, and with a

935 more pronounced pentagonal shape in anterior view compared to that of Mollesaurus periallus

936 (Fernández, 1999) and Arthropterygius chrisorum (Maxwell, 2010).

937

938 In lateral view (Fig 13B), the two rib facets of the atlas are well demarcated, of which the

939 diapophysis is confluent with the dorsal margin. The parapophysis is situated approximately

940 midway between the dorsal and ventral margins. The facets are confluent with the anterior

941 margin as in Arthropterygius chrisorum (Maxwell, 2010), in contrast to Ophthalmosaurus

942 icenicus (Moon \& Kirton, 2016) where the parapophysis is interpreted to be situated posteriorly

943 on the atlas and axis part of the element. On the axis, a circular facet is situated in the dorsal half

944 and is interpreted to be the diapophysis as in Ophthalmosaurus icenicus (Moon \& Kirton, 2016).

945 The position of the facets are similar to those seen in Platypterygius americanus (Maxwell \&

946 Kear, 2010) but differs from Athabascasaurus bitumineus where they form a continuous ridge of

947 bone (Druckenmiller \& Maxwell, 2010). The ventral margin is approximately one $\mathrm{cm}$ wide in

948 anterior and posterior view and slightly concave, possibly for articulation with an intercentrum.

949 The groove runs along entire element and is similar to that of Palvennia hoybergeti

950 (Druckenmiller et al., 2012).

951

952 The remaining vertebrae from the cervical and anterior dorsal region show an increase in height

953 posteriorly (Figs. 13D-E). The anteroposterior length varies, but in general the more posterior 
954 vertebrae are longer than those more anterior, typical of ophthalmosaurids (Buchholtz, 2001;

955 Massare et al., 2006; Kolb \& Sander, 2009). The vertebrae are approximately circular in anterior

956 or posterior view. The neural arch of the atlas-axis complex is fused and is smaller than the other

957 preserved neural arches. None of the neural arches are fused to the centra.

958

959 The anterior ribs (Fig. 13E) show a variable morphology in cross-section; while some display the

960 typical ophthalmosaurid figure- 8 cross-section proximally and more rounded distally (e.g.

961 Roberts et al., 2014), others have a thickened dorsal margin resulting in a T-shape in cross-

962 section. Some ribs have longitudinal striations in the proximal part as in the Ophthalmosauridae

963 indet. PMO 222.670 (Delsett et al., 2017), but the striations are shallower. Many ribs show signs

964 of having been broken and healed based on the presence of calluses.

965

966 Gastralia

967 The gastralia are narrow and have a circular cross section.

968

$969 * * * *$

970 Ichthyosauria de Blainville 1835

971 Neoichthyosauria Sander 2000

972 Thunnosauria Motani 1999

973 Ophthalmosauridae Baur 1887

974 Ophthalmosauridae indet.

975

976 Referred material: PMO 222.658/PMO 230.097; skull remains, forefins, partial pectoral girdle 977 and associated vertebrae (Figs. 14-16, Table 2, Supplemental table 2).

978

979 Locality: Island of Spitsbergen, north side of Janusfjellet, approximately 13 kilometres north of

980 Longyearbyen, Svalbard, Norway. UTM WGS84 33X 05188448696066.

981

982 Horizon and stage: Slottsmøya Member, Agardhfjellet Formation, Janusfjellet Subgroup, 
983 latest Tithonian (Late Jurassic) or possibly earliest Berriasian (Early Cretaceous). 39.1 metres

984 above the echinoderm marker bed (Delsett et al., 2016).

985

986 Preservation

987 A partial humerus, two partial coracoids and some unidentified pieces were found disarticulated

988 close to the other humerus, radius, ulna and intermedium preserved associated with three smaller

989 forefin elements, a partial coracoid, an element which might be a partial scapula or an

990 ischiopubis and seventeen caudal vertebrae (Fig. 14). The forefin elements are very well

991 preserved, complete and in three dimensions. The vertebral centra are three-dimensional and,

992 with the exception of one vertebra, complete. Fragments from the skull, ribs and what is

993 probably the rest of the pectoral girdle are present but preserved in an extremely poor state that

994 prohibits further description.

995

996 Ontogeny

997 The elements are relatively small compared to other SML specimens considered to be adult

998 (Druckenmiller et al., 2012; Roberts et al., 2014), but are approximately the same size of the

999 subadult to adult Keilhauia nui holotype (Delsett et al., 2017). The smooth and finished surface

1000 on all elements support an adult ontogenetic stage (Johnson, 1977). Other ontogenetically

1001 informative features of the skull, neural spines and forefins are not applicable (Johnson, 1977;

1002 Kear \& Zammit, 2014).

1003

\section{Humerus (Fig. 15A-D)}

1005 The most complete humerus is interpreted to be a left, based on McGowan and Motani (2003).

1006 The proximal end is anteroposteriorly wider than the distal end, in contrast to PMO 222.669,

1007 PMO 224.250 and Ophthalmosaurus icenicus (Moon \& Kirton, 2016). The humerus is narrower

1008 anteroposteriorly compared to proximodistal length than these taxa, with a stronger constriction

1009 mid-shaft, and is more similar to that of Sveltonectes insolitus (Fischer et al., 2011) and

1010 Acamptonectes densus (Fischer et al., 2012). In dorsal view, the anterior margin is more concave

1011 than the posterior. In the proximal part the posterior margin is remarkably dorsoventrally thin.

1012 
1013 The dorsal process originates proximally slightly posterior to the anteroposterior midpoint. It is

1014 of the same relative height as in PMO 222.669 and PMO 224.250, but more prominent than in

1015 Keilhauia nui (Delsett et al., 2017). It extends slightly distal to the proximodistal mid-point of

1016 the element similar to PMO 224.250, which is further than in Undorosaurus gorodischensis and

1017 Aegirosaurus leptospondylus (Efimov, 1999a; Bardet \& Fernández, 2000). The deltopectoral

1018 crest is restricted to the anterior portion of the ventral surface and is limited in size; however, it

1019 extends to the proximodistal midpoint and thus resembles PMO 222.667 and PMO 222.669,

1020 whereas it is more prominent in PMO 224.250. The distal end has three articular facets for the

1021 preaxial accessory element, radius and ulna. Unlike PMO 222.667, PMO 224.250, Undorosaurus

1022 trautscholdi, the Russian Arthropterygius sp. specimen SGM 1502 (Arkhangelsky \& Zverkov,

1023 2014; Zverkov et al., 2015; Delsett et al., 2017) and many Ophthalmosaurus icenicus specimens

1024 (Moon \& Kirton, 2016), the ulnar facet is the largest as in Baptanodon natans and some

1025 specimens of Acamptonectes densus (Gilmore, 1905; Fischer et al., 2012). It is similar to

1026 Sveltonectes insolitus, but this species lacks a third facet. The facet for the preaxial accessory

1027 element is small and shallow compared to other SML ichthyosaurs (Roberts et al., 2014; Delsett

1028 et al., 2017). The ulnar facet is posteriorly deflected as in Acamptonectes densus and Keilhauia

$1029 n u \mathrm{i}$ in contrast to Gengasaurus nicosiai and platypterygiine ophthalmosaurids (Fischer et al.,

1030 2012; Paparella et al., 2016; Delsett et al., 2017). A small area of finished bone surface is

1031 situated posterior to the ulnar facet on the posterior margin, either representing a minute facet or

1032 an area covered by articular cartilage in life.

1033

1034 Epipodials and remaining forefin elements (Fig. 15A-B)

1035 The ulna is approximately 50\% larger than the radius in length and width. In PMO 222.669 the

1036 ulna is also anteroposteriorly longer than the radius, but not to such an extent. The radius and

1037 ulna of Platypterygius australis and Undorosaurus trautscholdi are in contrast of similar size

1038 (Zammit, Norris \& Kear, 2010; Arkhangelsky \& Zverkov, 2014) whereas the ulna is

1039 significantly larger in Paraophthalmosaurus ("Yasykovia”)(Efimov, 1999b). The ulna of PMO

1040230.097 has a dorsoventrally tall articular facet for the humerus and appears to have little contact

1041 with the radius. The radius has a dorsoventrally tall articular side towards the humerus and a

1042 small facet for the ulna, and the facet for the intermedium is longer. The intermedium is smaller

1043 than radius and ulna. The largest of the three additional elements is oval in dorsal view. In 
1044 addition, there is a smaller element with a shape similar to the possible pisiform identified in

1045 PMO 222.669. It has one straight side that is dorsoventrally short and one that is tall and

1046 concave. The third element is small and oval and likely a phalanx.

1047

1048 Coracoid (Fig. 15E)

1049 The more saddle-shaped surface is interpreted to be ventral. Compared to most other

1050 ophthalmosaurids, the element is relatively flat on both surfaces (e. g. PMO 222.669,

1051 Sveltonectes insolitus and Ophthalmosaurus icenicus and (Fischer et al., 2011; Moon \& Kirton,

1052 2016)). As the coracoids are incomplete, accurate measurements are not possible, but they were

1053 probably relatively wider compared to the very mediolaterally narrow elements of

1054 Nannopterygius enthekiodon and Paraophthalmosaurus (Kirton, 1983; Arkhangelsky, 1997) The

1055 intercoracoid facet is unique among ophthalmosaurids in reaching much farther anteriorly

1056 compared to the anterior margin of the scapular facet. In medial view, the intercoracoid facet is

1057 dorsoventrally tallest anteriorly. An anterior notch is present as in other ophthalmosaurids, but

1058 the size and shape of the anterior process is unknown. The glenoid and scapular facets are well

1059 demarcated, and are thus more similar to PMO 222.669 than to PMO 222.667, Janusaurus lundi

1060 and Grendelius alekseevi where the transition between the two facets is more gradual (Roberts et

1061 al., 2014; Zverkov, Arkhangelsky \& Stenshin, 2015). The glenoid facet is longer than the

1062 scapular facet, but less so than in most other ophthalmosaurids e. g. Undorosaurus

1063 gorodischensis (Efimov, 1999a) where the glenoid facet is considerably longer, and it resembles

1064 PMO 222.669 in this aspect (Moon \& Kirton, 2016). Both the scapular and glenoid facets are

1065 triangular in lateral view, with the apex pointing anteriorly in the former, and posteriorly in the

1066 latter. In contrast the facets are fusiform in Arthropterygius chrisorum (Maxwell, 2010). The

1067 scapular facet has a more rugose surface than the glenoid facet. The articular facet of the glenoid

1068 faces slightly ventrally and not just laterally, more than in most ophthalmosaurids, and resembles

1069 PMO 222.669 in this aspect..

1070

1071 Vertebrae (Fig. 16)

1072 The vertebrae are interpreted as caudals as they bear a single ventrolaterally positioned rib facet

1073 (Buchholtz, 2001; Moon \& Kirton, 2016). The centra are amphicoelous, which differs from

1074 Arthropterygius chrisorum where this is absent in caudal centra (Maxwell, 2010) and is in this 
1075 regard more similar to Sveltonectes insolitus (Fischer et al., 2011) and Gengasaurus nicosiai

1076 (Paparella et al., 2016). The relative proportions of height, length and width are similar to the

1077 anterior caudal series of Ophthalmosaurus icenicus (Buchholtz, 2001) and Sveltonectes insolitus

1078 (Fischer et al., 2011). In contrast, the caudal centra have relatively higher height: length

1079 proportions in Arthropterygius chrisorum (Maxwell, 2010), whereas the ratio is slightly lower in

1080 Gengasaurus nicosiai (Paparella et al., 2016) and Athabascasaurus bitumineus (Druckenmiller \&

1081 Maxwell, 2010). The eight vertebrae with the largest absolute dorsoventral height have a

1082 dorsoventrally elongated apophysis (Fig. 16B), whereas the remaining nine vertebrae have

1083 circular facets (Fig.16D). The largest centra are interpreted to have been the anteriormost in the

1084 series (Buchholtz, 2001; Maxwell \& Caldwell, 2006; Maxwell, 2010; Moon \& Kirton, 2016) and

1085 the elongated facet is probably a result of its position just posterior to fusion of the diapophysis

1086 and parapophysis. When the centra are ordered based on height, there is a significant decrease in

1087 width and a small decrease in length posteriorly, which is found in many ophthalmosaurids

1088 (Massare et al., 2006; Fischer et al., 2011; Druckenmiller et al., 2012). The maximum

1089 anteroposterior length consistently appears on the ventral side of the centrum as in

1090 Platypterygius americanus possibly for a slight dorsal curvature anterior to the tail bend

1091 (Maxwell \& Kear, 2010). In most vertebrae the maximum mediolateral width occurs ventral to

1092 the midpoint as in Platypterygius americanus (Maxwell \& Kear, 2010), whereas some of the

1093 more posteriorly placed centra are more circular in anterior view, similar to the anterior caudal

1094 vertebrae of Keilhauia nui (Delsett et al., 2017) and Platypterygius australis (Zammit, Norris \&

1095 Kear, 2010). The elongated facets of more anterior centra are more ventrally situated than the

1096 circular facets on more posterior vertebrae. This resembles the situation interpreted for

1097 ?Ichthyosaurus ?somersetensis (NHMUK OR14563 in McGowan \& Motani, 2003; Massare \&

1098 Lomax, 2018) and Platypterygius hercynicus (Kolb \& Sander, 2009). The elongated and ventral

1099 facets are placed at a more equal distance between the anterior and posterior margin, whereas the

1100 circular facets touches the anterior margin. Six of the vertebrae with ventrally placed and

1101 elongated facets possess a distinct horizontal ridge dorsal to the lateral midpoint (Fig. 16B). The

1102 neural canal has dorsoventrally tall lateral margins formed by the neural arch facets. In most

1103 vertebrae, the minimum mediolateral width is encountered midway between the anterior and

1104 posterior margins but is not wholly hourglass-shaped.

1105 
1107 Referred material: PMO 224.250; partial basioccipital and a nearly complete pectoral girdle

1108 and forefins (Figs. 17-20, Table 2, Supplemental table 3).

1110 Locality: Island of Spitsbergen, Wimanfjellet, approximately 14 kilometres north of

1111 Longyearbyen, Svalbard, Norway. UTM WGS84 33X 05235498696407.

1113 Horizon and stage: Slottsmøya Member, Agardhfjellet Formation, Janusfjellet Subgroup,

1114 late Tithonian, Late Jurassic. 19 metres above the echinoderm marker bed (Delsett et al., 2016).

1116 Preservation

1117 The clavicle-interclavicle complex is severely fractured and incomplete and the right clavicle

1118 lacks the distal tip (Fig. 17). The scapulae preserve only the anteriormost part of the element.

1119 The two coracoids are preserved in articulation, three dimensional and nearly complete, but the

1120 left is broken along the anterior margin. The humeri are complete and preserved three

1121 dimensionally. It is not possible to assign all of the forefin elements to either the left or right

1122 sides due to disarticulation. The left humerus and elements preserved closest to it are more

1123 deformed than the others. The preaxial accessory element, radius and ulna are articulated to the

1124 right humerus. The left ulna is articulated with the humerus and the radius is found in close

1125 proximitiy together with an unknown element that is possibly the left preaxial accessory element.

1126 The remaining, unassigned elements vary largely in size and probably include carpals,

1127 metacarpals and phalanges.

1128

1129 Ontogeny

1130 The elements are comparable in size or larger than largest specimens such as Cryopterygius

1131 kristiansenae and the ophthalmosaurid PMO 222.670 from the SML (Druckenmiller et al., 2012;

1132 Roberts et al., 2014), suggestive of an adult stage. As the elements are severely fractured, the

1133 surface texture is not easily detectable, but the surfaces visible on the humerus and pectoral

1134 girdle appear to be finished bone, also indicative of an advanced ontogenetic stage (Johnson, 1135 1977). 


\section{Basioccipital (Fig. 18)}

1138 The basioccipital has a figure 8-shaped notochordal pit, with the ventral loop being smaller than

1139 the dorsal. The preserved extracondylar area appears reduced compared to Ophthalmosaurus

1140 icenicus (Moon \& Kirton, 2016) and more similar to Palvennia hoybergeti and Grendelius

1141 alekseevi (Druckenmiller et al., 2012; Zverkov, Arkhangelsky \& Stenshin, 2015), but is present

1142 laterally and ventrally as a peripheral groove.

1144 Humerus (Fig. 19)

1145 The proximal end of the humerus is slightly anteroposteriorly narrower than the distal end, as in

1146 PMO 222.669 and many other ophthalmosaurids e. g. Aegirosaurus leptospondylus, Janusaurus

1147 lundi and Ophthalmosaurus icenicus (Bardet \& Fernández, 2000; Roberts et al., 2014; Moon \&

1148 Kirton, 2016) in contrast to Gengasaurus nicosiai where the distal end is anteroposteriorly wider

1149 (Paparella et al., 2016). The dorsal process is tall relative to the total dorsoventral height of the

1150 element. Its proximal end originates slightly posterior to the middle of the proximal head and

1151 ends near the approximate proximodistal midpoint of the element. As a result, the height and

1152 proximodistal length are markedly greater than that of PMO 222.669, being more similar to

1153 Platypterygius hercynicus (Kolb \& Sander, 2009) and Platypterygius americanus (Maxwell \&

1154 Kear, 2010). In ventral view, the deltopectoral crest is triangular in outline and of similar height

1155 to the dorsal process. It extends distally to the mid-point of the humerus. Its large size differs

1156 from PMO 222.669 and Arthropterygius chrisorum (Maxwell, 2010), which have small

1157 deltopectoral crests. It is more similar to PMO 222.667 and Ophthalmosaurus icenicus (Moon \&

1158 Kirton, 2016) although not as large as in Acamptonectes densus and Sveltonectes insolitus

1159 (Fischer et al., 2011; Fischer et al., 2012).

1160

1161 The distal end bears three articular facets for the preaxial accessory element, radius and ulna

1162 typical of most ophthalmosaurids, including other SML specimens (Roberts et al., 2014;

1163 Fernández \& Campos, 2015; Moon \& Kirton, 2016; Paparella et al., 2016; Delsett et al., 2017) in

1164 contrast to e.g. Cryopterygius kielanae and Nannopterygius enthekiodon (Kirton, 1983;

1165 Tyborowski, 2016). The facet for the preaxial element is anteriorly deflected as in e.g.

1166 Acamptonectes densus (Fischer et al., 2012), triangular in distal view and less concave than the

1167 other two facets. As in PMO 222.669, the radial facet is the largest. The ulnar facet is posteriorly 
1168 deflected as in e.g. PMO 222.669 and Acamptonectes densus, in contrast to PMO 230.097,

1169 Gengasaurus nicosiai and Arthropterygius chrisorum (Maxwell, 2010; Fischer et al., 2012;

1170 Paparella et al., 2016).

1171

1172 Epipodium and intermedium (Fig. 19A-C)

1173 The preaxial accessory element is approximately circular in dorsal view and smaller than the

1174 radius and ulna. The dorsoventral height of the humeral facet is taller than the other margins.

1175 Compared to PMO 222.669, this element in PMO 224.250 is dorsoventrally taller along its

1176 anterior margin. The radius and ulna are of approximately equal size as in Undorosaurus

1177 trautscholdi (Arkhangelsky \& Zverkov, 2014). The facets of the radius are less well-defined than

1178 in PMO 222.669 but the radius seems to have possessed the same number of facets, with a

1179 similar relative size and general shape. The ulna varies in dorsoventral thickness, being taller

1180 proximally than distally. It is equal in anteroposterior length and proximodistal width. Similar to

1181 PMO 222.669, it has a straight posterior margin in dorsal view. Compared to PMO 222.669, the

1182 facets are less well defined, and the margins more rounded, but they are otherwise very similar in

1183 shape and in the relative size of the facets. PMO 224.250 lacks the well-defined posterior "fifth

1184 facet" on the posterior margin of the ulna as seen in PMO 222.669. The intermedium is nearly

1185 circular in dorsal view and smaller than the epipodials. It articulates with the radius and ulna

1186 proximally, and the facet for the ulna is approximately $1.0 \mathrm{~cm}$ long and more well-defined than

1187 other facets. The dorsoventral height is nearly uniform, but it is somewhat taller anteriorly.

1188

1189 Pectoral girdle

1190 Clavicle-interclavicle complex (Fig. 20A)

1191 The interclavicle shows the typical T-shape of ophthalmosaurids; the transverse bar is straight

1192 and probably shorter than the medial stem, as in Ophthalmosaurus icenicus (Moon \& Kirton,

1193 2016). The medial stem of the interclavicle is the best preserved portion of the element, and is

1194 almost complete. It is significantly more slender mediolaterally than PMO 222.669 and

1195 Grendelius alekseevi (Zverkov, Arkhangelsky \& Stenshin, 2015). The minimum mediolateral

1196 width is encountered just posterior to the transverse bar, and posterior to this the stem widens

1197 only slightly, as in Cryopterygius kristiansenae and some specimens of Ophthalmosaurus 
1198 icenicus (e.g. OUMNH J48012, pers. obs. LLD). The visceral surface is concave, but lacks the

1199 narrow trough of Janusaurus lundi (Roberts et al., 2014).

1200

\section{Scapula (Fig. 20B-D)}

1202 The anterior portion is expanded dorsally and ventrally, resembling PMO 222.669. The shape of

1203 the acromion process is also similar to PMO 222.669, with a distinct dorsolateral flange that is

1204 smaller than in Sveltonectes insolitus (Fischer et al., 2011) and proportionately larger than in

1205 PMO 222.667, Cryopterygius kristiansenae and Keilhauia nui (Druckenmiller et al., 2012;

1206 Delsett et al., 2017). The glenoid and coracoid facets are not clearly separated, unlike PMO

1207222.669 where there is a clear separation. The coracoid facet is dorsoventrally taller than the

1208 glenoid facet. A deep dorsoventrally-oriented groove is visible primarily along the coracoid

1209 facet; it is present in both elements, and is likely not a taphonomic artefact.

1210

\section{Coracoid (Fig. 20E)}

1212 The two coracoids appear to be fused along the midline as in PMO 222.669. Each coracoid is

1213 slightly anteroposteriorly longer than mediolaterally wide, as in PMO 222.669 differing from the

1214 mediolaterally narrow coracoids of Sveltonectes insolitus, Paraophthalmosaurus and

1215 Nannopterygius enthekiodon (Kirton, 1983; Efimov, 1999b; Fischer et al., 2011). In ventral

1216 view, the coracoids are roughly hexagonal, with medial and lateral sides that are parallel, and the

1217 medial being the longest. The posterior margin is angled like a wide V compared to the broadly

1218 rounded or nearly straight posterior margins of Janusaurus lundi (Roberts et al., 2014) and

1219 Undorosaurus spp. (Efimov, 1999a). Cryopterygius kristiansenae (Druckenmiller et al., 2012)

1220 and Acamptonectes densus (Fischer et al., 2012) possess an angled posterior margin, however,

1221 the angle is less acute. An anterior notch is present with approximately the same relative size as

1222 in PMO 222.669 and Sveltonectes densus (Fischer et al., 2011), but mediolaterally narrower than

1223 in Acamptonectes densus (Fischer et al., 2012). The anterior process is longer than in PMO

1224222.669 and the anteromedial margin is angled slightly posteriorly towards the intercoracoid

1225 facet, differing from the uniquely concave margin medial to the anterior process found in

1226 Janusaurus lundi (LLD pers. obs.). The intercoracoid facets are dorsoventrally thick near the

1227 symphysis and larger ventrally than dorsally. Similar to PMO 222.669, the glenoid and scapular

1228 facets well demarcated and have a more acute angle than in Arthropterygius chrisorum 
1229 (Maxwell, 2010). The scapular facet is relatively short relative to the glenoid facet when

1230 compared to PMO 222.669, but similar to the situation in Acamptonectes densus (Fischer et al.,

1231 2012) and Platypterygius hercynicus (Kolb \& Sander, 2009).

1232

1233 Results of the landmark analysis (Fig. 21)

1234 PC1 explains $35.0 \%$, PC2 22.0\% and PC3 16.5\%, and the remaining PCs each explain less than

$123510 \%$, of the variation. Increasing values of $\mathrm{PC} 1$ scores describes an increasing anteroposterior

1236 length: mediolateral width and a mediolaterally narrower posterior portion, an increasing

1237 demarcation of the glenoid and scapular facets, as well as an increasingly mediolaterally

1238 narrower anterior notch. PC2 is related to the relative size of the anteromedial process, and PC3

1239 describes mostly the shape of the anteromedial process. In the discriminant analysis, the groups

1240 with specimens of Ophthalmosaurus and of Stenopterygius are discriminated, and the MANOVA

1241 test find the two groups to be significantly different (MANOVA: $\mathrm{p}=0.0001$ ).

1242

1243 PC1 manages to separate coracoids that have a distinctly different outline; namely, specimens

1244 with a more rounded, equal-sided coracoid can be distinguished from those that are longer than

1245 wide, and narrower in the posterior half than in the anterior half. The former are represented by

1246 Arthropterygius chrisorum, Acamptonectes densus, PMO 222.667 and Ophthalmosaurus

1247 icenicus specimens. The latter type is found in Sveltonectes insolitus and Paraophthalmosaurus

1248 kabanovi, and in the SML material PMO 230.097.

1249

1250 PCA is a quantitative approach to the comparison of coracoid outlines, but the selection of

1251 landmarks might introduce some subjectivity, even when homologous points are used, and a

1252 possible extension of the analysis is the use of sliding landmarks. Among ophthalmosaurids,

1253 many species are represented by a single specimen, which is a challenge for the investigation of

1254 intraspecific or intrageneric variation. Using this method on a larger number of the taxa with

1255 many species could be an important next step to understand the phylogenetic importance of the

1256 coracoid. One limitation with PCA is that the coracoids need a complete or almost complete

1257 outline, a requirement that excludes specimens where elements are broken, such as the holotype

1258 of Keilhauia nui (PMO 222.655)(Delsett et al., 2017), or covered by other elements. A possible 
1259 source of error when both dorsal and ventral surfaces are included are those specimens where the

1260 intercoracoid facet is strongly inclined.

1261

\section{Discussion}

\section{Taxonomic referral of the new material}

1264 PMO 222.669 is referred to Palvennia hoybergeti, an ophthalmosaurid previously described 1265 from the SML (Druckenmiller et al., 2012). The assignment is based on a large number of 1266 similarities, most notably the presence of a greatly enlarged parietal foramen (Fig. 7), the 1267 autapomorphy of this species. It also shares most other features, including a strongly bowed jugal 1268 (Fig. 8B), a gracile and constricted stapedial shaft (Fig. 9G), a facet for preaxial accessory 1269 element on humerus (Fig. 12) and a strikingly similar basioccipital (Fig. 9A-D). Additionally, 1270 previously undescribed material from the holotype (Fig. 4) is similar to the new specimen.

1271 Lastly, both the holotype specimen and PMO 222.669 are nearly identical in size and were 1272 recovered within 4 metres of one another stratigraphically (Fig. 2). While both specimens are 1273 referable to the same species, the exoccipital of PMO 222.669 differs from the holotype (SVB 1274 1451) in two aspects. In PMO 222.669 the exoccipital has two foramina while foramina are 1275 lacking in the holotype. An elongated ventral facet on the exoccipital is present in PMO 222.669,

1276 but it was not observed in the holotype. Given that the preservation of this element is far better in 1277 PMO 222.669, these differences are ascribed to taphonomic artefacts or it could result from 1278 individual variation (Maisch, 1997) and the mention of these traits have been removed from the 1279 diagnosis. The angular of PMO 222.669 (Fig. 10G, H) seems to lack the long anterior extension 1280 found in most ophthalmosaurids, whereas it is present in the holotype of Palvennia hoybergeti 1281 (SVB 1451)(Druckenmiller et al., 2012). The lateral head of the stapes is slightly relatively 1282 smaller in PMO 222.669 than in the holotype (Druckenmiller et al., 2012).

1284 The two additional specimens described above, PMO 230.097 and PMO 224.250, are confidently 1285 referred to Ophthalmosauridae on the basis of possessing a humerus (Figs. 15, 19) with a plate1286 like dorsal ridge (Moon, 2017) and lacking a tuberosity on the anterodistal extremity of the 1287 humerus as well as lacking notching on forefin elements (Moon \& Kirton, 2016). PMO 230.097 1288 represents a relatively small ophthalmosaurid that shares some humeral characters with the SML 1289 ophthalmosaurid Keilhauia nui (Delsett et al., 2017), including a relatively small deltopectoral 
1290 crest, a preaxial facet for an accessory element, the absence of humerus-intermedium contact and

1291 a posteriorly deflected ulnar facet. In PMO 230.097 the proximodistal length of the humerus is

1292 similar (18 millimetres longer) to that of the holotype of $K$. nui and the two specimens were

1293 found only 5.7 metres apart stratigraphically. However, the specimens also display differences:

1294 The radial facet is slightly larger than the ulnar facet in $K$. nui while the reverse is true in PMO

1295 230.097, although this might vary intraspecifically (Moon \& Kirton, 2016; Lomax, Massare \&

1296 Mistry, 2017). The preaxial accessory element facet is relatively larger in $K$. nui, and the relative

1297 anteroposterior length of the distal compared to the proximal end of the humerus is different. The

1298 intercoracoid facet of the coracoid (Fig. 15E) reaches further anteriorly in PMO 230.097 than in

$1299 K$. nui, resulting in a markedly different outline and the anterior caudal vertebrae have a height:

1300 length relationship of 2.1-3.0, less than in K. nui (contra Delsett et al. 2017). Diagnostic features

1301 in the hindfin and pelvic girdle cannot be assessed. Given both the differences and similarities to

$1302 K$ K. nui, it is not possible to assign PMO 230.097 to this taxon, especially considering that several

1303 of these characters are shared with other ophthalmosaurid taxa (e.g., Acamptonectes densus,

1304 Ophthalmosaurus icenicus, Baptanodon natans and Arthropterygius chrisorum) (Gilmore, 1905;

1305 Maxwell, 2010; Fischer et al., 2012; Moon \& Kirton, 2016).

PMO 224.250 shares features with many ophthalmosaurids such as Ophthalmosaurus icenicus,

1308 Cryopterygius kristiansenae and Acamptonectes densus (Druckenmiller et al., 2012; Fischer et

1309 al., 2012; Moon \& Kirton, 2016) but is not sufficiently complete for a generic or species

1310 assignment. An interesting feature is its size, as it represents the remains of one of the largest

1311 ichthyosaur specimens from the SML (Druckenmiller et al., 2012; Roberts et al., 2014; Delsett et

1312 al., 2017). It is not possible to make a direct size comparison with PMO 222.670, a large

1313 Ophthalmosauridae indet. specimen having an approximate total length of 6 metres (Delsett et al.,

1314 2017) due to a lack of overlapping material, but based on a comparison to the complete holotype

1315 specimen of Cryopterygius kristiansenae, which is 5.5 metres (Druckenmiller et al., 2012), PMO

1316224.250 is either of a similar size to PMO 222.670 or slightly larger.

1318 New data on the cranial morphology of Palvennia hoybergeti

1319 The new specimen of Palvennia hoybergeti, PMO 222.669, is more complete than the holotype

1320 specimen and helps to clarify and expand the list of diagnostic characters of this taxon. The most 
1321 conspicuous feature of Palvennia hoybergeti is the large egg-shaped parietal ("pineal") foramen

1322 (Fig. 7), which is far larger in relative size than that known in any ophthalmosaurid. A specimen

1323 of Eurhinosaurus longirostris (based on exhibited specimen SNSB-BSPG; LLD pers. obs.) and a

1324 cf. Leptonectes specimen also possess enlarged parietal foramina that are egg-shaped and

1325 bilobed, respectively (Vincent et al., 2014). There is no clear trend through time for the

1326 development of this feature in ichthyosaurs as parietal foramina that are relatively large but still

1327 smaller than in Palvennia hoybergeti are found Triassic ichthyopterygians such as Utatsusaurus

1328 (Cuthbertson, Russell \& Anderson, 2014) and shastasaurid ichthyosaurs such as Shonisaurus

1329 sikanniensis (Nicholls \& Manabe, 2004), both from British Colombia in Canada. The parietal

1330 foramen is interpreted as the opening for the parietal/ pineal eye, a photoreceptive organ variably

1331 present in amniotes. In lizards, the lack of a pineal eye is significantly more likely in lower

1332 latitudes, and its presence is hypothesized to be advantageous for poikilotherms in harsh climates

1333 for synchronization of reproduction and for thermoregulation (Gundy, Ralph \& Wurst, 1975). A

1334 recent study on South African Permo-Triassic therapsids did not confirm the latitudinal trend for

1335 mammal ancestors, but suggests that loss of the parietal foramen was due to increased body

1336 temperature control or nocturnality (Benoit et al., 2016). There is at present insufficient material

1337 to investigate any latitude-dependent trend or a relationship to physiology for ichthyosaurs, and

1338 from the present knowledge, this feature is restricted to a single species from the SML

1339 ichthyosaur assemblage.

1340

1341 Among ophthalmosaurids, complete but disarticulated skulls are rare (see exceptions in Kear,

1342 2005; Wahl, 2009; Moon \& Kirton, 2016) and information has been gained from the new

1343 referred specimen because both mandibles with a majority of the elements are intact and

1344 preserved in partial articulation. The right surangular is complete anteriorly (Fig. 10A), a feature

1345 unknown in Ophthalmosaurus icenicus (Moon \& Kirton, 2016). The left and right prearticulars

1346 are also preserved and the left side preserves most of the element so that the posterior margin and

1347 dorsal extent can be observed (Fig. 10E-F). This is significant because this element is seldom

1348 identified (Moon \& Kirton, 2016). PMO 222.669 also preserves the anterior portion of the

1349 pterygoid, which is rarely preserved (Kear, 2005; Fischer et al., 2011; Moon \& Kirton, 2016).

1350 The preservation of a hyoid (Fig. 8F) is also significant because this element is seldom described

1351 in detail in ichthyosaurs (Wahl, 2011; Motani et al., 2013; Moon \& Kirton, 2016). 
1353 Palvennia hoybergeti is typically recovered in the ophthalmosaurid subclade Ophthalmosaurinae,

1354 along with other SML taxa (e.g. Cryopterygius kristiansenae) and Ophthalmosaurus icenicus

1355 (Fischer et al., 2011; Fischer et al., 2012; Fischer et al., 2013; Delsett et al., 2017). The other

1356 ophthalmosaurid subclade, Platypterygiinae, includes near-contemporaneous taxa such as

1357 Brachypterygius and Caypullisaurus (same refs). Based on the new material, Palvennia

1358 hoybergeti possesses the ophthalmosaurine synapomorphy of a supratemporal-stapes contact

1359 (Fischer et al., 2013). However, a basioccipital with little or no exposure of extracondylar area in

1360 posterior view without a ventral notch is typical of platypterygiinae ophthalmosaurids (Fischer et

1361 al., 2012; Fischer et al., 2014a), and both of these traits are present in Palvennia hoybergeti. A

1362 peripheral groove on the basioccipital is often considered an ophthalmosaurine trait and is also

1363 present in this specimen, but extremely shallow.

1364

1365 Taxonomic utility of the pectoral girdle

1366 PC1 and PC2 almost separate the groups of Ophthalmosaurus and Stenopterygius specimens (Fig.

1367 21). The morphospace is thus adjacent, but only to a small degree overlapping, and the

1368 MANOVA test proved the two groups to be statistically different. Variation within

1369 Ophthalmosaurus is relatively large, but the specimens do form a cluster. Four of the SML

1370 specimens (Figs. 21-22) fall outside this cluster, while the Ophthalmosauridae indet. PMO

1371224.250 and the holotype of Cryopterygius kristiansenae holotype cluster inside, together with

1372 the Acamptonectes densus and Undorosaurus gorodischensis holotypes. Except from this, the

1373 SML specimens are well separated from each other. The coracoid of Cryopterygius kristiansenae

1374 cannot be separated from the variation within Ophthalmosaurus, as suggested earlier

1375 (Druckenmiller et al., 2012). The holotype specimens of Undorosaurus gorodischensis and

1376 Cryopterygius kristiansenae share many similarities on the coracoids, which is consistent with

1377 other features, and Cryopterygius might be a junior synonym of Undorosaurus (Druckenmiller et

1378 al., 2012; Arkhangelsky \& Zverkov, 2014; Delsett et al., 2017).

1379

1380 A diagnostic character for the genus Stenopterygius is the lack or reduction of a posterior notch

1381 of the coracoids (Maxwell, 2012). This feature is also found in ophthalmosaurids in contrast to

1382 e.g. Ichthyosaurus (Maxwell, 2012; Massare \& Lomax, 2017) and might explain why 
1383 Stenopterygius is not separated from ophthalmosaurids in this analysis. The specimens of

1384 Stenopterygius in this analysis have a squarer outline than the ophthalmosaurids and a more

1385 demarcated glenoid facet at its posterior margin.

1386

1387 The analysis confirms that there is a significant degree of variation in the outline of the

1388 coracoids, as shown by the plot and the relatively low values of the principal components

1389 (Johnson, 1979; Maxwell \& Druckenmiller, 2011; Moon \& Kirton, 2016). Individual or

1390 intrageneric variation is known from taxa with many specimens such as Stenopterygius and

1391 Ichthyosaurus, for instance in the shape and size of the anterior notch (Johnson, 1979; Lomax \&

1392 Massare, 2017; Lomax, Massare \& Mistry, 2017). However, the PCA, discriminant analysis and

1393 the MANOVA test show that there is a phylogenetic signal in the coracoid shape, as argued by

1394 Lomax (2017; Lomax, Evans \& Carpenter, 2018). The phylogenetic character presently in use to

1395 cover the phylogenetic variation in coracoids is the relationship between length and width

1396 (Fischer et al., 2016). This catches little of the actual variation, but is well-suited as a

1397 phylogenetic character because the scoring is relatively objective. Caution should be taken as in

1398 the more circular or square coracoids the difference between length and width may be slight, and

1399 in Stenopterygius this is not a consistent relationship (Johnson, 1979; Maxwell, 2012).

1401 In the scapulae, the acromion process is an important feature, phylogenetically and functionally.

1402 A "prominent" acromion process is a synapomorphy of Baracromia (Fischer et al., 2013; Moon,

1403 2017), but evaluating the relative sizes in different specimens for scoring into data matrices is a

1404 source of uncertainty. Its prominence actually results from two different factors that vary

1405 independently; first, the degree of dorsal expansion of the anterior portion of the scapula relative

1406 to the dorsal margin of the shaft, and secondly, the anterior extent of the dorsolateral flange.

1407 Sveltonectes insolitus, PMO 222.667, PMO 222.669 and Cryopterygius kristiansenae represent

1408 all four possible combinations of strong/slight dorsal expansion and large/small extent of the

1409 dorsolateral flange (Figs. 11, 22) (Fischer et al., 2011; Druckenmiller et al., 2012). The acromion

1410 process also varies intraspecifically in Ophthalmosaurus icenicus and Acamptonectes densus, in

1411 the latter probably due to ontogeny (Fischer et al., 2012; Moon \& Kirton, 2016). 
1413 Clavicles and interclavicles are rarely preserved and studied because they are more fragile than

1414 the scapula and coracoid (Johnson, 1979; McGowan \& Motani, 2003). The SML specimens (Fig.

1415 22) show that there are variations also in these elements that might be phylogenetically valuable,

1416 such as the relative length of the medial stem of the interclavicle compared to the transverse bar.

1417 However, this relationship might also vary individually (Lomax, Massare \& Mistry, 2017). The

1418 shape of the median stem of the interclavicle is variable, both in terms of outline in ventral view

1419 and the presence or absence of a trough dorsally, but the amount of phylogenetic signal is

1420 unknown (Johnson, 1979; Roberts et al., 2014; Moon \& Kirton, 2016).

\section{Conclusion}

1425

Three ichthyosaur specimens from the important Late Jurassic - Early Cretaceous Slottsmøya

1427 Member Lagerstätte on Spitsbergen provide new information about cranial and pectoral features

1428 in ophthalmosaurids and represent valuable data points in the understanding of the ichthyosaur

1429 distribution during this critical time. The species Palvennia hoybergeti is now better understood

1430 based on an almost complete partly disarticulated skull and a complete pectoral girdle with two

1431 forefins and two distinctly different Ophthalmosauridae indet. specimens add to the knowledge

1432 about variation in pectoral girdle and forefin morphology.

1434 Individual variation in ichthyosaur skeletal elements is currently not well understood. To gain a

1435 more quantitative understanding of coracoid outline variation, a principal component analysis of

1436 2D landmarks from six Slottsmøya Member Lagerstätte specimens and 24 other baracromian

1437 specimens was conducted for the first time and provided a valuable input to the debate on the

1438 amount of phylogenetic value in the coracoid in post-Triassic ichthyosaurs. Future studies should

1439 aim to include a large number of specimens and use quantitative approaches to reveal

1440 phylogenetic and evolutionary patterns.

1443 Acknowledgments 
1444 A thank you is offered to the Spitsbergen Mesozoic Research Group with special thanks to Ø.

1445 Hammer for statistical support, H. A. Nakrem, and the volunteers Ø. Enger, M. Høyberget, L.

1446 Kristiansen, B. Lund, S. Larsen, T. Wensås and C.S. Bjorå for excavation of the specimens. M.-

1447 L. K. Funke and V. S. Engelschiøn are thanked for preparation. B. Cordonnier, I. H. Økland, D.

1448 Foffa and D. Lomax are thanked for valuable input. For providing collection access and/or

1449 pictures of specimens thanks to N. Zverkov, M. S. Arkhangelsky, V. Fischer, B. Kear, R. Vanis

1450 (SMSS), J. L. Wujek, E. Maxwell (SMNS), M. Fernández (MOZ, MLP), M. Riley (CAMSM), E.

1451 Howlett and H. Ketchum (OUMNH), V. Ward (LEIUG), O. Rauhut (SNSB-BSPG), N. Clark

1452 (GLAHM), V.M. Efimov (UPM), K. Sherburn (MANCH), M. Evans (LEICT). The reviewers V.

1453 Fischer and D. Lomax are thanked for very valuable comments to the paper.

\section{References}

Arkhangelsky MS. 1997. On a new ichthyosaurian genus from the Lower Volgian Substage of the Saratov, Volga region. Paleontological Journal 31: 87-90.

Arkhangelsky MS, Zverkov NG. 2014. On a new ichthyosaur of the genus Undorosaurus. Proceedings of the Zoological Institute RAS 318: 187-196.

Bardet N. 1992. Stratigraphic evidence for the extinction of the ichthyosaurs. Terra Nova 4: 649656.

Bardet N, Fernández M. 2000. A new ichthyosaur from the Upper Jurassic lithographic limestones of Bavaria. Journal of Paleontology 74: 503-511. DOI: 10.1666/00223360(2000)074<0503:aniftu $>2.0 . c 0 ; 2$.

Baur G. 1887. On the morphology and origin of the Ichthyopterygia. American Naturalist 21: 837-840.

Benoit J, Abdala F, Manger PR, Rubidge BS. 2016. The Sixth Sense in Mammalian Forerunners: Variability of the Parietal Foramen and the Evolution of the Pineal Eye in South African Permo-Triassic Eutheriodont Therapsids. Acta Palaeontologica Polonica 61: 777-789. DOI: 10.4202/app.00219.2015.

Buchholtz EA. 2001. Swimming styles in Jurassic ichthyosaurs. Journal of Vertebrate Paleontology 21: 61-73. DOI: 10.1671/0272-4634(2001)021[0061:SSIJI]2.0.CO;2.

Collignon M, Hammer Ø. 2012. Petrography and sedimentology of the Slottsmøya Member at Janusfjellet, central Spitsbergen. Norwegian Journal of Geology 92: 89-101.

Cuthbertson RS, Russell AP, Anderson JS. 2014. The first substantive evidence of Utatsusaurus (Ichthyopterygia) from the Sulphur Mountain Formation (Lower-Middle Triassic) of British Columbia, Canada: a skull roof description in comparison with other early taxa. Canadian Journal of Earth Sciences 51: 180-185. DOI: 10.1139/cjes-2013-0185. de l'analyse d'un systéme général d'erpétologie et d'amphibiologie Nouvelles annales du muséum d'histoire naturelle 4: 233-296. 
1483 Delsett LL, Novis LK, Roberts AJ, Koevoets MJ, Hammer Ø, Druckenmiller PS, Hurum JH.

1484

1485

1486

1487

1488

1489

1490

1491

1492

1493

1494

1495

1496

1497

1498

1499

1500

1501

1502

1503

1504

1505

1506

1507

1508

1509

1510

1511

1512

1513

1514

1515

1516

1517

1518

1519

1520

1521

1522

1523

1524

1525

1526

1527
2016. The Slottsmøya marine reptile Lagerstätte: depositional environments, taphonomy and diagenesis. Geological Society Special Publications: Mesozoic Biotas of Scandinavia and its Arctic Territories 434: 165-188. DOI: 10.1144/sp434.2.

Delsett LL, Roberts AJ, Druckenmiller PS, Hurum JH. 2017. A new ophthalmosaurid (Ichthyosauria) from Svalbard, Norway, and evolution of the ichthyopterygian pelvic girdle. PLoS ONE 12: e0169971. DOI: 10.1371/journal.pone.0169971.

Dick DG. 2015. An ichthyosaur carcass-fall community from the Posidonia shale (Toarcian) of Germany. Palaios 30: 353-361. DOI: 10.2110/palo.2014.095.

Druckenmiller PS, Maxwell EE. 2010. A new Lower Cretaceous (lower Albian) ichthyosaur genus from the Clearwater Formation, Alberta, Canada. Canadian Journal of Earth Sciences 47: 1037-1053. DOI: 10.1139/e10-028.

Druckenmiller PS, Hurum JH, Knutsen EM, Nakrem HA. 2012. Two new ophthalmosaurids (Reptilia: Ichthyosauria) from the Agardhfjellet Formation (Upper Jurassic: Volgian/Tithonian), Svalbard, Norway. Norwegian Journal of Geology 92: 311-339.

Druckenmiller PS, Maxwell EE. 2013. A Middle Jurassic (Bajocian) ophthalmosaurid (Reptilia, Ichthyosauria) from the Tuxedni Formation, Alaska and the early diversification of the clade. Geological Magazine 151: 41-48. DOI: 10.1017/S0016756813000125.

Dypvik H, Zakharov V. 2012. Fine-grained epicontinental Arctic sedimentation - mineralogy and geochemistry of shales from the Late Jurassic-Early Cretaceous transition. Norwegian Journal of Geology 92: 65-87.

Efimov VM. 1999a. A new family of Ichthyosaurs, the Undorosauridae fam. nov. from the Volgian Stage of the European part of Russia. Paleontological Journal 33: 174-181.

Efimov VM. 1999b. Ichthyosaurs of a new genus Yasykovia from the Upper Jurassic Strata of European Russia. Paleontological Journal 33: 91-98.

Fernández M. 2007. Redescription and phylogenetic position of Caypullisaurus (Ichthyosauria: Ophthalmosauridae). Journal of Paleontology 81: 368-375. DOI: 10.1666/00223360(2007)81[368:rappoc]2.0.co;2.

Fernández M, Campos L. 2015. Ophthalmosaurids (Ichthyosauria: Thunnosauria): Alpha taxonomy, clades and names. Publicación Electrónica de la Asociación Paleontológica Argentina 15: 20-30. DOI: 10.5710/PEAPA.15.09.2015.96.

Fernández MS. 1997. A new ichthyosaur from the Tithonian (Late Jurassic) of the Neuquen basin, Northwestern Patagonia, Argentina. Journal of Paleontology 71: 479-484.

Fernández MS. 1999. A new ichthyosaur from the Los Molles Formation (Early Bajocian), Neuquen Basin, Argentina. Journal of Paleontology 73: 677-681.

Fischer V, Masure E, Arkhangelsky MS, Godefroit P. 2011. A new Barremian (Early Cretaceous) ichthyosaur from Western Russia. Journal of Vertebrate Paleontology 31: 1010-1025. DOI: 10.1080/02724634.2011.595464.

Fischer V. 2012. New data on the ichthyosaur Platypterygius hercynicus and its implications for the validity of the genus. Acta Palaeontologica Polonica 57: 123-134. DOI: 10.4202/app.2011.0007.

Fischer V, Maisch MW, Naish D, Kosma R, Liston J, Joger U, Krüger FJ, Pardo-Pérez JM, Tainsh J, Appleby RM. 2012. New ophthalmosaurid ichthyosaurs from the European Lower Cretaceous demonstrate extensive ichthyosaur survival across the JurassicCretaceous boundary. PLOS ONE 7: e29234. DOI: 10.1371/journal.pone.0029234. 
1528 Fischer V, Arkhangelsky MS, Uspensky GN, Stenshin IM, Godefroit P. 2013. A new Lower

1529

1530

1531

1532

1533

1534

1535

1536

1537

1538

1539

1540

1541

1542

1543

1544

1545

1546

1547

1548

1549

1550

1551

1552

1553

1554

1555

1556

1557

1558

1559

1560

1561

1562

1563

1564

1565

1566

1567

1568

1569

1570

1571
Cretaceous ichthyosaur from Russia reveals skull shape conservatism within

Ophthalmosaurinae. Geological Magazine 151: 60-70. DOI:

doi:10.1017/S0016756812000994.

Fischer V, Arkhangelsky MS, Naish D, Stenshin IM, Uspensky GN, Godefroit P. 2014a.

Simbirskiasaurus and Pervushovisaurus reassessed: implications for the taxonomy and cranial osteology of Cretaceous platypterygiine ichthyosaurs. Zoological Journal of the Linnean Society 171: 822-841. DOI: 10.1111/zoj.12158.

Fischer V, Bardet N, Guiomar M, Godefroit P. 2014b. High diversity in Cretaceous ichthyosaurs from Europe prior to their extinction. PLoS ONE 9: e84709. DOI:

10.1371/journal.pone.0084709.

Fischer V, Bardet N, Benson RBJ, Arkhangelsky MS, Friedman M. 2016. Extinction of fishshaped marine reptiles associated with reduced evolutionary rates and global environmental volatility. Nature Communications 7: 1-11. DOI: 10.1038/ncomms 10825.

Gilmore CW. 1905. The osteology of Baptanodon (Marsh). Memoirs of the Carnegie Museum 2: 77-129.

Gilmore CW. 1906. Notes on osteology of Baptanodon. With a description of a new species. Memoirs of the Carnegie Museum 2: 325-342.

Gundy G, Ralph C, Wurst G. 1975. Parietal eyes in lizards: Zoogeographical correlates. Science 190: 671-673. DOI: 10.1126/science.1237930.

Hammer Ø, Harper DAT, Ryan TD. 2001. PAST: Paleontological statistics software package for education and data analysis. Palaeontologia Electronica 4.

Hammer Ø, Collignon M, Nakrem HA. 2012. Organic carbon isotope chemostratigraphy and cyclostratigraphy in the Volgian of Svalbard. Norwegian Journal of Geology 92: 103112.

Home E. 1818. Additional facts respecting the fossil remains of an animal, on the subject of which two papers have been printed in the Philosophical transactions, showing that the bone of the sternum resemble those of the Ornithorhynchus paradoxus. Philosophical Transactions of the Royal Society of London 108: 24-32.

Hryniewicz K, Nakrem HA, Hammer Ø, Little CTS, Kaim A, Sandy MR, Hurum JH. 2015. The palaeoecology of the latest Jurassic-earliest Cretaceous hydrocarbon seep carbonates from Spitsbergen, Svalbard. Lethaia 48: 353-374. DOI: 10.1111/let.12112.

Hulke JW. 1892. On the shoulder girdle in Ichthyosauria and Sauropterygia. Proceedings of the Royal Society of London 51: 471. DOI: 10.1098/rspl.1892.0034.

Hurum JH, Nakrem HA, Hammer Ø, Knutsen EM, Druckenmiller PS, Hryniewicz K, Novis LK. 2012. An Arctic Lagerstätte - the Slottsmøya Member of the Agardhfjellet Formation (Upper Jurassic - Lower Cretaceous) of Spitsbergen. Norwegian Journal of Geology 92: 55-64.

Johnson R. 1977. Size independent criteria for estimating age and the relationships among growth parameters in a group of fossil reptiles (Reptilia: Ichthyosauria). Canadian Journal of Earth Sciences 14: 1916-1924.

Johnson R. 1979. The osteology of the pectoral complex of Stenopterygius Jaekel (Reptilia: Ichthyosauria). Neues Jahrbuch für Geologie und Paläontologie Abhandlungen 159: 4186. 
1572 Kear BP. 2005. Cranial morphology of Platypterygius longmani Wade, 1990 (Reptilia:

1573

1574

1575

1576

1577

1578

1579

1580

1581

1582

1583

1584

1585

1586

1587

1588

1589

1590

1591

1592

1593

1594

1595

1596

1597

1598

1599

1600

1601

1602

1603

1604

1605

1606

1607

1608

1609

1610

1611

1612

1613

1614

1615

1616

1617
Ichthyosauria) from the Lower Cretaceous of Australia. Zoological Journal of the Linnean Society 145: 583-622. DOI: 10.1111/j.1096-3642.2005.00199.x.

Kear BP, Zammit M. 2014. In utero foetal remains of the Cretaceous ichthyosaurian Platypterygius: ontogenetic implications for character state efficacy. Geological Magazine 151: 71-86. DOI: 10.1017/S0016756813000113.

Kirton AM. 1983. A review of British Upper Jurassic Ichthyosaurs. Unpublished PhD thesis, University of Newcastle upon Tyne.

Koevoets MJ, Abay TB, Hammer Ø, Olaussen S. 2016. High-resolution organic carbon-isotope stratigraphy of the Middle Jurassic-Lower Cretaceous Agardhfjellet Formation of central Spitsbergen, Svalbard. Palaeogeography, Palaeoclimatology, Palaeoecology 449: 266274. DOI: 10.1016/j.palaeo.2016.02.029.

Koevoets MJ. 2017. The palaeontology, Stratigraphy and Palaeo-environment of the Agardhfjellet Formation (Middle Jurassic- Lowermost Cretaceous) of Spitsbergen, Svalbard. PhD thesis, University of Oslo.

Koevoets MJ, Hammer Ø, Olaussen S, Senger K, Smelror M. 2018. Integrating subsurface and outcrop data of the Middle Jurassic to Lower Cretaceous Agardhfjellet Formation in central Spitsbergen. Norwegian Journal of Geology 98: 1-34. DOI: 10.17850/njg98-4-01.

Kolb C, Sander PM. 2009. Redescription of the ichthyosaur Platypterygius hercynicus (Kuhn 1946) from the Lower Cretaceous of Salzgitter (Lower Saxony, Germany). Palaeontographica Abteilung A: Paläozoologie - Stratigraphie 288: 151-192.

Lomax DR, Massare JA. 2015. A new species of Ichthyosaurus from the Lower Jurassic of West Dorset, England, U.K. Journal of Vertebrate Paleontology 35: e903260. DOI: 10.1080/02724634.2014.903260.

Lomax DR. 2017. A new leptonectid ichthyosaur from the Lower Jurassic (Hettangian) of Nottinghamshire, England, UK, and the taxonomic usefulness of the ichthyosaur coracoid. Journal of Systematic Palaeontology 15: 387-401. DOI: 10.1080/14772019.2016.1183149.

Lomax DR, Massare JA. 2017. Two new species of Ichthyosaurus from the lowermost Jurassic (Hettangian) of Somerset, England. Papers in Palaeontology 3: 1-20. DOI: 10.1002/spp2.1065.

Lomax DR, Massare JA, Mistry RT. 2017. The taxonomic utility of forefin morphology in Lower Jurassic ichthyosaurs: Protoichthyosaurus and Ichthyosaurus. Journal of Vertebrate Paleontology 37: e1361433. DOI: 10.1080/02724634.2017.1361433.

Lomax DR, Evans M, Carpenter S. 2018. An ichthyosaur from the UK Triassic-Jurassic boundary: A second specimen of the leptonectid ichthyosaur Wahlisaurus massarae Lomax 2016. Geological Journal Early View DOI: 10.1002/gj.3155.

Maisch MW. 1997. Variationen im Verlauf der Gehirnnerven bei Ophthalmosaurus (Ichthyosauria, Jura). Nenes Jahrbuch für Geologie und Paläontologie Monatshefte 7: 425-433.

Marek RD, Moon BC, Williams M, Benton MJ. 2015. The skull and endochranium of a Lower Jurassic ichthyosaur based on digital reconstructions. Palaeontology 58: 723-742. DOI: 10.1111/pala.12174.

Massare JA, Buchholtz EA, Kenney JM, Chomat A-M. 2006. Vertebral morphology of Ophthalmosaurus natans (Reptilia: Ichthyosauria) from the Jurassic Sundance Formation of Wyoming. Paludicola 5: 242-254. 
1618 Massare JA, Lomax DR. 2017. A taxonomic reassessment of Ichthyosaurus communis and I.

1619

1620

1621

1622

1623

1624

1625

1626

1627

1628

1629

1630

1631

1632

1633

1634

1635

1636

1637

1638

1639

1640

1641

1642

1643

1644

1645

1646

1647

1648

1649

1650

1651

1652

1653

1654

1655

1656

1657

1658

1659

1660

1661

1662 intermedius and a revised diagnosis for the genus. Journal of Systematic Palaeontology: 1-15. DOI: 10.1080/14772019.2017.1291116.

Massare JA, Lomax DR. 2018. Hindfins of Ichthyosaurus: effects of large sample size on 'distinct' morphological characters. Geological Magazine: 1-20. DOI: 10.1017/S0016756818000146.

Maxwell EE, Caldwell MW. 2006. A new genus of ichthyosaur from the Lower Cretaceous of Western Canada. Palaeontology 49: 1043-1052. DOI: 10.1111/j.14754983.2006.00589.x.

Maxwell EE. 2010. Generic reassignment of an ichthyosaur from the Queen Elizabeth Islands, Northwest Territories, Canada. Journal of Vertebrate Paleontology 30: 403-415. DOI: $10.1080 / 02724631003617944$.

Maxwell EE, Kear BP. 2010. Postcranial anatomy of Platypterygius americanus (Reptilia: Ichthyosauria) from the Cretaceous of Wyoming. Journal of Vertebrate Paleontology 30: 1059-1068. DOI: 10.1080/02724634.2010.483546.

Maxwell EE, Caldwell MW, Lamoureux DO. 2011. Tooth histology in the Cretaceous ichthyosaur Platypterygius australis, and its significance for the conservation and divergence of mineralized tooth tissues in amniotes. Journal of Morphology 272: 129135. DOI: $10.1002 /$ jmor. 10898.

Maxwell EE, Druckenmiller PS. 2011. A small ichthyosaur from the Clearwater Formation (Alberta, Canada) and a discussion of the taxonomic utility of the pectoral girdle. Paläontologische Zeitschrift 85: 457-463. DOI: 10.1007/s12542-011-0106-0.

Maxwell EE. 2012. New Metrics To Differentiate Species of Stenopterygius (Reptilia: Ichthyosauria) from the Lower Jurassic of Southwestern Germany. Journal of Paleontology 86: 105-115. DOI: 10.1666/11-038.1.

Maxwell EE, Dick D, Padilla S, Parra ML. 2015. A new ophthalmosaurid ichthyosaur from the Early Cretaceous of Colombia. Papers in Palaeontology 2: 59-70. DOI: $10.1002 / \mathrm{spp} 2.1030$.

McGowan C. 1974. A revision of the Longipinnate Ichthyosaurs of the Lower Jurassic of England, with Descriptions of Two New Species (Reptilia: Ichthyosauria). Life Sciences Contributions Royal Ontario Museum 97: 1-37.

McGowan C. 1976. Description and phenetic relationships of a new ichthyosaur genus from the Upper Jurassic of England. Canadian Journal of Earth Sciences 13: 668-683.

McGowan C. 1997. The taxonomic status of the Late Jurassic Ichthyosaur Grendelius mordax: A preliminary report. Journal of Vertebrate Paleontology 17: 428-430.

McGowan C, Motani R. 2003. Ichthyopterygia. München, Verlag Dr. Friedrich Pfeil.

Moon BC, Kirton AM. 2016. Ichthyosaurs of the British Middle and Upper Jurassic. Part 1 Ophthalmosaurus. Monograph of the Palaeontographical Society 170: 1-84.

Moon BC. 2017. A new phylogeny of ichthyosaurs (Reptilia: Diapsida). Journal of Systematic Palaeontology: 1-27. DOI: 10.1080/14772019.2017.1394922.

Motani R. 1999. Phylogeny of the Ichthyopterygia. Journal of Vertebrate Paleontology 19: 473496.

Motani R. 2005. Evolution of fish-shaped reptiles (Reptilia: Ichthyopterygia) in their physical environments and constraints. Annual Review of Earth and Planetary Sciences 33: 395420. DOI: 10.1146/annurev.earth.33.092203.122707. 
1663 Motani R, Ji C, Tomita T, Kelley N, Maxwell E, Jiang D-y, Sander PM. 2013. Absence of

1664

1665

1666

1667

1668

1669

1670

1671

1672

1673

1674

1675

1676

1677

1678

1679

1680

1681

1682

1683

1684

1685

1686

1687

1688

1689

1690

1691

1692

1693

1694

1695

1696

1697

1698

1699

1700

1701

1702

1703

1704

1705

1706

1707 Suction Feeding Ichthyosaurs and Its Implications for Triassic Mesopelagic Paleoecology. PLoS ONE 8: e66075. DOI: 10.1371/journal.pone.0066075.

Nicholls EL, Manabe M. 2004. Giant ichthyosaurs of the Triassic - A new species of Shonisaurus from the Pardonet Formation (Norian: Late Triassic) of British Columbia. Journal of Vertebrate Paleontology 24: 838-849. DOI: 10.1671/02724634(2004)024[0838:giottn]2.0.co;2.

Paparella I, Maxwell EE, Cipriani A, Roncacè S, Caldwell MW. 2016. The first ophthalmosaurid ichthyosaur from the Upper Jurassic of the Umbrian-Marchean Apennines (Marche, Central Italy). Geological Magazine 154: 837-858. DOI: 10.1017/S0016756816000455.

Pardo-Pérez JM, Kear BP, Gómez M, Moroni M, Maxwell EE. 2017. Ichthyosaurian palaeopathology: evidence of injury and disease in fossil 'fish lizards'. Journal of Zoology 304: 21-33. DOI: 10.1111/jzo.12517.

Prasad GVR, Pandey DK, Alberti M, Fürsich FT, Thakkar MG, Chauhan GD. 2017. Discovery of the first ichthyosaur from the Jurassic of India: Implications for Gondwanan palaeobiogeography. PLOS ONE 12: e0185851. DOI: 10.1371/journal.pone.0185851.

Roberts AJ, Druckenmiller PS, Sætre G-P, Hurum JH. 2014. A New Upper Jurassic Ophthalmosaurid Ichthyosaur from the Slottsmøya Member, Agardhfjellet Formation of Central Spitsbergen. PLoS ONE 9: e103152. DOI: 10.1371/journal.pone.0103152.

Rousseau J, Nakrem HA. 2012. An Upper Jurassic Boreal echinoderm Lagerstätte from Janusfjellet, central Spitsbergen. Norwegian Journal of Geology 92: 133-148.

Rousseau J, Gale AS, Thuy B. 2018. New articulated asteroids (Echinodermata, Asteroidea) and ophiuroids (Echinodermata, Ophiuroidea) from the Late Jurassic (Volgian/Tithonian) of central Spitsbergen. European Journal of Taxonomy 411: 1-26. DOI: 10.5852/ejt.2018.411.

Sander PM. 2000. Ichthyosauria: their diversity, distribution, and phylogeny. Paläontologische Zeitschrift 74: 1-35.

Seeley HG. 1874. On the Pectoral Arch and Fore Limb of Ophthalmosaurus, a new Ichthyosaurian Genus from the Oxford Clay. Quarterly Journal of the Geological Society 30: 696-707. DOI: 10.1144/gsl.jgs.1874.030.01-04.64.

Seeley HG. 1893. Further observations on the shoulder girdle and clavicular arch in the Ichthyosauria and Sauropterygia. Proceedings of the Royal Society of London 54: 149168. DOI: $10.1098 /$ rspl.1893.0063.

Torsvik TH, van der Voo R, Preeden U, Mac Niocaill C, Steinberger B, Doubrovine PV, van Hinsbergen DJJ, Domeier M, Gaina C, Tohver E, Meert JG, McCausland PJA, Cocks LRM. 2012. Phanerozoic polar wander, palaeogeography and dynamics. Earth-Science Reviews 114: 325-368. DOI: 10.1016/j.earscirev.2012.06.007.

Tyborowski D. 2016. A New Ophthalmosaurid Ichthyosaur from the Late Jurassic of OwadówBrzezinki Quarry, Poland. Acta Palaeontologica Polonica 61: 791-803. DOI: 10.4202/app.00252.2016.

Vincent P, Taquet P, Fischer V, Bardet N, Falconnet J, Godefroit P. 2014. Mary Anning's legacy to French vertebrate palaeontology. Geological Magazine 151: 7-20. DOI: doi:10.1017/S0016756813000861.

Wahl WR. 2009. Taphonomy of a nose dive: bone and tooth displacement and mineral accretion in an ichthyosaur skull. Paludicola 7: 107-116. 
1708 Wahl WR. 2011. Hyoid structure and breathing in ichthyosaurs. 71st Annual Meeting Society of $1709 \quad$ Vertebrate Paleontology, Las Vegas, USA.

1710 Zammit M, Norris RM, Kear BP. 2010. The Australian Cretaceous ichthyosaur Platypterygius

1711

1712 australis: A description and review of postcranial remains. Journal of Vertebrate Paleontology 30: 1726-1735. DOI: 10.1080/02724634.2010.521930.

1713 Zverkov NG, Arkhangelsky MS, Pardo-Pérez J, Beznosov PA. 2015. On the Upper Jurassic

1714

1715 ichthyosaur remains from the Russian North. Proceedings of the Zoological Institute RAS 319: 81-97.

1716

Zverkov NG, Arkhangelsky MS, Stenshin IM. 2015. A review of Russian Upper Jurassic Ichthyosaurs with an intermedium/humeral contact. Reassessing Grendelius McGowan, 1719 1976. Proceeding of the Zoological Institute RAS 319: 558-588.

1720 
Figure 1

Map showing the discovery sites of the three ichthyosaur specimens described herein and the holotype specimen (SVB 1451) of Palvennia hoybergeti (red dots).

Reference map (lower left corner) shows the Svalbard archipelago and the excavation area (orange dot) on the main island Spitsbergen. Adapted from Hurum et al. (2012).

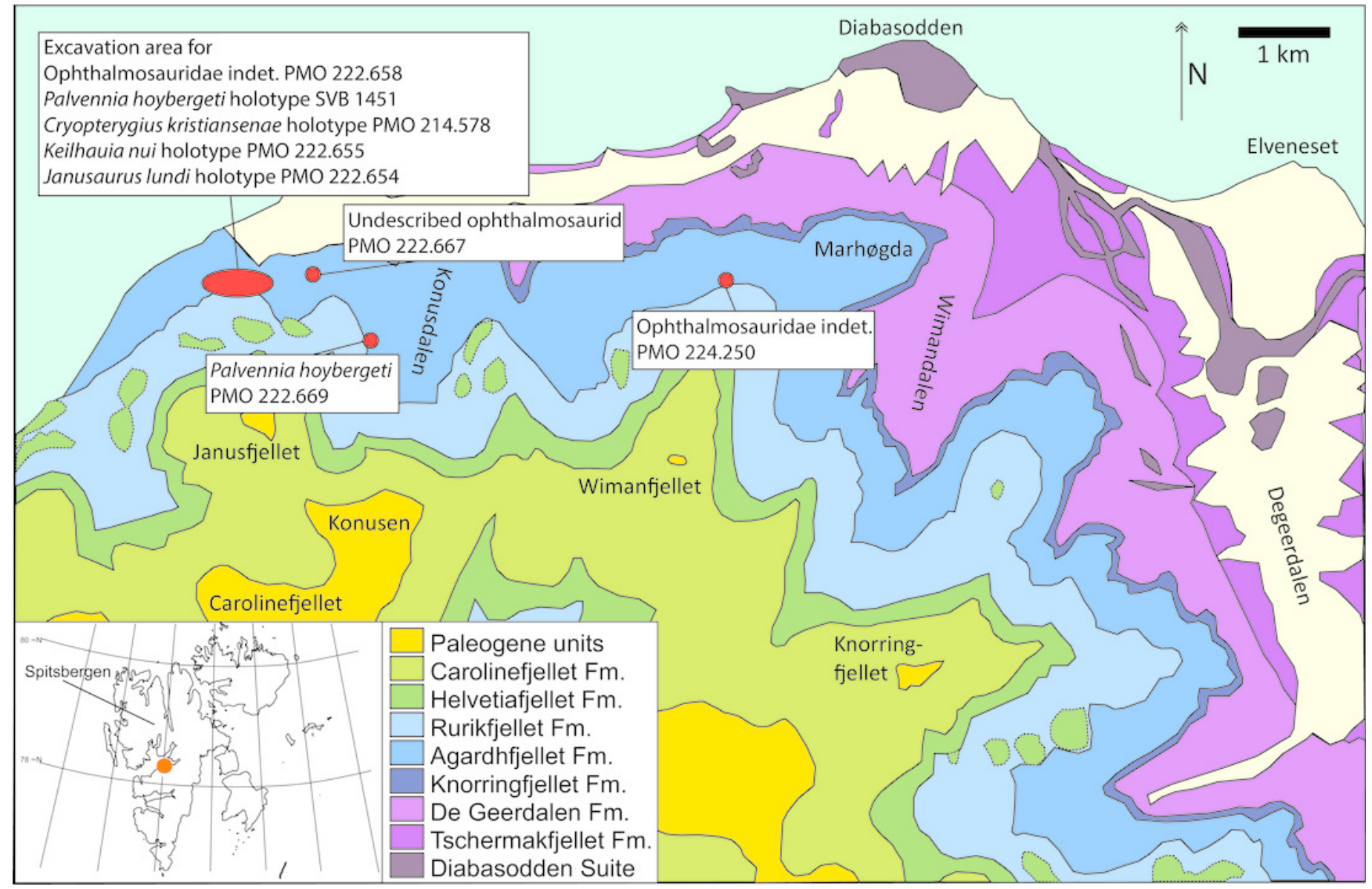


Figure 2 (on next page)

Composite section of the Slottsmøya Member Lagerstätte showing the vertical distribution of ophthalmosaurid specimens with preserved pectoral girdles discussed in the text.

New specimens described in this contribution in bold. Modified from Delsett et al. (2017) and Koevoets (2017). 


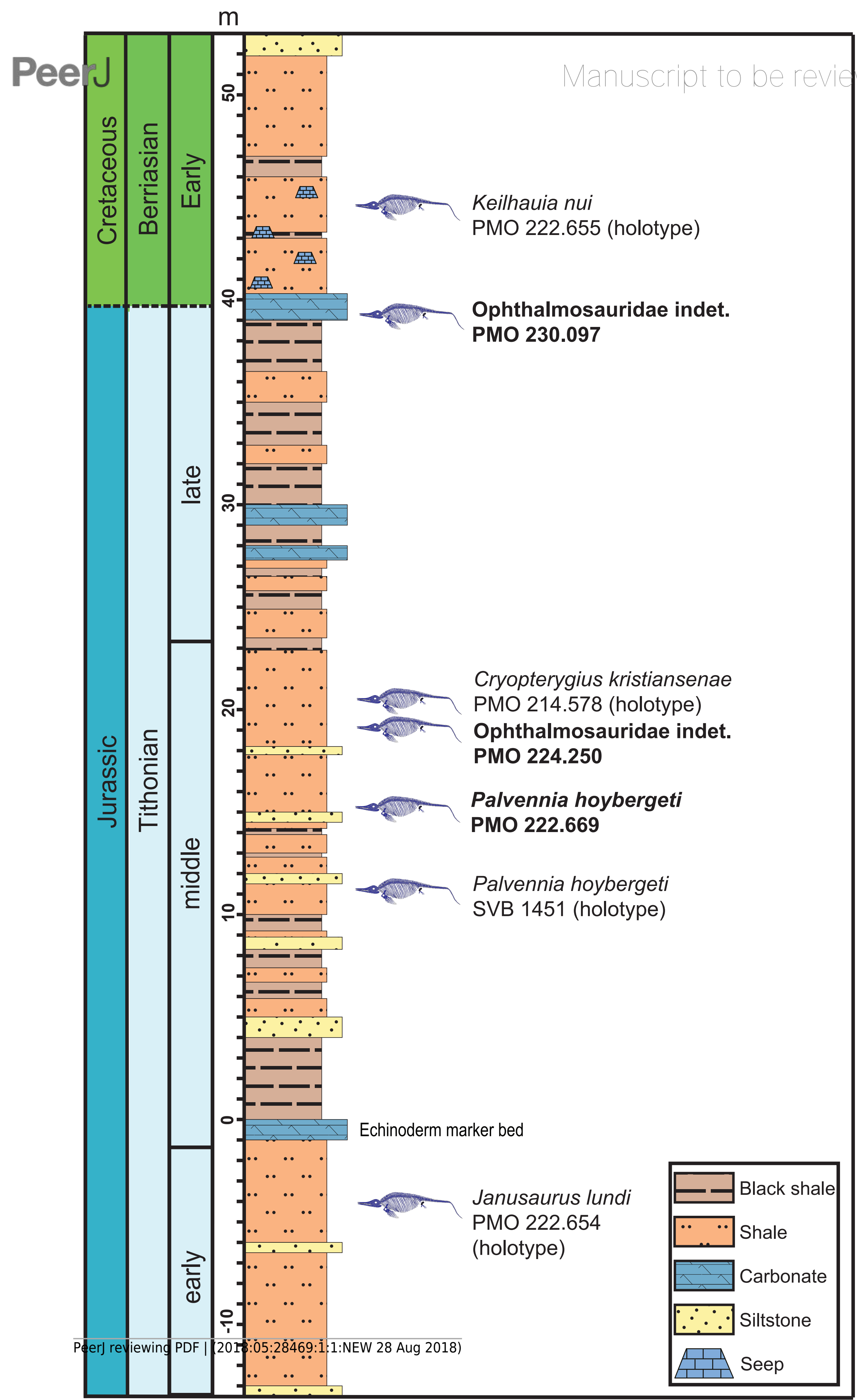




\section{Figure 3}

Landmarks used in the PCA.

The landmarks are shown on an outline of a representative coracoid (PMO 222.669) as an example. Numbered points: (1) Anterolateral corner of the anteromedial process. (2) Anterior end of the intercoracoid facet. (3) Posterior end of the intercoracoid facet. (4) Posterior end of the glenoid contribution. (5) Border between glenoid contribution and scapular facet. (6) Anterior end of scapular facet. 


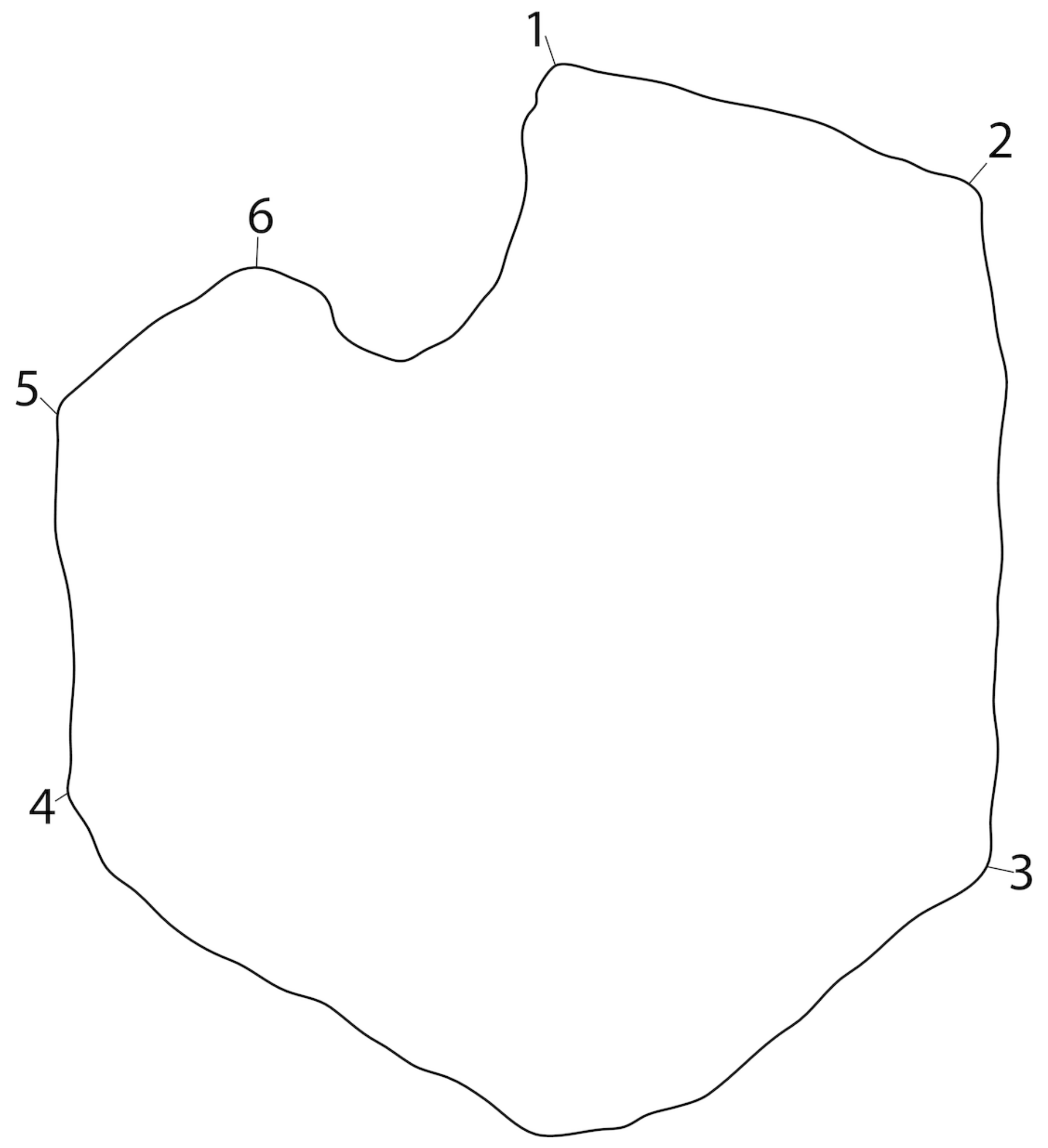




\section{Figure 4}

Articulars and forefin elements of SVB 1451, holotype of Palvennia hoybergeti .

Left articular in A, medial view and right articular in B, medial view. Zeugo- and autopodial elements in $\mathrm{C}$, dorsal (or ventral) view. Radius and intermedium in articulation, the other elements are disarticulated. Abbreviations: art $=$ articular end, $\mathrm{dc}=$ distal $\mathrm{carpal}, \mathrm{im}=$ incomplete margin, in = intermedium, $\mathrm{mc}=$ metacarpal, $\mathrm{p}=$ phalan $\mathrm{x}, \mathrm{pi}=$ pisiform, $\mathrm{R}=$ radius . Scale bar $=50 \mathrm{~mm}$. Photo: Lene Liebe Delsett.
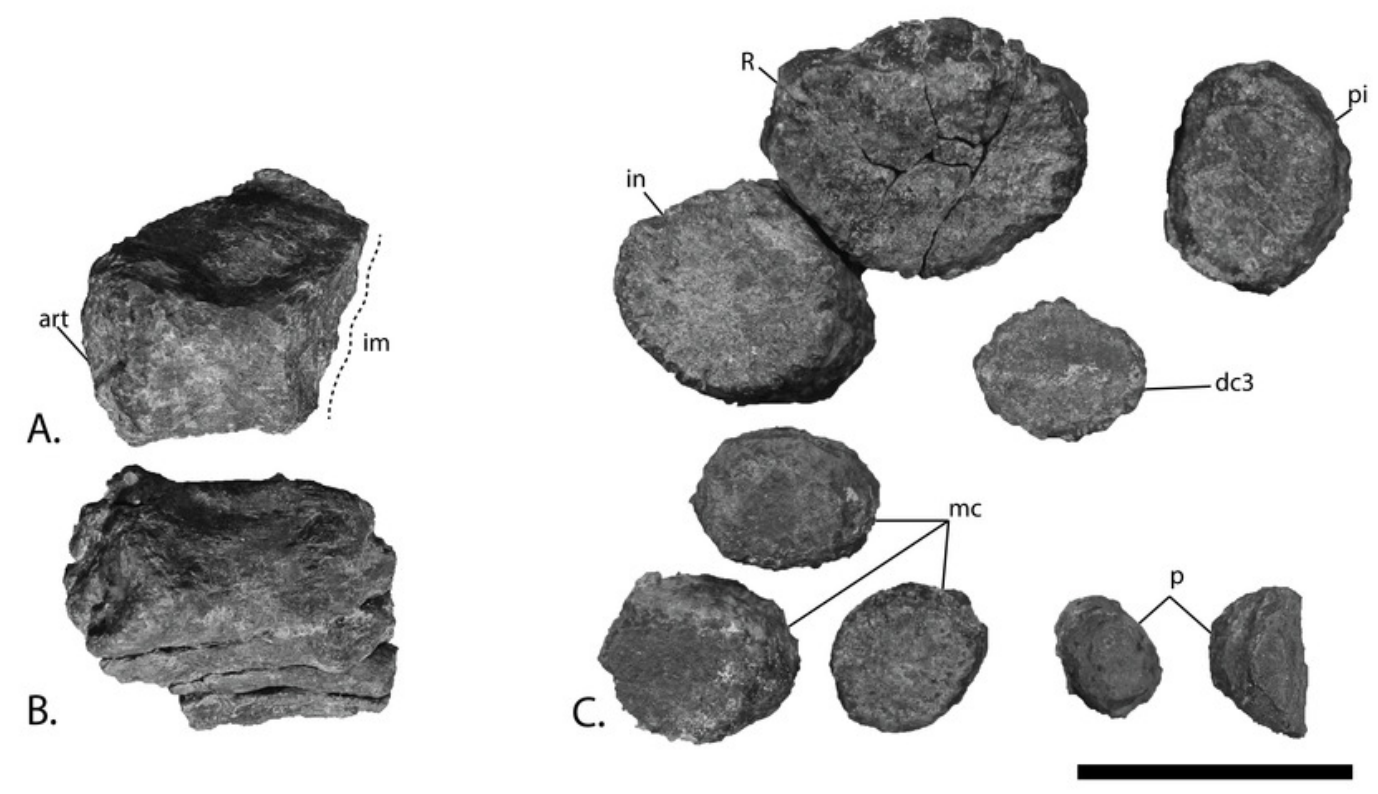


\section{Figure 5}

Skeletal map of PMO 222.669, newly referred specimen of Palvennia hoybergeti , in ventral view (stratigraphically up).

Only elements visible in this view are included. Abbreviations: aa= atlas-axis, an= angular, ann= anterior notch, ar= articular, bo= basioccipital, $\mathrm{c}=$ coracoid, $\mathrm{cl}=$ clavicle, $\mathrm{dt}=$ dentary, $\mathrm{fr}=$ frontal, $\mathrm{h}=$ humerus, hy= hyoid, $\mathrm{j}=$ jugal, $\mathrm{icl}=$ interclavicle, $\mathrm{n}=$ nasal, $\mathrm{op}=\mathrm{opisthotic}$, $\mathrm{pmx}=$ premaxilla, $\mathrm{pt}=$ pterygoid, $\mathrm{pof}=$ postfrontal, $\mathrm{pra}=$ prearticular, $\mathrm{q}=$ quadrate, $\mathrm{s}=$ supratemporal, $\mathrm{sa}=$ surangular, $\mathrm{sca}=\mathrm{scapula}, \mathrm{sp}=$ splenial, $\mathrm{st}=$ stapes, $\mathrm{v}=$ vomer. Black triangles $=$ teeth. Scale bar $=50 \mathrm{~cm}$. Modified and corrected from Delsett et al. (2016).

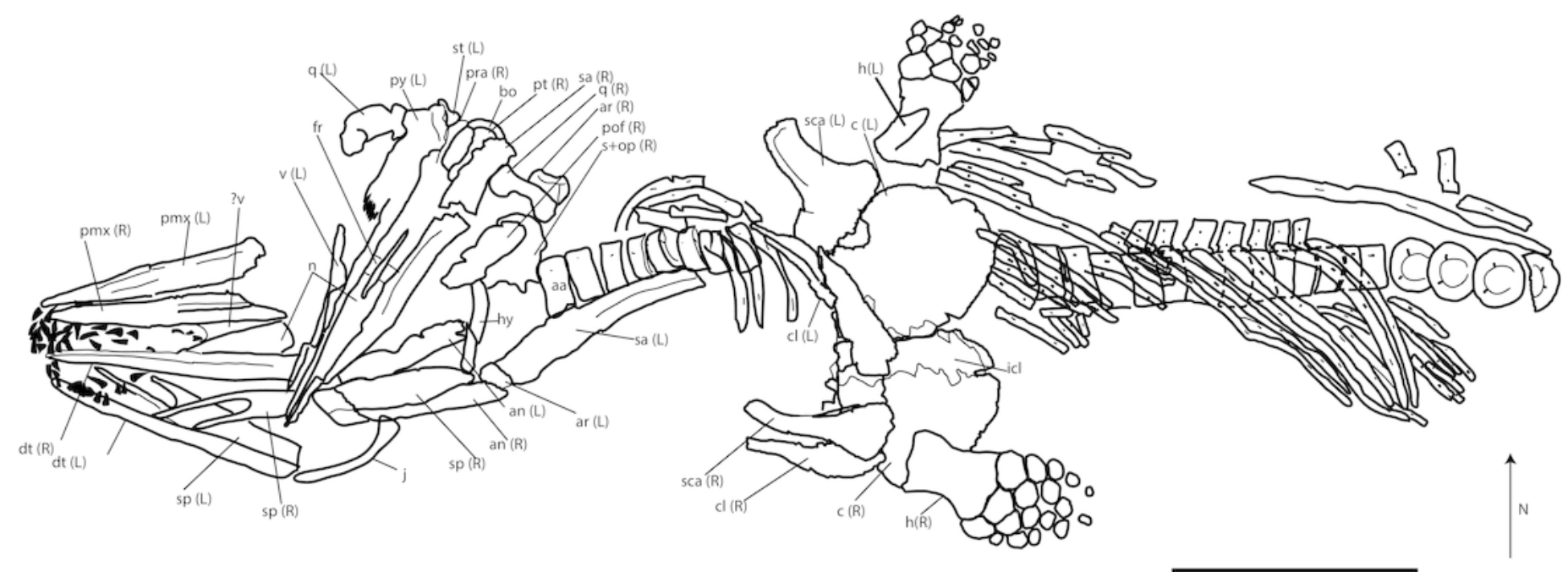




\section{Figure 6}

Rostrum and teeth of PMO 222.669, referred specimen of Palvennia hoybergeti.

A, photograph and $B$, interpretation of the rostrum from the surface stratigraphically down. Disarticulated teeth in $C$, and $D$, different views of the same tooth and $E$, and $F$, different views of a second tooth. Abbreviations: $d t=$ dentary, $f p m x=$ fossa premaxillaris, $I=$ lacrimal, $\mathrm{n}=$ nasal, $\mathrm{pmx}=$ premaxilla, $\mathrm{sc}=$ sclerotic plate $\mathrm{sp}=$ splenial. Grey triangles $=$ teeth. Scale bar for $A-B=100 \mathrm{~mm}$ and $C-F=10 \mathrm{~mm}$. Photo: Lene Liebe Delsett.

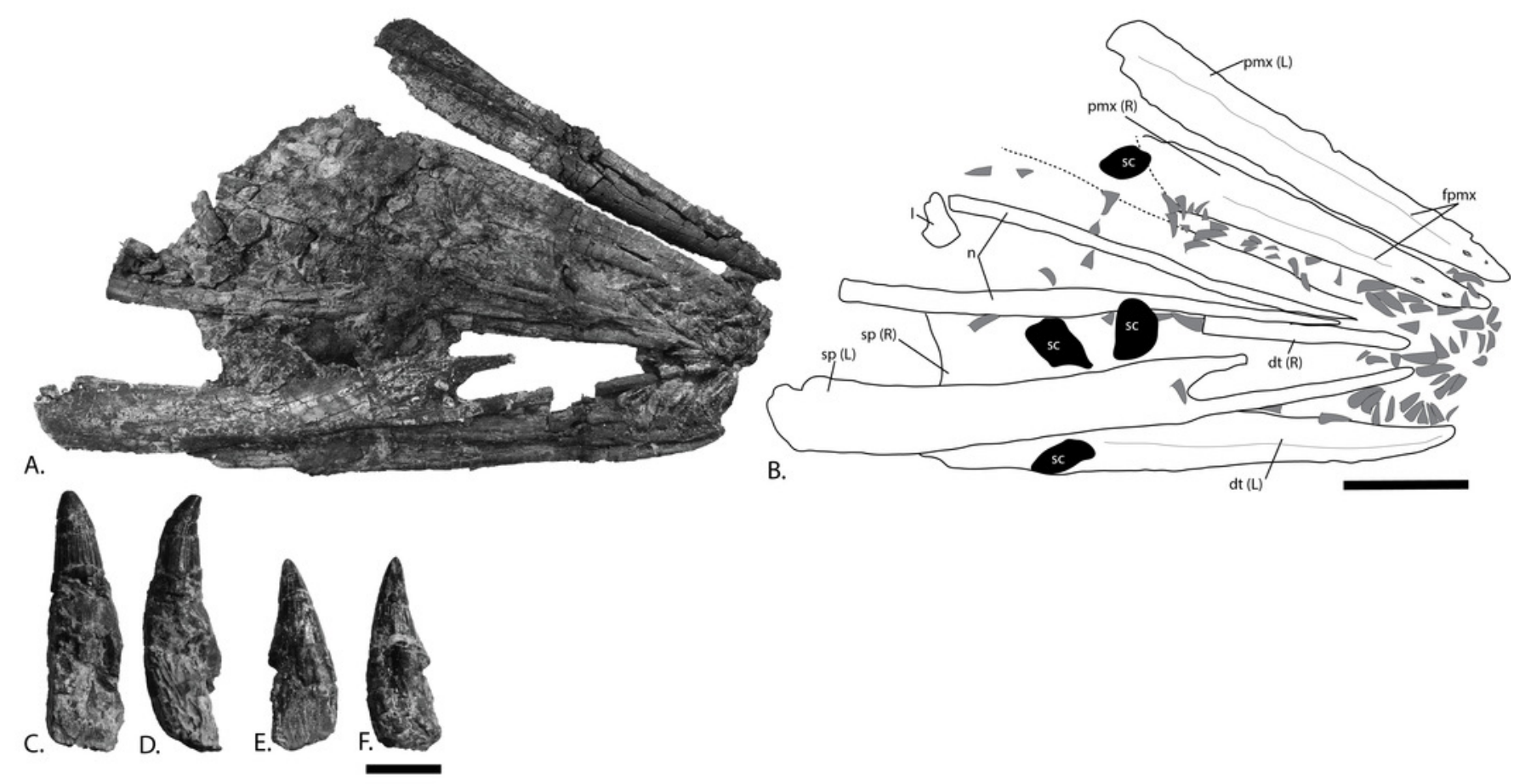




\section{Figure 7}

Skull roof of PMO 222.669, referred specimen of Palvennia hoybergeti.

A, photograph and $B$, interpretation of the skull roof in dorsal view. Abbreviations: $b o=$ basioccipital , ex= exoccipital, $f m=$ foramen magnum, $f r=$ frontal, $n=$ nasal, $o p=$ opisthotic, $\mathrm{pa}=$ parietal, $\mathrm{paf}=$ parietal foramen, $\mathrm{pf}=$ prefrontal, $\mathrm{pof}=$ postfrontal, $\mathrm{s}=$ supratemporal, $\mathrm{so}=$ supraocciptal, suf $=$ supratemporal fenestra, $t=$ tubercles, $?=$ uncertain suture. Scale bar= $100 \mathrm{~mm}$. Photo: Lene Liebe Delsett.
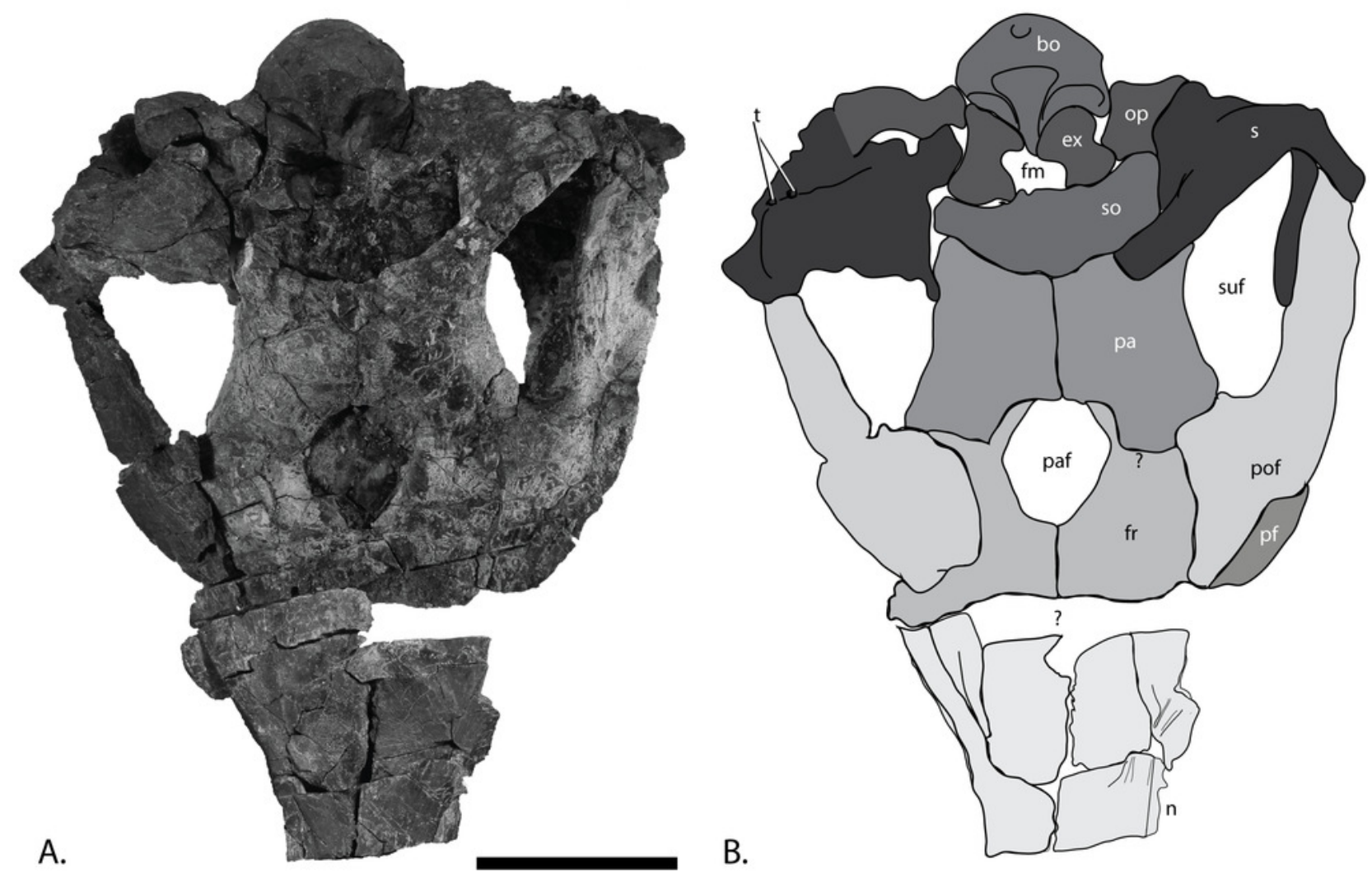


\section{Figure 8}

Cranial elements of PMO 222.669, referred specimen of Palvennia hoybergeti.

A, right postorbital in lateral view. B, left jugal in medial view. C, left lacrimal in lateral view.

$D$, left vomer in lateral view. $E$, left pterygoid in ventral view. $F$, hyoid in unknown orientation. Abbreviations: $a p=$ anterior process, $d=$ depression, $d p=$ dorsal process, $i m=$ incomplete margin, $\mathrm{hr}=$ horizontal ridge, $\mathrm{hs}=$ horizontal shelf, $\mathrm{Im}=$ lateral process, $\mathrm{lp}=$ lateral process, $\mathrm{ma}=$ matrix, $\mathrm{mp}=$ medial process, $\mathrm{pab}=$ posteriorly ascending $\mathrm{bar}, \mathrm{pf}=$ prefrontal, $\mathrm{qr}=$ quadrate ramus, $s b=$ suborbital bar, $v r=$ vertical ridge. Scale $b a r=50 \mathrm{~mm}$. Photo: Lene Liebe Delsett. 

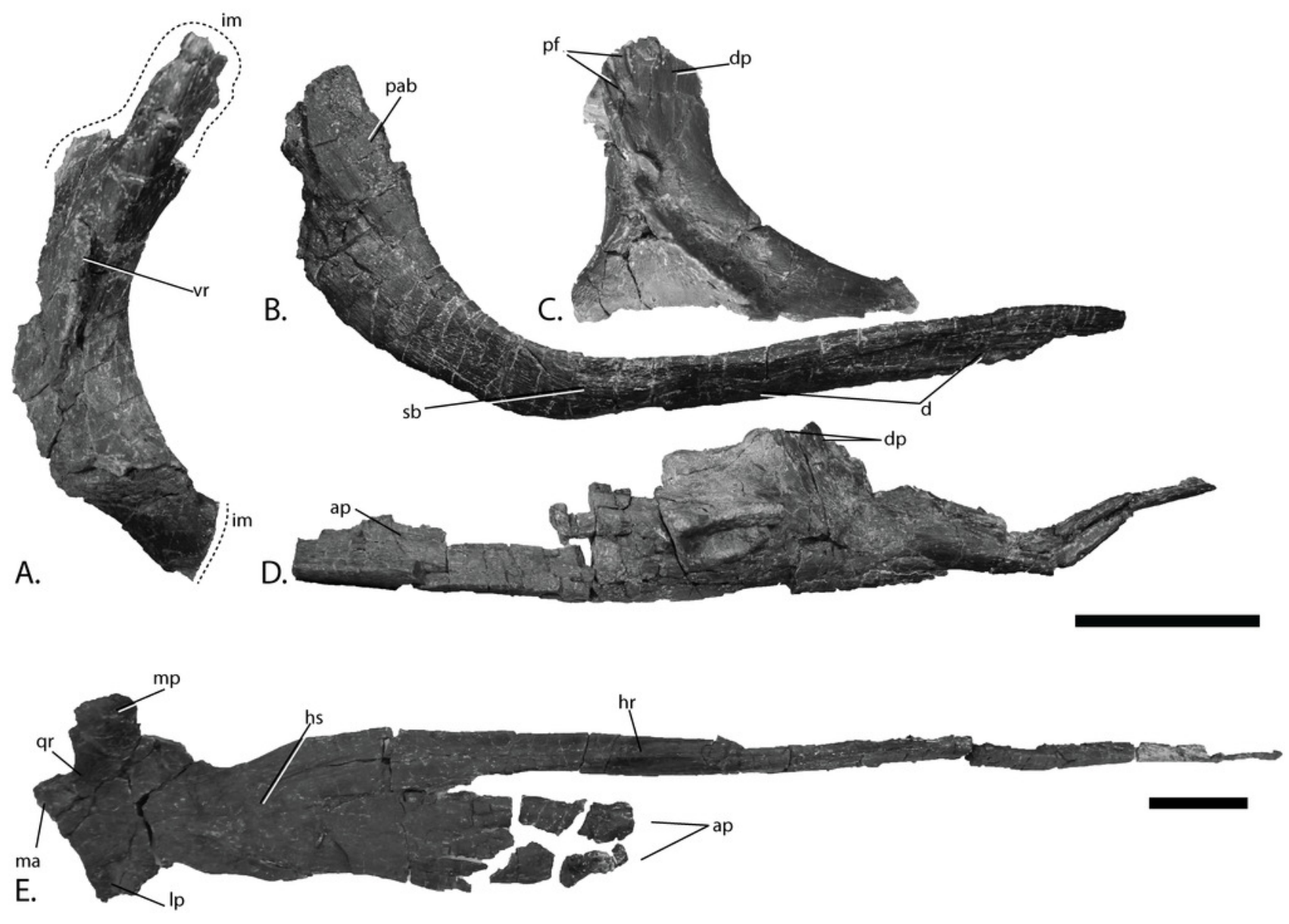

F.

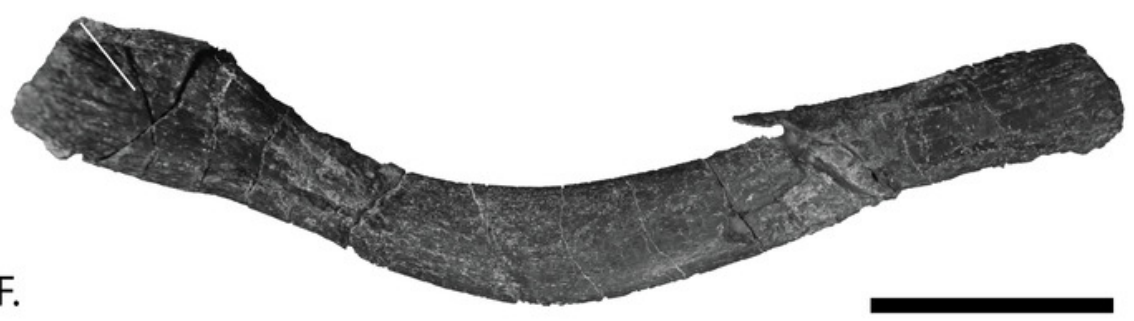




\section{Figure 9}

Basicranium elements of PMO 222.669, referred specimen of Palvennia hoybergeti.

Basioccipital in $\mathrm{A}$, posterior, and $\mathrm{B}$, dorsal view with articulated exoccipitals and $\mathrm{C}$, lateral and $D$, ventral view. Basisphenoid in $E$, ventral view. Anterior to the top. Right opisthotic in $F$, posterior view. Right stapes in $\mathrm{G}$, posterior view. Left quadrate in $\mathrm{H}$, posterior and I, ventral view. Abbreviations: $a c=$ articular condyle, $a f=$ articular facet, $b p p=$ basipterygoid process, eca = extracondylar area, ex= exoccipital, $\mathrm{ffm}=$ floor of foramen magnum, icf= intercarotid foramen, $\mathrm{im}=$ incomplete margin, $\mathrm{mp}=$ medial process, $\mathrm{np}=$ notochordal $\mathrm{pit}, \mathrm{of}=$ opisthotic facet, ol= occipital lamella, $\mathrm{pl}=$ pterygoid lamella, $\mathrm{pop}=$ paroccipital process, $\mathrm{ps}=$ parasphenoid, qjf $=$ quadratojugal facet, saf $=$ surangular facet, $\mathrm{stf}=$ stapedial facet. Scale bar $=50 \mathrm{~mm}$. Photo: Lene Liebe Delsett. 

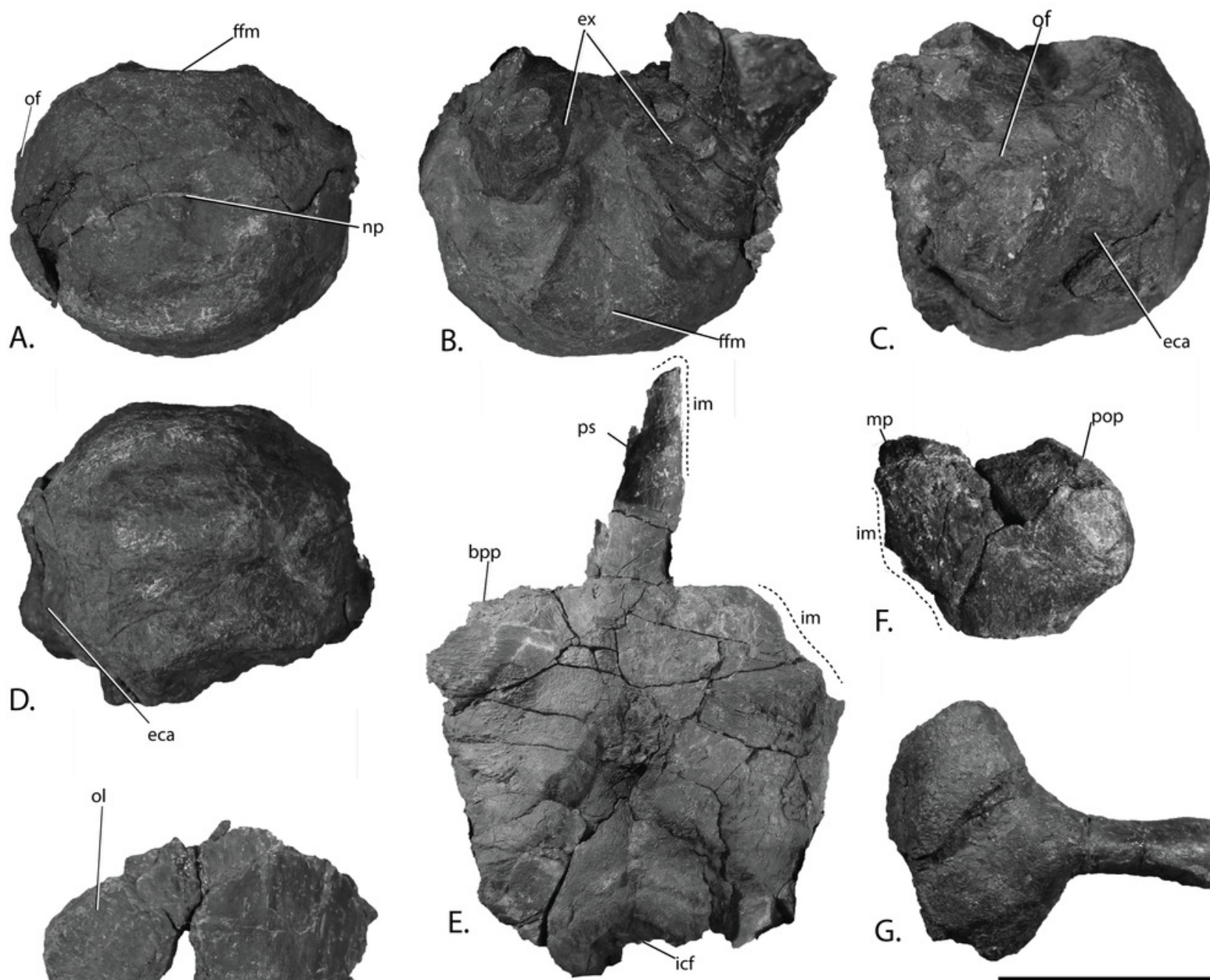

C.

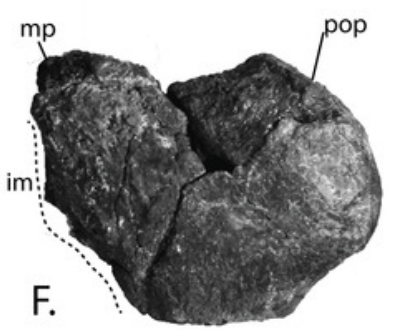

G.

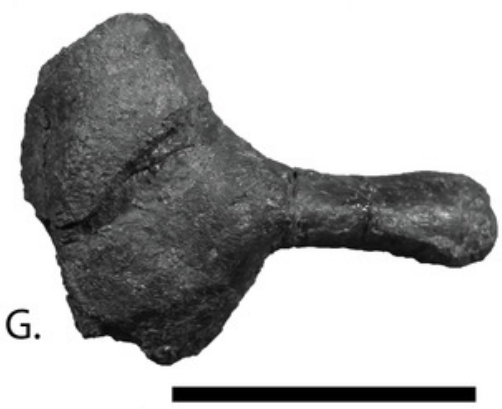

$\mathrm{H}$.
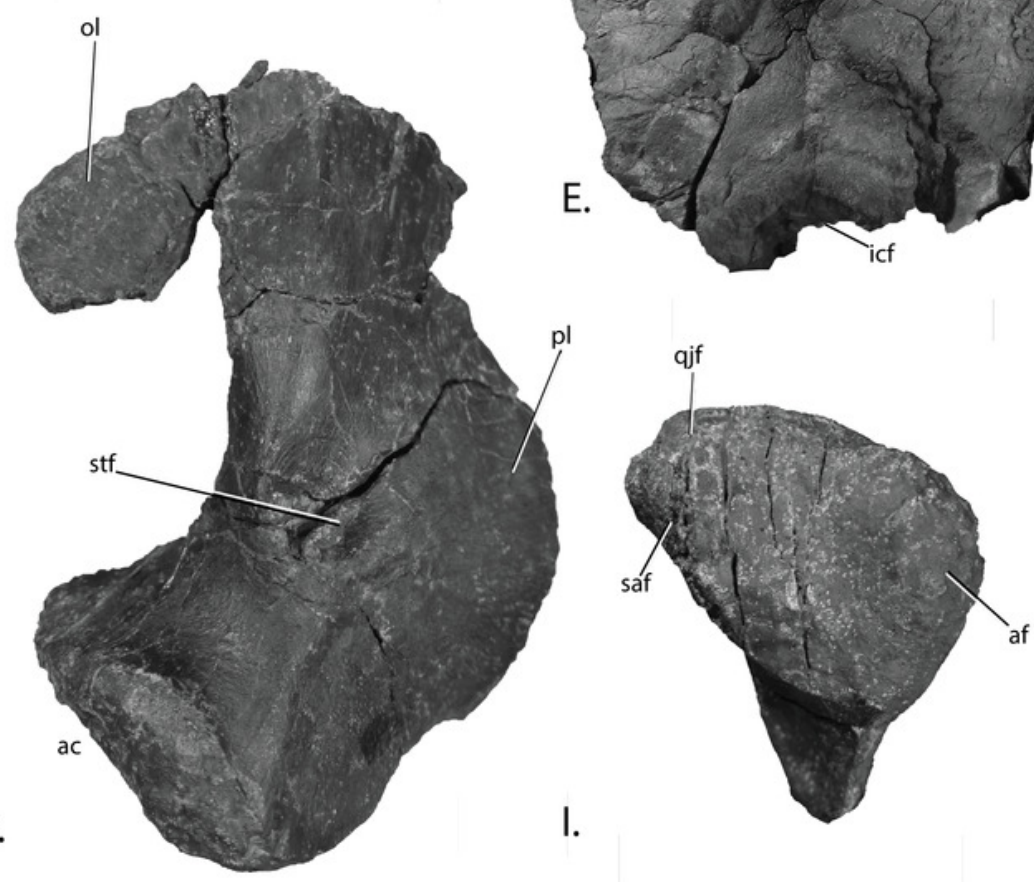


\section{Figure 10}

Mandibles of PMO 222.669, referred specimen of Palvennia hoybergeti.

Right articular in A, medial, B, lateral and C, articular view. Right mandible with quadrate in $D$, lateral view. Left mandible in $E$, medial view and $F$, interpretation. Left angular in $G$, medial and $\mathrm{H}$, lateral view. Abbreviations: $\mathrm{ar}=$ articular, $\mathrm{fsa}=$ fossa surangularis, $\mathrm{gf}=\mathrm{glenoid}$ fossa, $\mathrm{im}=$ incomplete margin, If= lateral flange, $M A M E=M$. adductor mandibulae extremus process, $\mathrm{Mc}=$ symphyseal portion of Meckelian canal, $\mathrm{mf}=$ medial flange, $\mathrm{pap}=$ paracoronoid process, $\mathrm{pra}=$ prearticular, $\mathrm{q}=$ quadrate, $\mathrm{sa}=$ surangular, $\mathrm{sc}=\mathrm{sclerotic}$ plate, $\mathrm{sf}=$ surangular foramen. Scale bar for $\mathrm{A}-\mathrm{C}=25 \mathrm{~mm}$ and for $\mathrm{D}-\mathrm{H}=100 \mathrm{~mm}$. Photo: Lene Liebe Delsett. 

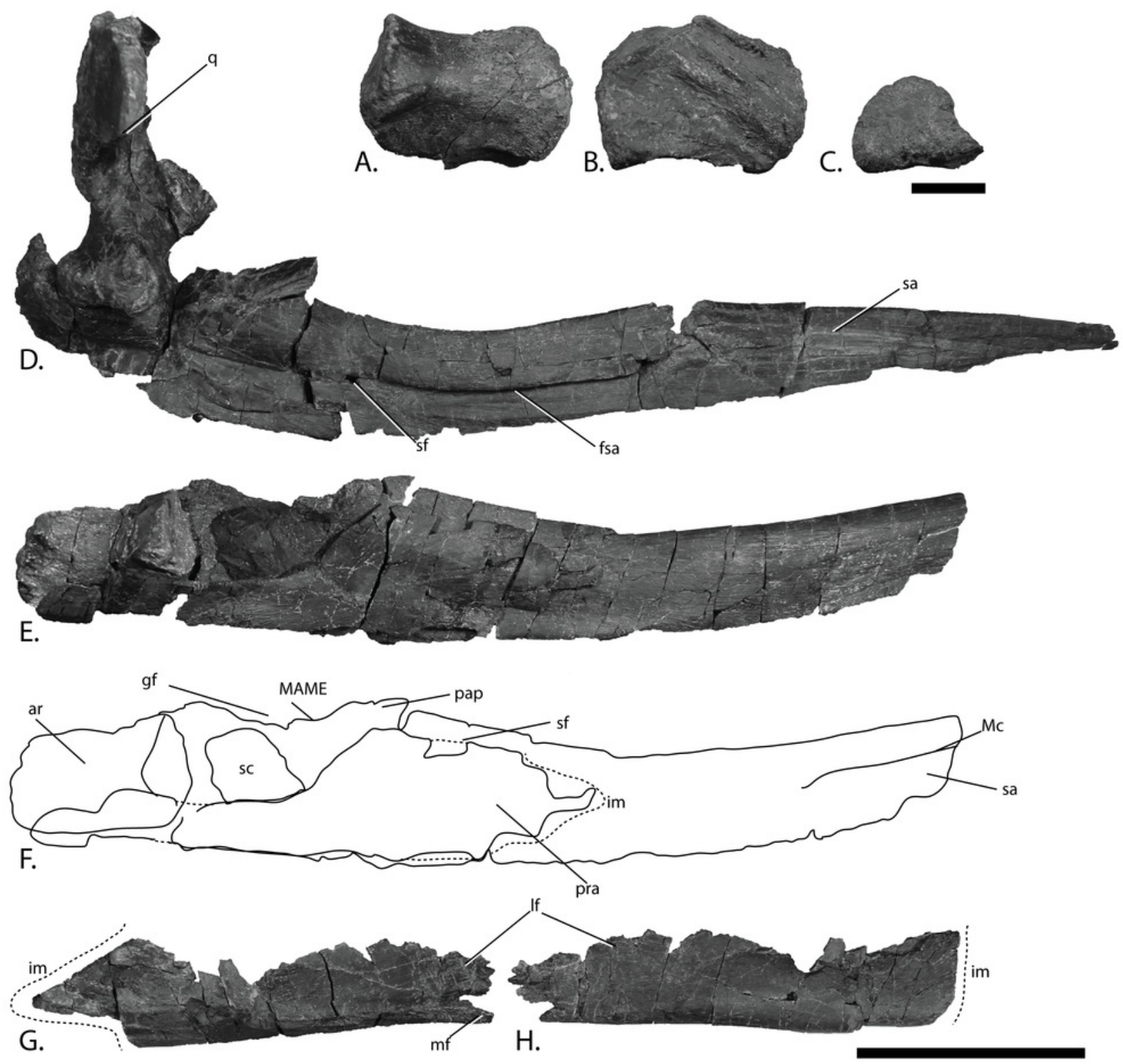


\section{Figure 11}

Pectoral girdle of PMO 222.669, referred specimen of Palvennia hoybergeti.

Interclavicle and clavicles in A, ventral view. Articular surface of left scapula in B, anterior view. Right scapula in C, lateral and E, medial view. Left scapula in D, lateral and F, medial view. Coracoids in $\mathrm{G}$, ventral and $\mathrm{H}$, dorsal view. Abbreviations: $\mathrm{acp}=$ acromion process, amp $=$ anteromedial process, $\mathrm{ann}=$ anterior notch, $\mathrm{cf}=$ coracoid facet, $\mathrm{cl}=$ clavicle, $\mathrm{gf}=$ glenoid facet, incf= intercoracoid facet, $\mathrm{ms}=$ median stem, scaf= scapular facet, $\mathrm{tb}=$ transverse bar. Scale bar for $A, F-G=100 \mathrm{~mm}$ and for $B-E=50 \mathrm{~mm}$. Photo: Lene Liebe Delsett. 


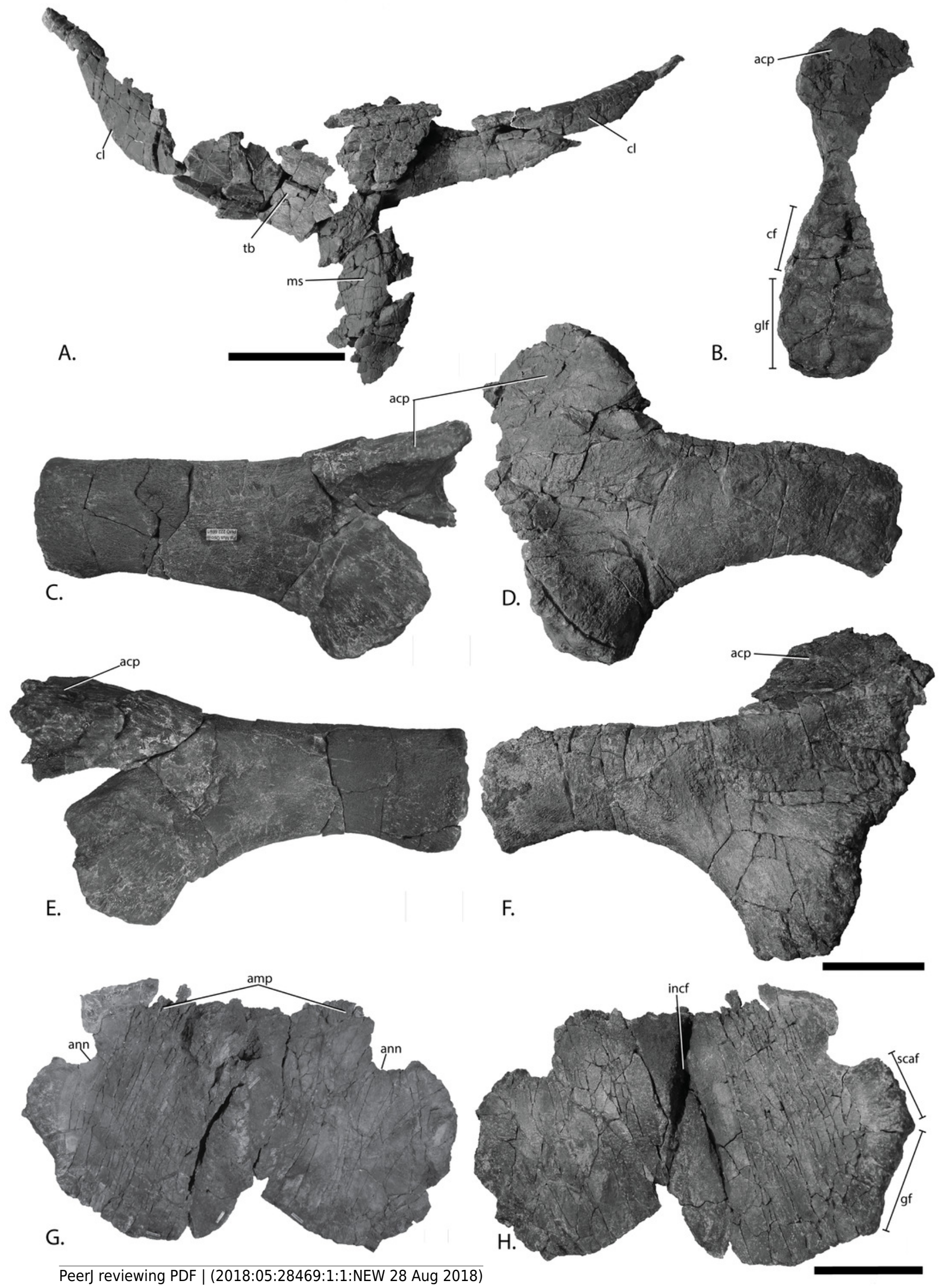




\section{Figure 12}

Forefins of PMO 222.669, referred specimen of Palvennia hoybergeti.

Right forefin in $A$, dorsal view $B$, interpretation and $C$ ventral view. Left humerus in $D$, ventral, $\mathrm{E}$, anterior and $\mathrm{F}$, posterior view. Abbreviations: $\mathrm{dc}=$ distal carpal, $\mathrm{dp}=$ dorsal process, $\mathrm{dpc}=$ deltopectoral crest, in = intermedium, $\mathrm{mc}=$ metacarpal, $\mathrm{p}=$ phalan $\mathrm{x}, \mathrm{pae}=$ preaxial accessory element, paef $=$ facet for preaxial accesory element, path $=$ pathological feature, $R=$ radius,

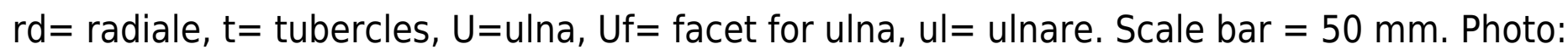
Lene Liebe Delsett. 


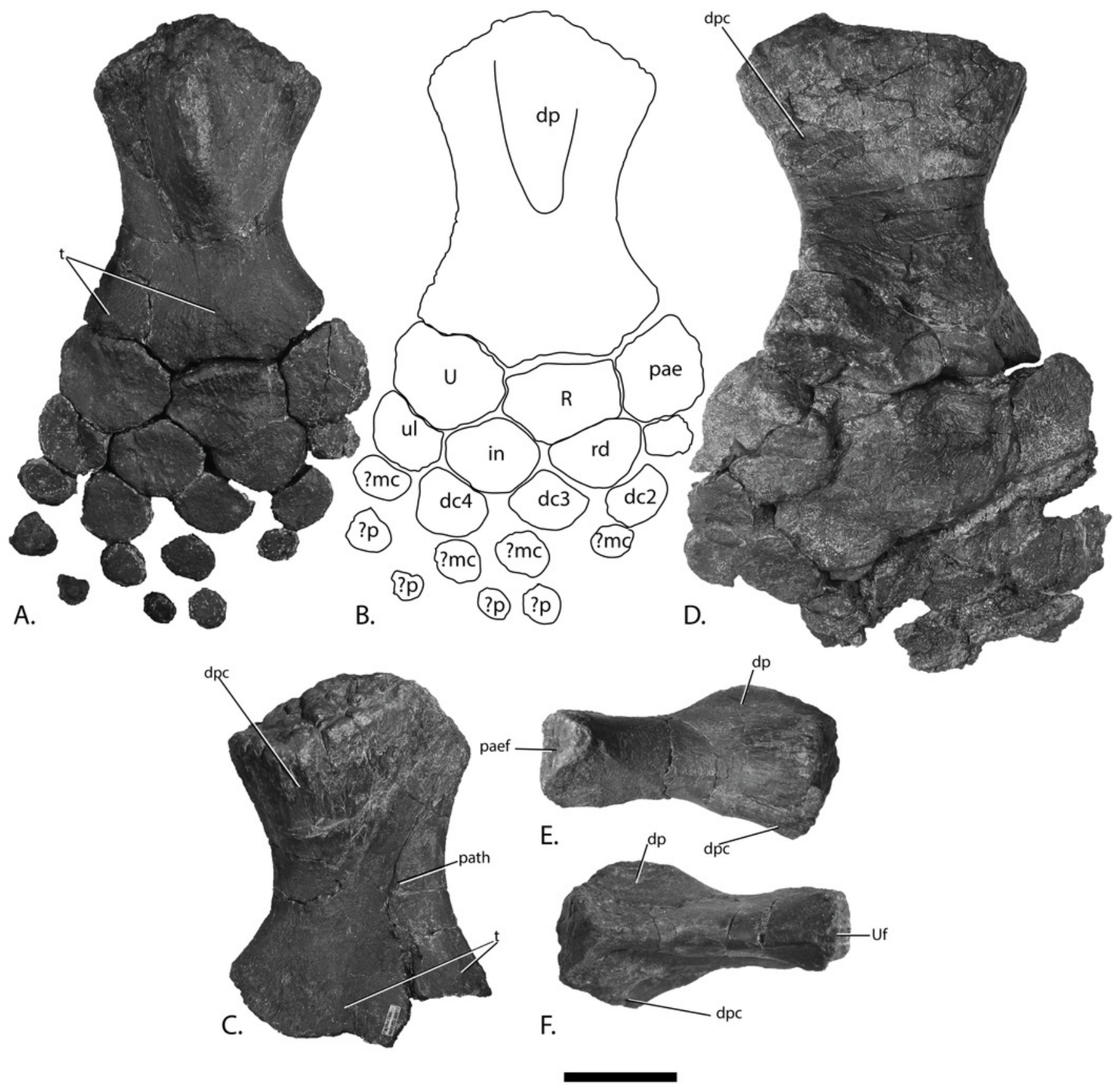




\section{Figure 13}

Vertebral column of PMO 222.669, referred specimen of Palvennia hoybergeti.

Atlas-axis in A, anterior, B, left lateral and C, ventral view (anterior to the left). Articulated anterior dorsal vertebrae in $\mathrm{D}$, dorsal view (anterior to the left). Articulated dorsal vertebrae in $E$, lateral view (anterior to the right). Abbreviations: dat= diapophysis on atlas, dax $=$ diapophysis on axis, pat $=$ parapophysis on atlas, pax $=$ parapophysis on axis, vca = ventral concave area. Scale bar for A-C= $25 \mathrm{~mm}$ and for $\mathrm{D}-\mathrm{E}=100 \mathrm{~mm}$. Photo: Lene Liebe Delsett.

A.

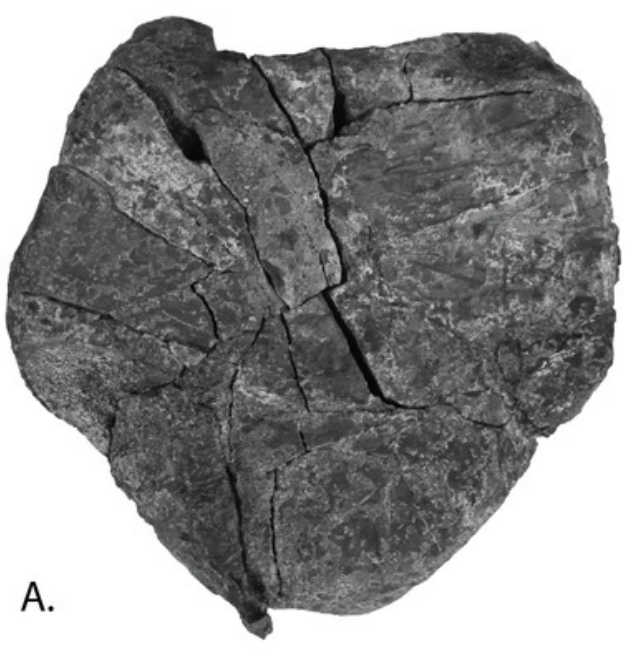

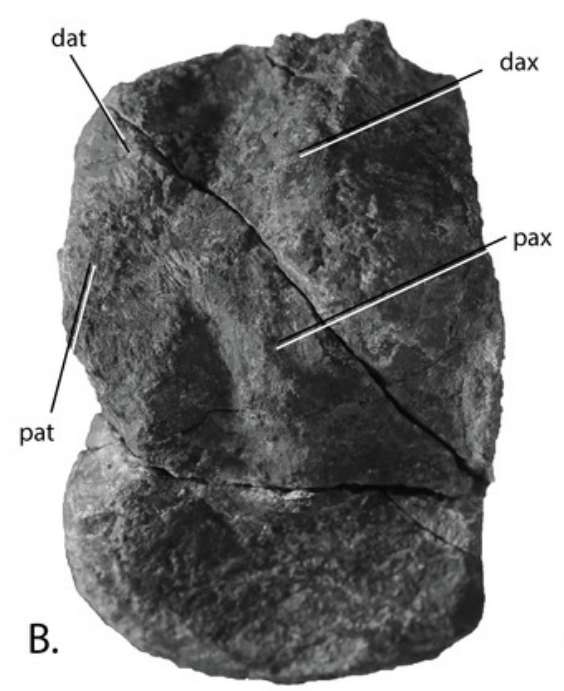

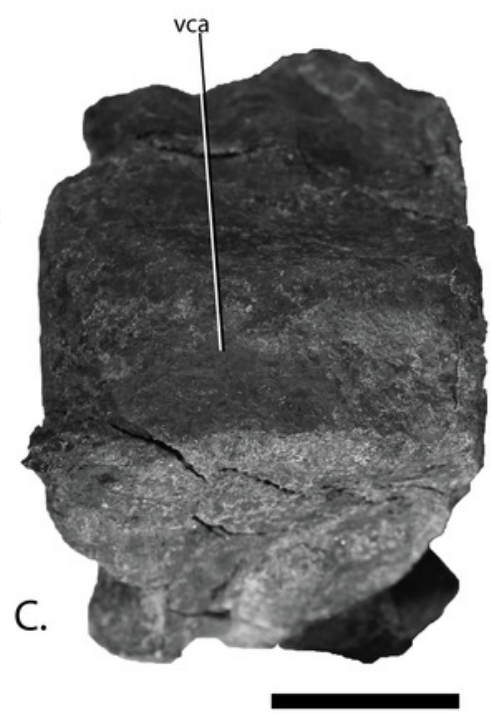

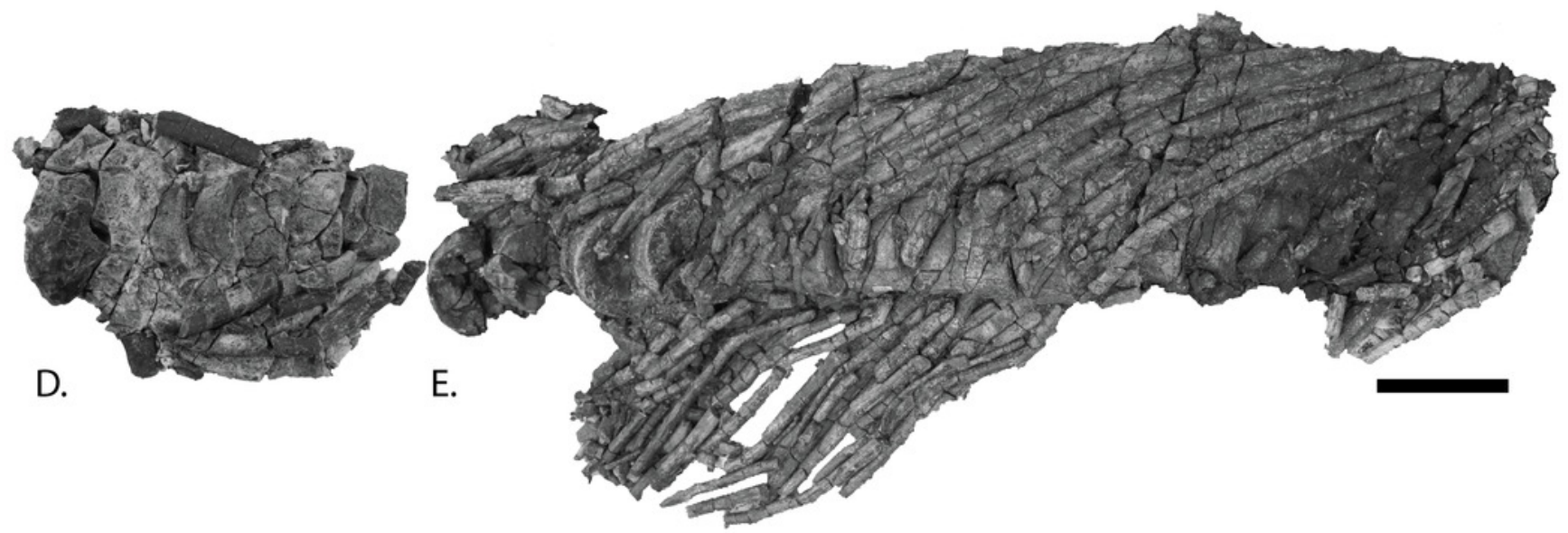


Figure 14

Skeletal map of PMO 230.097, referred specimenof Ophthalmosauridae indet.

Abbreviations: $\mathrm{c}=$ coracoid, $\mathrm{h}=$ humerus, in $=$ intermedium, $\mathrm{R}=$ radius, $\mathrm{sca}=$ scapula $\mathrm{U}=\mathrm{ulna}$, $?=$ undetermined elements. Scale $=100 \mathrm{~mm}$.

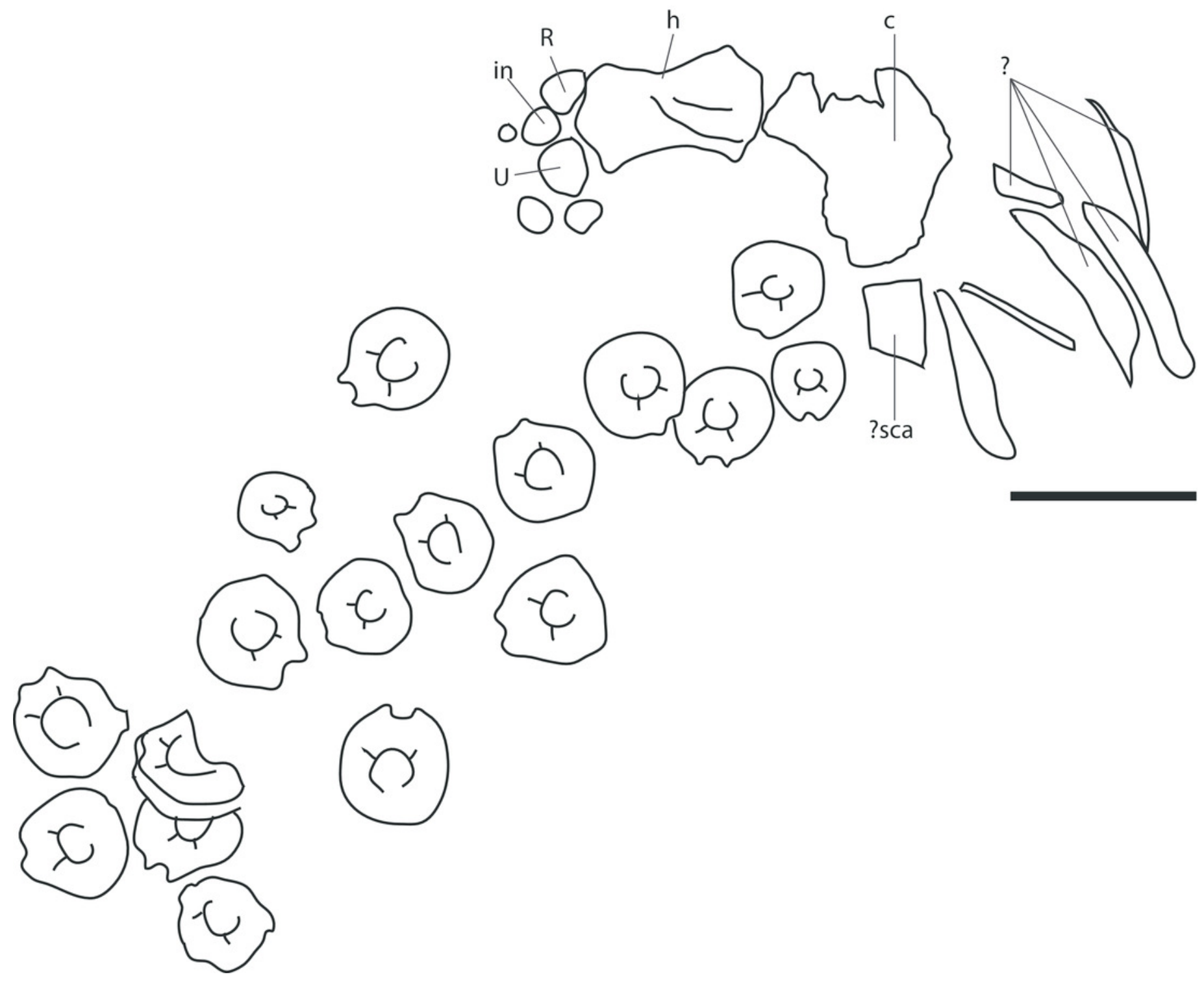




\section{Figure 15}

Pectoral girdle and forefins of PMO 230.097, referred specimen of Ophthalmosauridae indet.

Left humerus with radius, ulna and intermedium in $A$, dorsal and B, ventral view. Left humerus in $C$, anterior and $D$, posterior view. Coracoids in $E$, ventral view. Abbreviations: $a n n=$ anterior notch, $d p=$ dorsal process, $d p c=$ deltopectoral crest, $g f=$ glenoid facet, $\mathrm{im}=$ incomplete margin, in = intermedium, $R=$ radius, scaf $=$ scapular facet, $U=u l n a . ~ S c a l e ~ b a r=50$ $\mathrm{mm}$. Photo: Lene Liebe Delsett. 


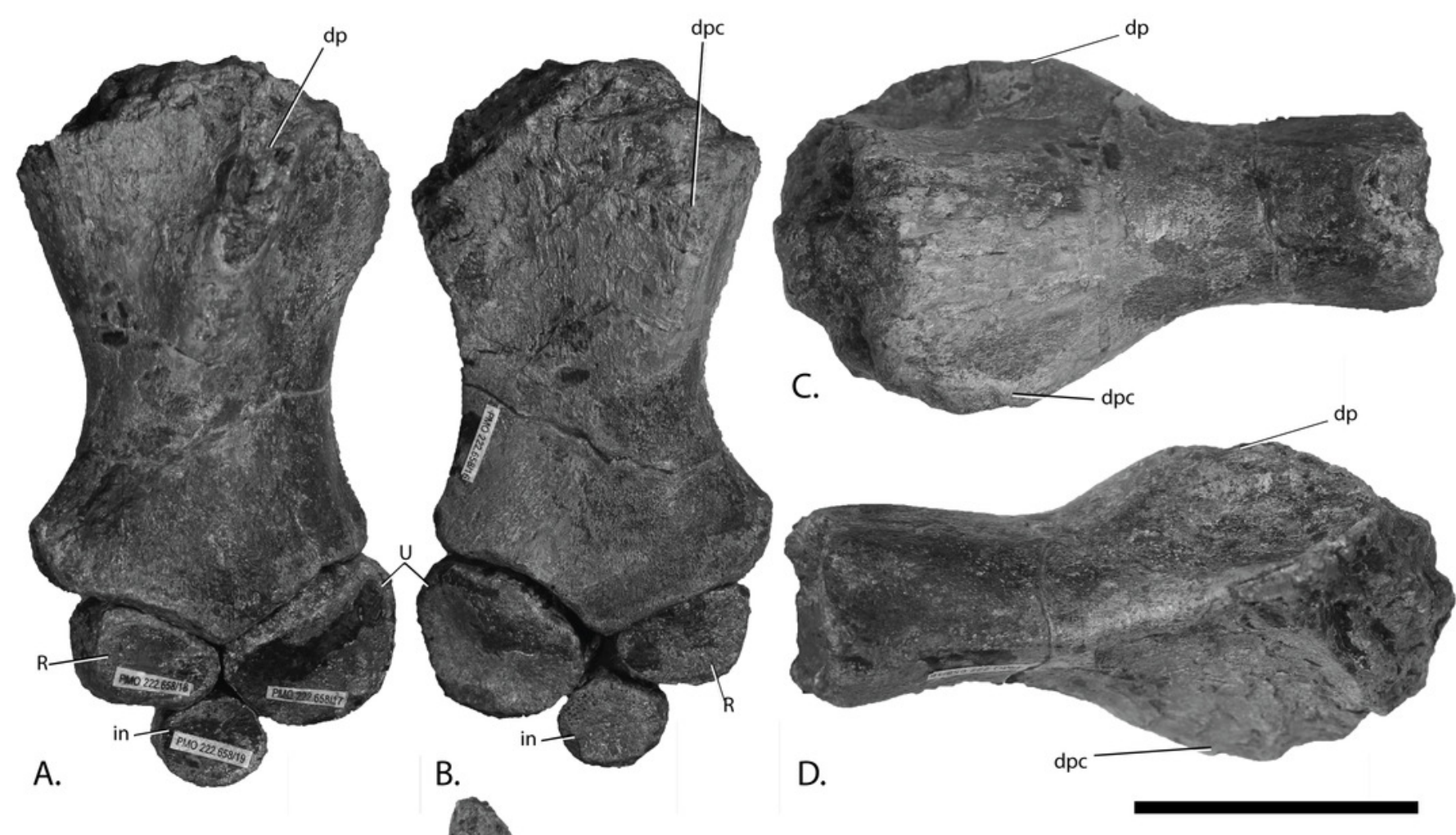

E.

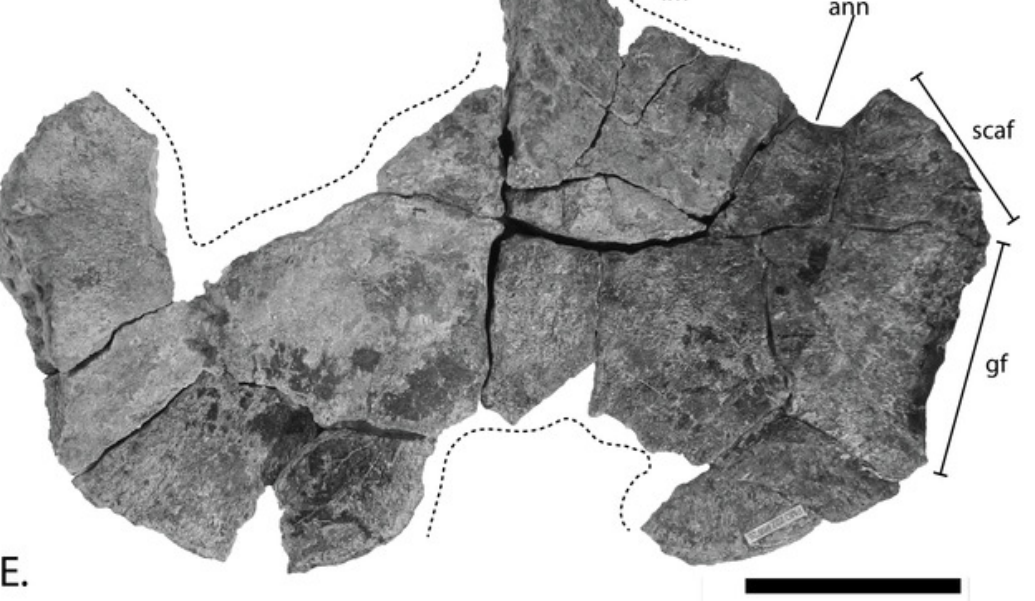




\section{Figure 16}

Anterior caudal vertebrae of PMO 230.097, referred specimen of Ophthalmosauridae indet.

A, centrum from the anteriormost portion of the assemblage with elongated facet and horizontal ridge in anterior view and in $\mathrm{B}$, lateral view. $\mathrm{C}$, centrum from the posteriormost portion of the assemblage with circular facet in anterior view and D lateral view. Abbreviations: $\mathrm{a}=$ apophysis, $\mathrm{hr}=$ horizontal ridge, $\mathrm{nc}=$ neural canal. Scale bar $=50 \mathrm{~mm}$. Photo: Lene Liebe Delsett.

A.

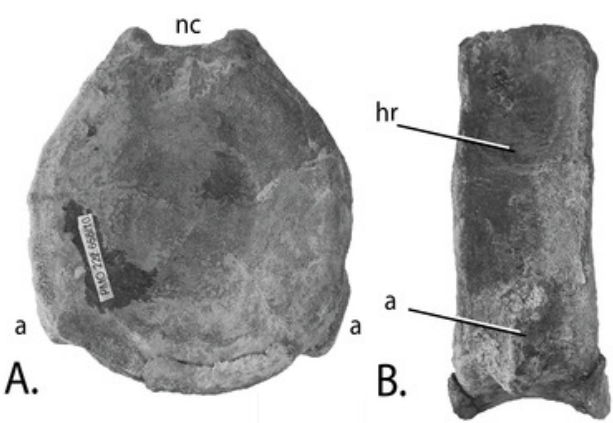

C.

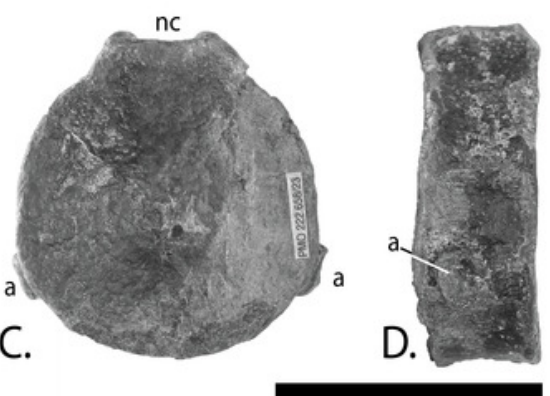




\section{Figure 17}

Skeletal map of PMO 224.250, referred specimen of Ophthalmosauridae indet. in dorsal view (stratigraphically up).

Abbreviations: $\mathrm{c}=$ coracoid, $\mathrm{cl}=$ clavicle $\mathrm{h}=$ humerus, $\mathrm{icl}=$ interclavicle, $\mathrm{im}=$ interclavicle, sca = scapula. Scale $=100 \mathrm{~mm}$. Modified from Delsett et al. 2016 .

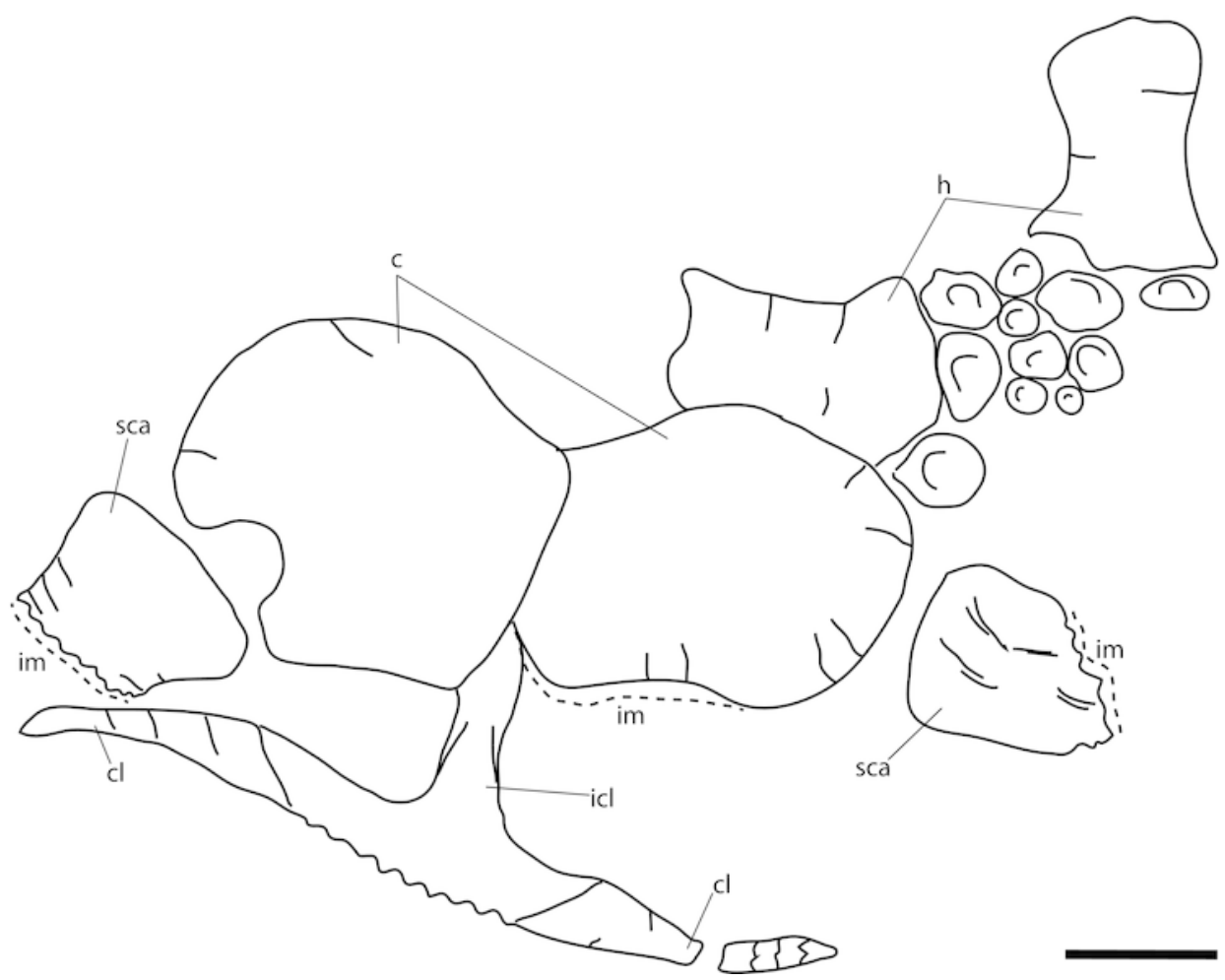




\section{Figure 18}

Basioccipital of PMO 224.250, referred specimen of Ophthalmosauridae indet.

The occipital condyle is shown in posterior view with the figure eight-shaped notochordal pit highlighted. Abbreviations: eca $=$ extracondylar area, $\mathrm{np}=$ notochordal pit. Scale bar $=25$ $\mathrm{mm}$. Photo: Lene Liebe Delsett.

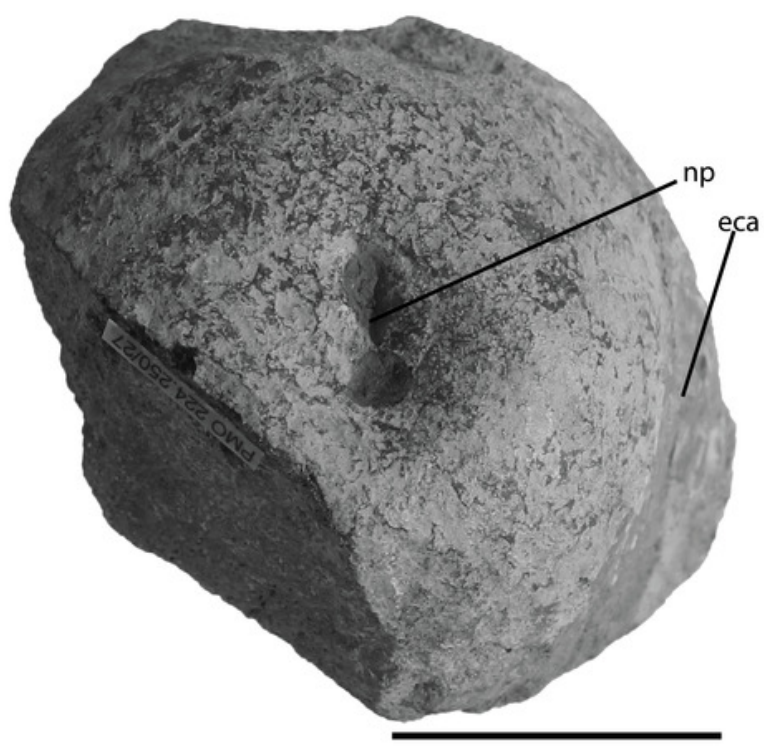




\section{Figure 19}

Forefins of PMO 224.250, referred specimen of Ophthalmosauridae indet.

Right humerus in A, dorsal view with epipodials and intermedium, D, ventral, E, anterior and $F$, posterior view. Left humerus in $B$, dorsal view with radius and ulna. Unknown left forefin element in $\mathrm{C}$, dorsal (or ventral) view. Abbreviations: $d p=$ dorsal process, $d p c=$ deltopectoral crest, in $=$ intermedium, pae $=$ preaxial accessory element, paef $=$ facet for preaxial accesory element, $\mathrm{R}=$ radius, $\mathrm{Rf}=$ facet for radius, $\mathrm{U}=\mathrm{ulna}, \mathrm{Uf}=$ facet for $\mathrm{ulna}$. Scale bar $=50 \mathrm{~mm}$. Photo: Lene Liebe Delsett. 

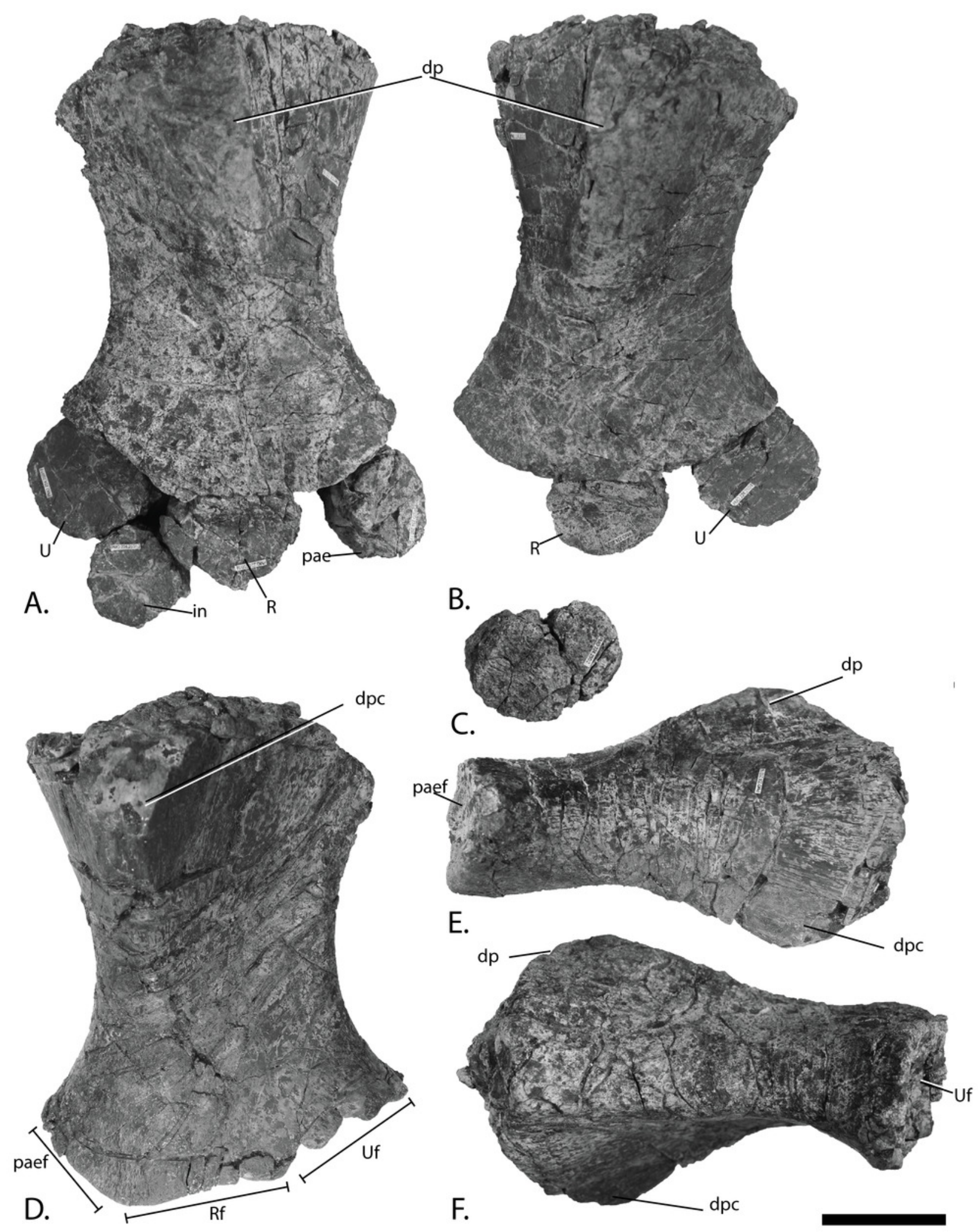


\section{Figure 20}

Pectoral girdle of PMO 224.250, referred specimen of Ophthalmosauridae indet.

Articulated interclavicle and clavicles in A, anterior view. White area on median stem is covered with fabric. Anterior portion of the right scapula in $\mathrm{B}$, lateral and $\mathrm{C}$, anterior view. Anteroventral portion of the left scapula in $D$. Coracoids in $E$, ventral view. Abbreviations: $\mathrm{acp}=$ acromion process, $\mathrm{amp}=$ anteromedial process, $\mathrm{ann}=$ anterior notch, $\mathrm{cf}=$ coracoid facet, $\mathrm{gf}=$ glenoid facet, $\mathrm{im}=$ incomplete margin, incf $=$ intercarotid facet, $\mathrm{ms}=$ median stem, $\mathrm{scaf}=\mathrm{scapular}$ facet, $\mathrm{tb}=$ transverse bar. Scale bar $=50 \mathrm{~mm}$. Photo: Lene Liebe Delsett. 
A.

B.

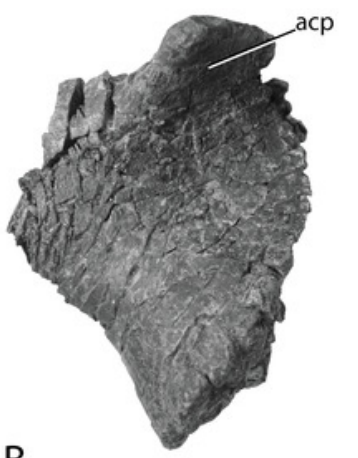

C.

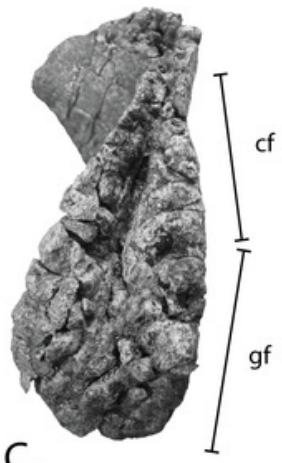

amp
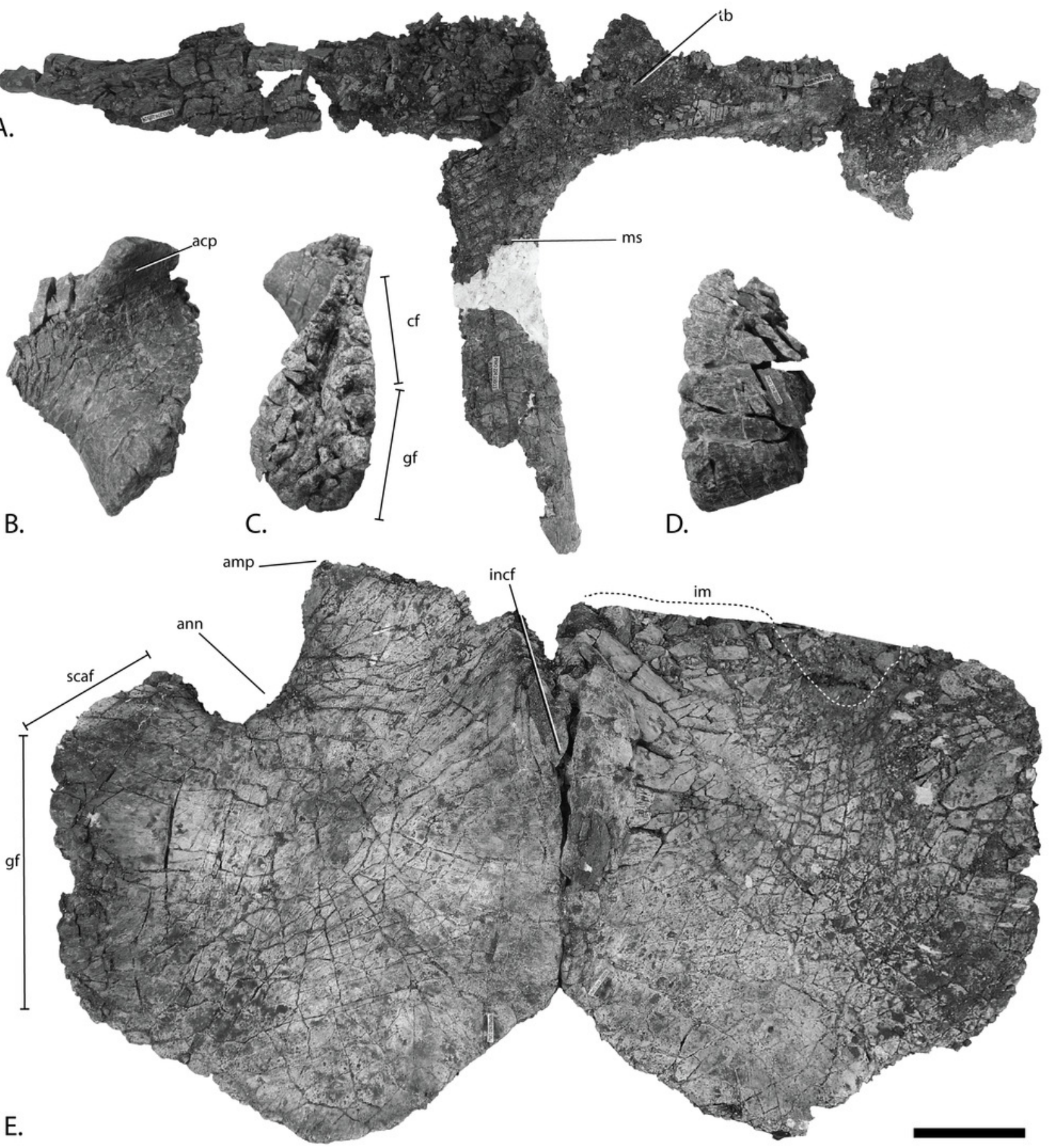
Figure 21 (on next page)

Principle component analysis of baracromian coracoids, delimited by the first two axes.

Morphospace for Ophthalmosaurus and Stenopterygius shown as convex hulls. Coracoid outlines shown for four example spcecimens. Specimen number and taxon see table 1. 


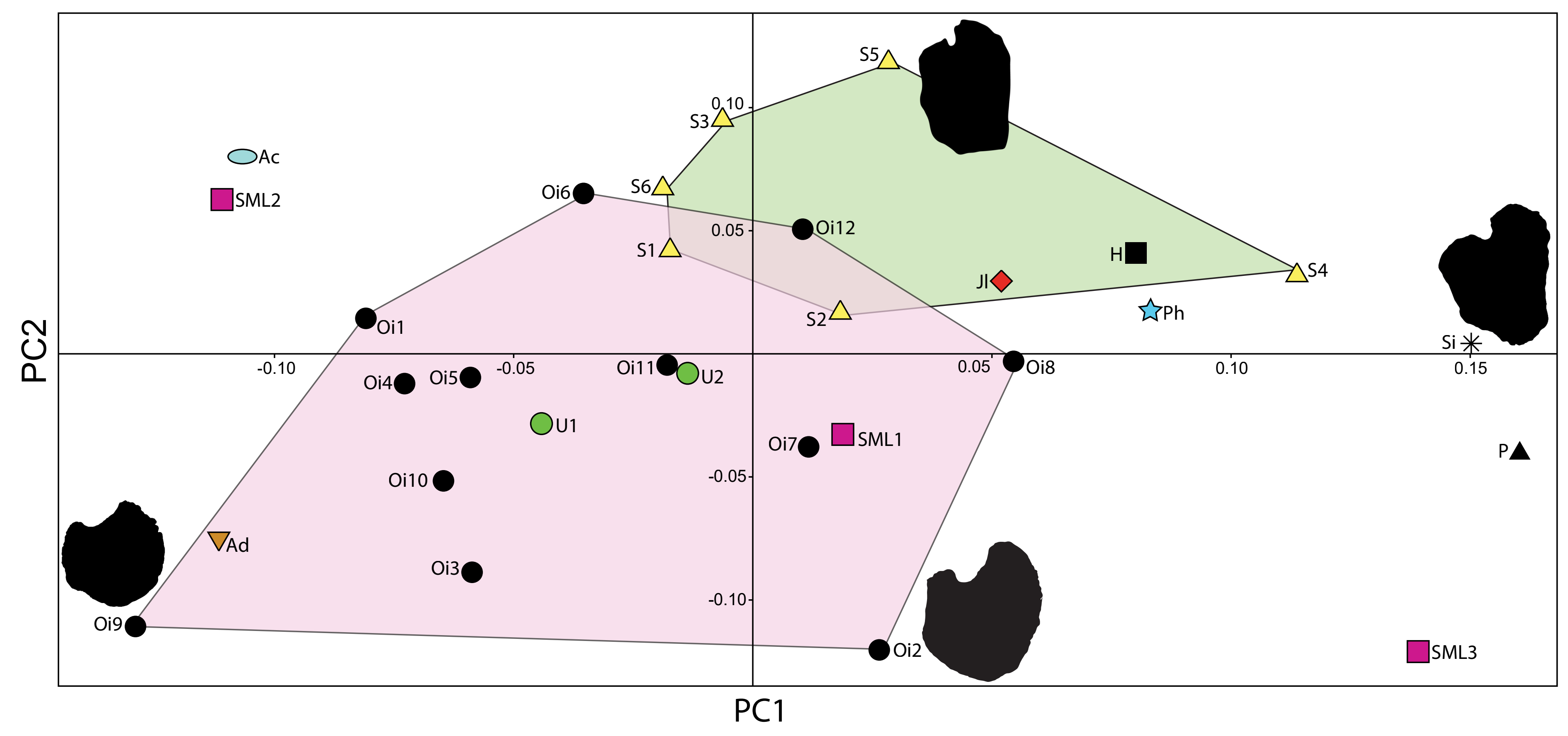


Figure 22

Pectoral girdle specimens from the Slottsmøya Member Lagerstätte.

Ventral view. Interclavicles and clavicles shown together for PMO 224.250. Scale bar $=50$ $\mathrm{mm}$.

\begin{tabular}{|c|c|c|c|c|c|c|c|}
\hline Element & $\begin{array}{l}\text { PMO 222.667 } \\
\text { Pophthalmosau }\end{array}$ & $\begin{array}{l}\text { PMO } 222.669 \\
\text { Palvennia hoyberget. }\end{array}$ & $\begin{array}{l}\text { PMO } 222.655 \\
\text { Keilhauianui }\end{array}$ & $\begin{array}{l}\text { PMO } 224.250 \\
\text { Ophthalmosaridae indet. }\end{array}$ & $\begin{array}{l}\text { PMO } 214.578 \\
\text { Cryopterygius k. }\end{array}$ & $\begin{array}{l}\text { PMO } 222.654 \\
\text { Janusaurss undii }\end{array}$ & $\begin{array}{l}\text { PMO 230.097 } \\
\text { Ophthalmosauridae inde }\end{array}$ \\
\hline Right clavicle & & & & with interclavicle below & & & \\
\hline Left clavicle & & & & with interclavicle below & $\sim$ & & \\
\hline Interclavicle & & & & & & & \\
\hline Right coracoid & & & & & & & \\
\hline Left coracoid & & & & & & & \\
\hline Right scapula & & & & & & & \\
\hline Left scapula & & & & & & & \\
\hline
\end{tabular}




\section{Table 1 (on next page)}

Baracromian specimens used in the PCA on 2D landmarks on coracoids. 
1 Baracromian specimens used in the PCA on 2D landmarks on coracoids.

\begin{tabular}{|c|c|c|c|}
\hline Abbrev. & Museum number & Taxon & Photo \\
\hline Ac & CMN 40608 & Arthropterygius chrisorum & E. Maxwell \\
\hline $\mathrm{Ad}$ & SNHM 1284-R & Acamptonectes densus & V. Fischer \\
\hline $\mathrm{H}$ & SMSS SGS & Platyperygius hercynicus & R. Vanis \\
\hline $\mathrm{Jl}$ & PMO 222.654 & Janusaurus lundi & AJR \\
\hline Oi1 & CAMSM J65583 & Ophthalmosaurus icenicus & LLD \\
\hline Oi2 & NHMUK R3013 & Ophthalmosaurus icenicus & AJR \\
\hline Oi3 & LEICT 100194920 & Ophthalmosaurus icenicus & LLD \\
\hline Oi4 & NHMUK R2137 & Ophthalmosaurus icenicus & AJR \\
\hline Oi5 & OUMNH J48008 & Ophthalmosaurus icenicus & LLD \\
\hline Oi6 & CAMSM J66275 & Ophthalmosaurus icenicus & LLD \\
\hline Oi7 & LEICT 100194918 & Ophthalmosaurus icenicus & LLD \\
\hline Oi8 & CAMSM J29809 & Ophthalmosaurus icenicus & LLD \\
\hline Oi9 & CAMSM J65813 & Ophthalmosaurus icenicus & LLD \\
\hline Oi10 & LEICT 10019492 & Ophthalmosaurus icenicus & LLD \\
\hline Oi11 & CAMSM J29807 & Ophthalmosaurus icenicus & LLD \\
\hline Oi12 & LEIUG 90986/913 & Ophthalmosaurus icenicus & LLD \\
\hline $\mathrm{P}$ & UPM EP-II-8 (1076) & Paraophthalmosaurus kabanovi & M. Arkhangelsky \\
\hline $\mathrm{Ph}$ & PMO 222.669 & Palvennia hoybergeti & LLD \\
\hline S1 & SMNS 81961 & Stenopterygius quadriscissus & LLD \\
\hline S2 & SMNS 55074 & Stenopterygius sp. & LLD \\
\hline S3 & SMNS 51142 & Stenopterygius quadriscissus & LLD \\
\hline S4 & BSPGHM S.q. & Stenopterygius quadriscissus & LLD \\
\hline S5 & SMNS 57532 & Stenopterygius uniter & LLD \\
\hline S6 & SMNS 50165 & Stenopterygius quadriscissus & LLD \\
\hline $\mathrm{Si}$ & IRSNB R269 & Sveltonectes insolitus & V. Fischer \\
\hline SML1 & PMO 224.250 & Ophthalmosauridae indet., SML & LLD \\
\hline SML2 & PMO 222.667 & Ophthalmosauridae indet., SML & LLD \\
\hline SML3 & PMO 230.097 & Ophthalmosauridae indet., SML & LLD \\
\hline U1 & UPM EP-II-20 (572) & Undorosaurus gorodischensis & N. Zverkov \\
\hline $\mathrm{U} 2$ & PMO 214.578 & Cryopterygius kristiansenae & LLD \\
\hline
\end{tabular}




\section{Table 2 (on next page)}

Selected measurements in millimetres from the forefin and pectoral girdle in the three described ophthalmosaurid specimens.

If both the right and the left element are preserved, the largest element is listed. Additional measurements in supplemental tables 1-3. 
1 Table 2: Selected measurements in millimetres from the forefin and pectoral girdle in the three

2 described ophthalmosaurid specimens. If both the right and the left element are preserved, the largest

3 element is listed. Additional meaurements in supplemental tables 1-3.

\begin{tabular}{|c|c|c|c|}
\hline & PMO 222.669 & PMO 230.097 & PMO 224.250 \\
\hline $\begin{array}{l}\text { Humerus } \\
\text { proximodistal length }\end{array}$ & 167 & 104 & 195 \\
\hline $\begin{array}{l}\text { Humerus } \\
\text { anteroposterior length } \\
\text { proximal end }\end{array}$ & 109 & 70 & 142 \\
\hline $\begin{array}{l}\text { Humerus } \\
\text { anteroposterior length } \\
\text { distal end }\end{array}$ & 120 & 63 & 149 \\
\hline $\begin{array}{l}\text { Radius proximodistal } \\
\text { length }\end{array}$ & 46 & 20 & 52 \\
\hline $\begin{array}{l}\text { Radius anteroposterior } \\
\text { width }\end{array}$ & 59 & 25 & 68 \\
\hline $\begin{array}{l}\text { Ulna proximodistal } \\
\text { length }\end{array}$ & 53 & 30 & 57 \\
\hline $\begin{array}{l}\text { Ulna anteroposterior } \\
\text { width }\end{array}$ & 61 & 36 & 57 \\
\hline $\begin{array}{l}\text { Preaxial accessory } \\
\text { element proximodistal } \\
\text { length }\end{array}$ & 45 & NA & 49 \\
\hline $\begin{array}{l}\text { Preaxial accessory } \\
\text { element } \\
\text { anteroposterior width }\end{array}$ & 41 & NA & 51 \\
\hline $\begin{array}{l}\text { Scapula proximodistal } \\
\text { length }\end{array}$ & 215 & NA & NA \\
\hline $\begin{array}{l}\text { Scapula dorsoventral } \\
\text { height proximal blade }\end{array}$ & NA & NA & 175 \\
\hline $\begin{array}{l}\text { Coracoid mediolateral } \\
\text { width }\end{array}$ & 220 & 110 & 240 \\
\hline $\begin{array}{l}\text { Coracoid } \\
\text { anteroposterior length }\end{array}$ & 260 & 150 & 270 \\
\hline $\begin{array}{l}\text { Clavicle proximodistal } \\
\text { length }\end{array}$ & NA & NA & NA \\
\hline
\end{tabular}

